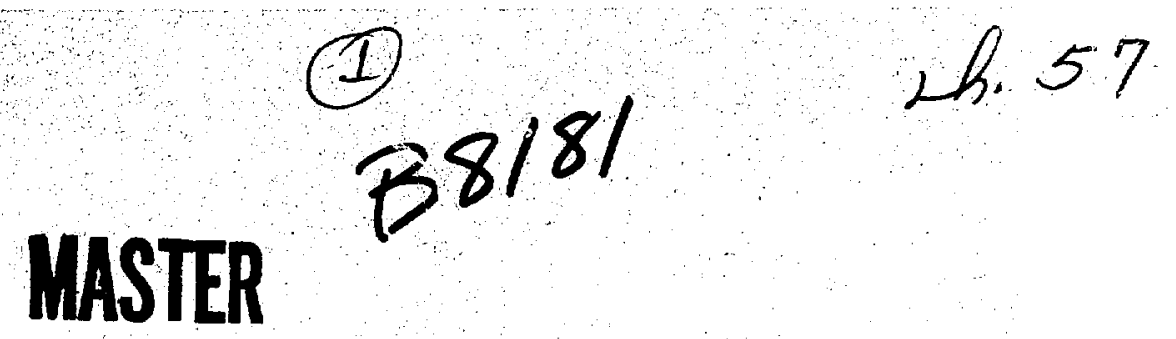

Loi Alamos Natione Laborasory ti operated by the Univerelty of Celifornia for the Unimd States Department of Energy under contrect W-7405-ENG-30.

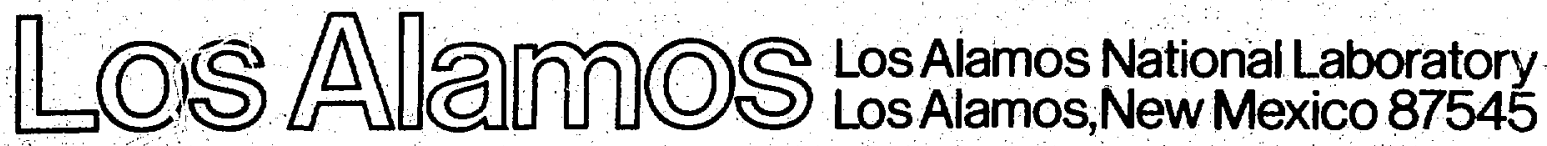


LA-8880

UC-28 and UC-48

Issued: September 1981

\section{PIGMI: A Design Report for a Pion \\ Generator for Medical Irradiations}

Compiled by

Lash D. Hansborough

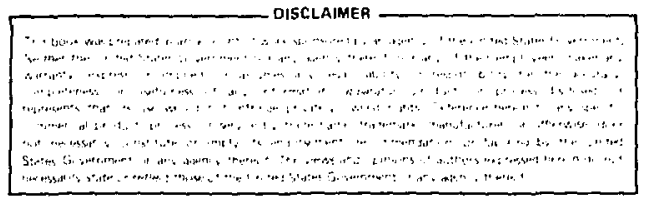

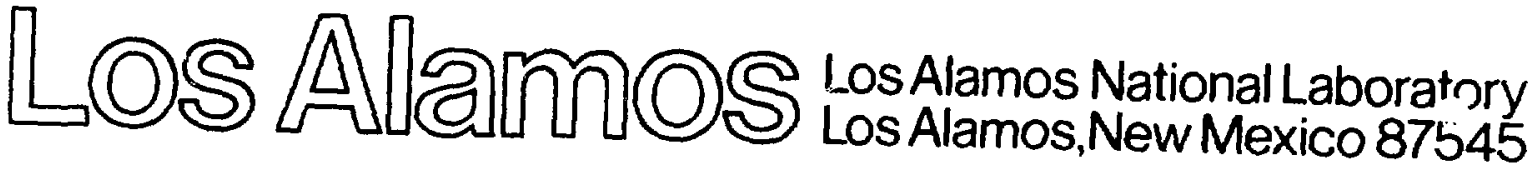




\section{CONTENTS}

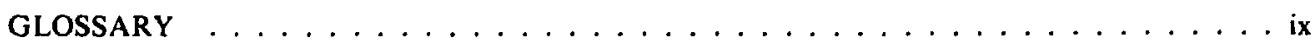

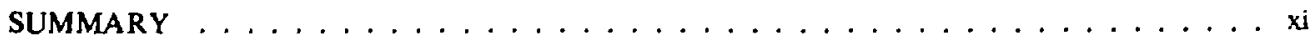

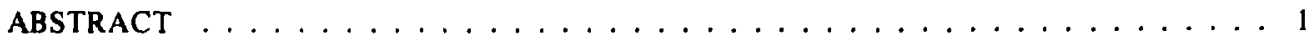

SUMMARY BY SECTIONS $\ldots \ldots \ldots \ldots \ldots \ldots \ldots \ldots \ldots \ldots$

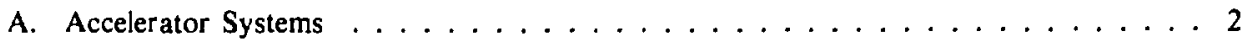

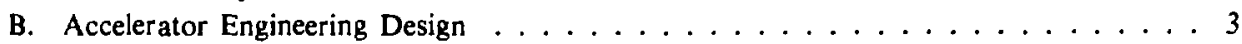

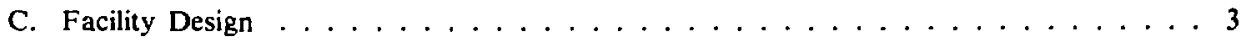

D. Facility Construction and Operation $\ldots \ldots \ldots \ldots \ldots \ldots$

E. Facility Costs ........................ 4

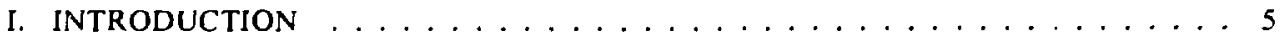

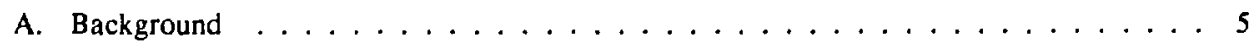

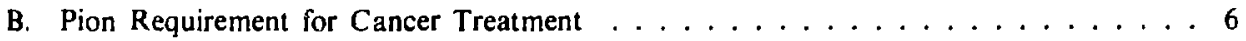

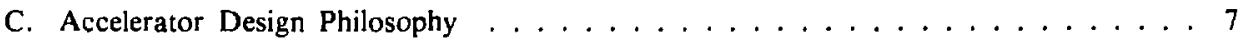

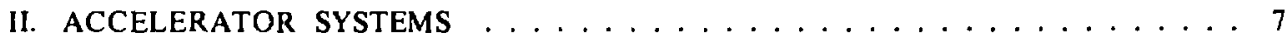

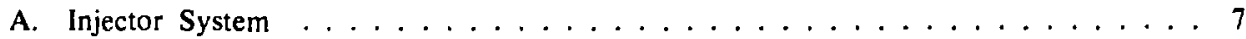

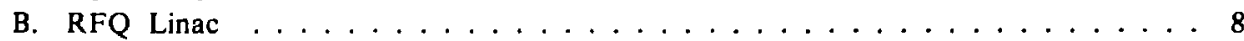

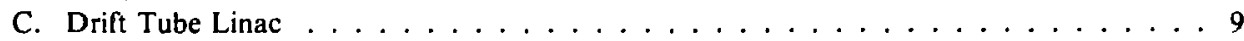

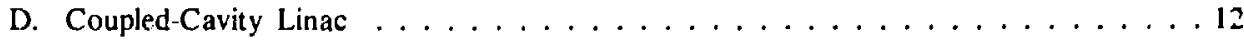

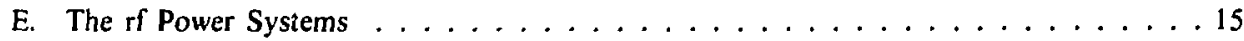
F. Computer Conisl and Instrumentation System $\ldots \ldots \ldots \ldots \ldots$

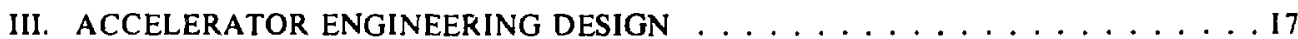

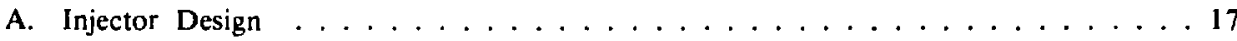

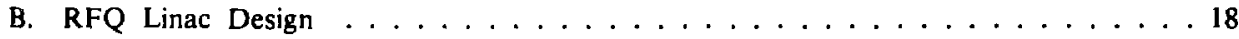

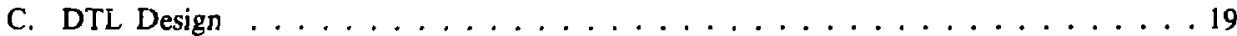

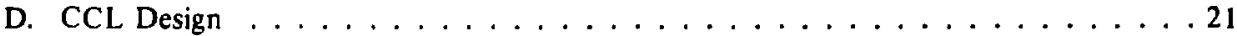

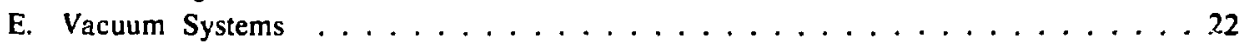

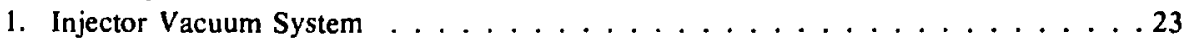

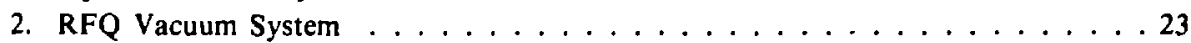

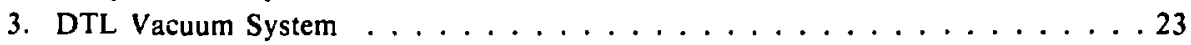

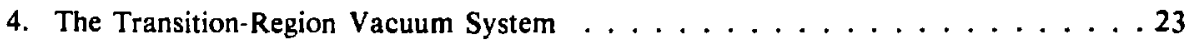
5. The CCL Vacuum Systems . . . . . . . . . . . . . . 24
6. The Target Area/Pion-Channel Lines . . . . . . . . . . . . . 24

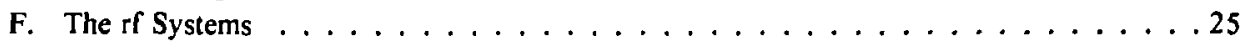

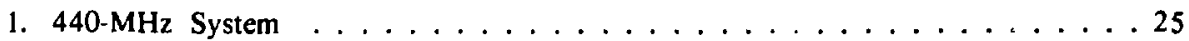

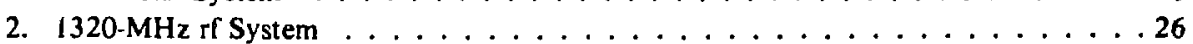

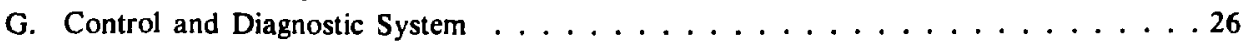




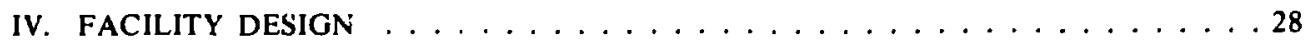

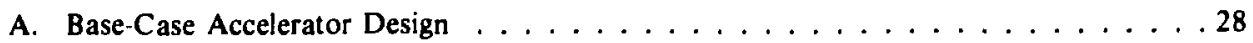

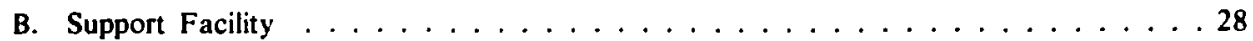

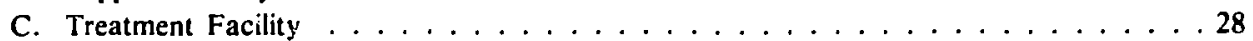

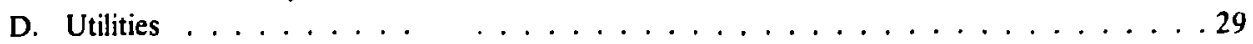

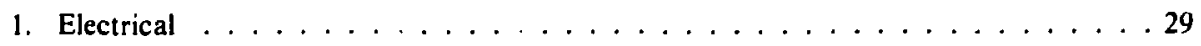

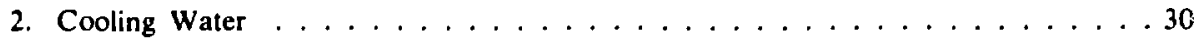

v. FACILITY CONSTRUCTION AND OPERATION $\ldots \ldots \ldots \ldots \ldots$

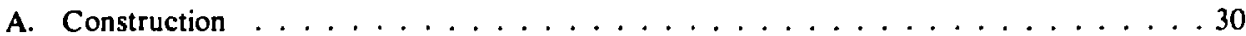

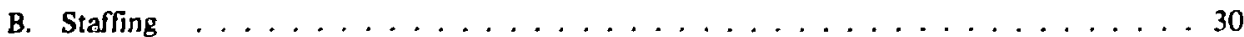

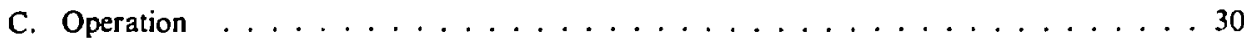

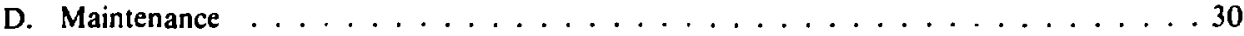

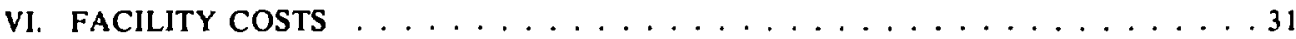

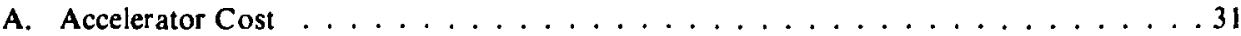

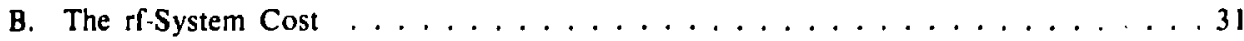

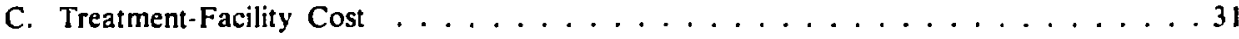

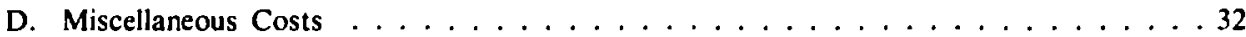

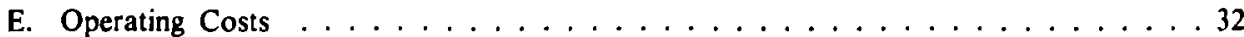

PUBLICATIONS RELEVANT TO THE PIGMI PROGRAM $\ldots \ldots \ldots \ldots$

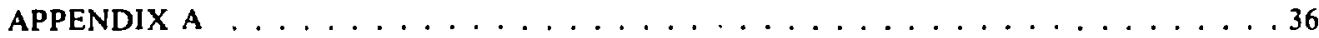

I. COMPONENT COSTS DETAILED COST ANALYSIS $\ldots \ldots \ldots \ldots \ldots \ldots$

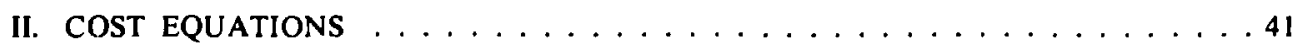

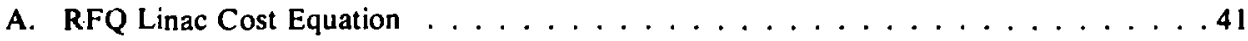

1. RFQ Resonator Manifold Cost. . . . . . . . . . . . . . . . 41

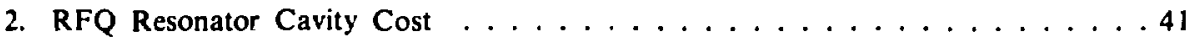

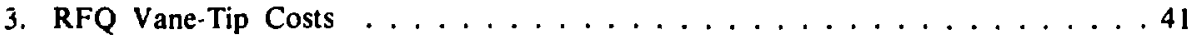

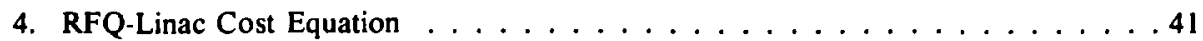

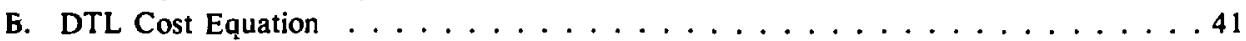

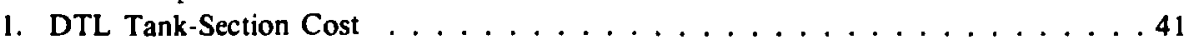

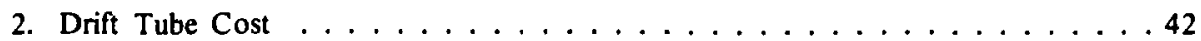

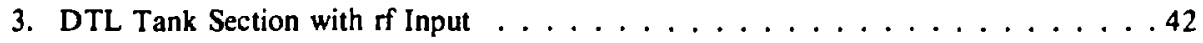

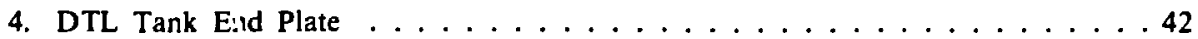

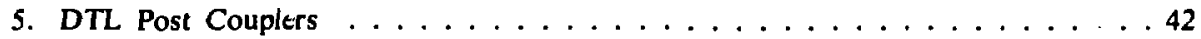

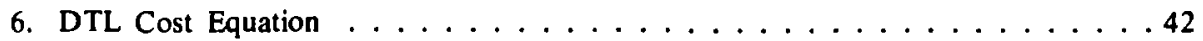

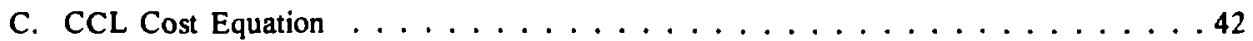

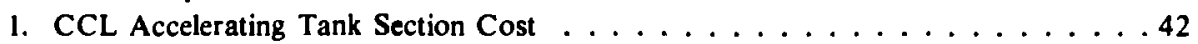

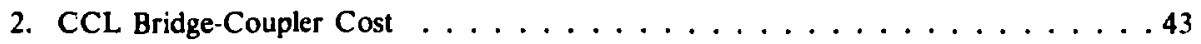

3. CCL Cost Equation ..................... 43 
APPENDIX B. PIGMI PROTOTYPE DEVELOPMENT ACHIEVEMENTS . . . . . . 44

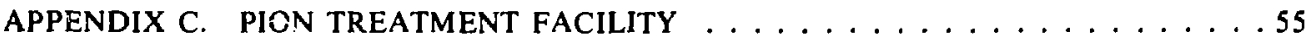

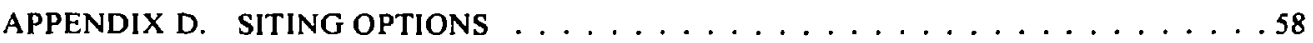

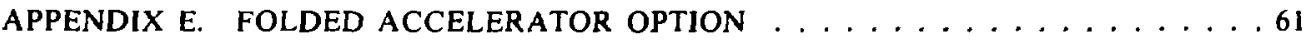

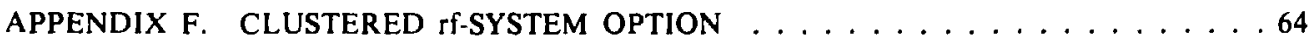

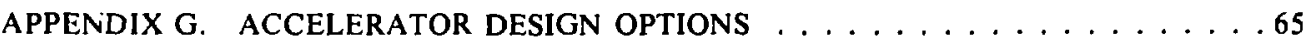

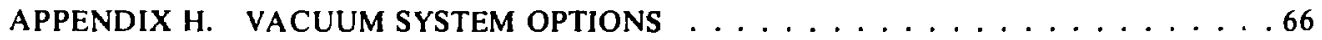

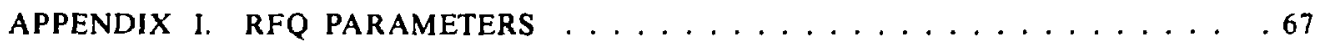

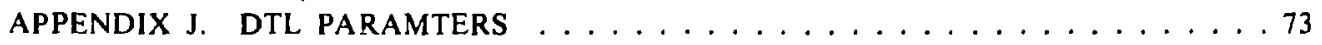

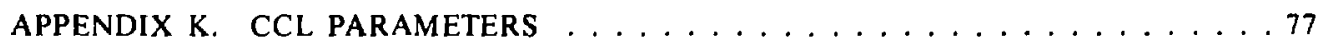

APPENDIX L. LIST OF CONTRIBUTORS TO PIGMI TECHNOLGGY . . . . . . . . . 80

\section{LIST OF TABLES}

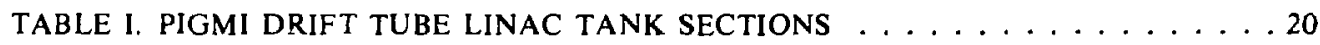

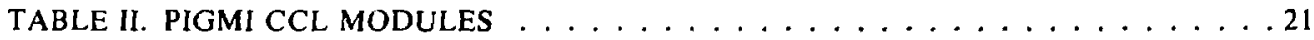

TABLE III. PIGMI FACILITY COST SUMMARY $\ldots \ldots \ldots \ldots \ldots \ldots \ldots$

TABLE A-I. ENGINEERING/PURCHASE/FABRICATION COSTS . . . . . . . . 36

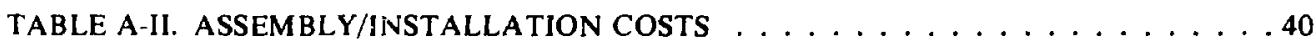

TABLE A-III. INITIAL START-UP/CHECK-OUT COSTS . . . . . . . . . . 40

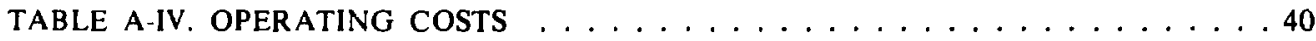

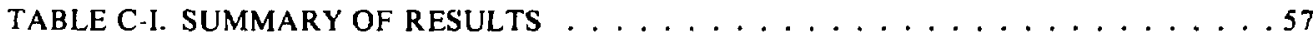

TABLE E-I. SOME DESIGN PARAMETERS FOR BENDING AND

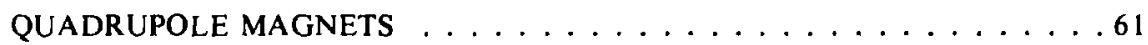

TABLE E-II. FIELD STRENGTHS OF THE QUADRUPOLE MAGNETS . . . . . . . . 63

\section{LIST OF FIGURES}

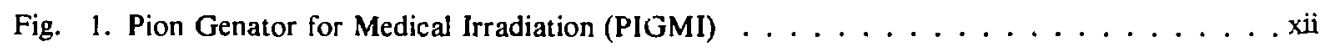

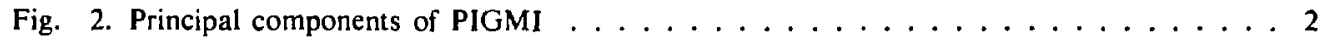

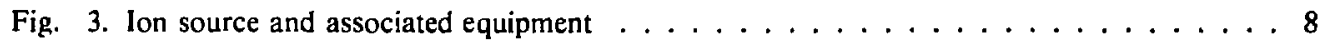

Fig. 4. Beam profile for the PIGM! injection system . . . . . . . . . . . . . . 8

Fig. 5. General configuration of the RFQ . . . . . . . . . . . . . . 9

Fig. 6. Computer-generated view of the RFQ vane tip . . . . . . . . . . . 10

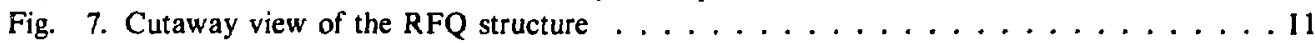

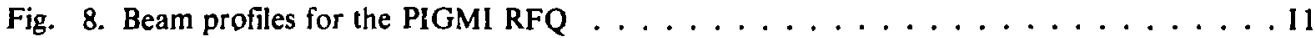

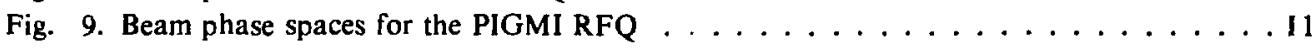

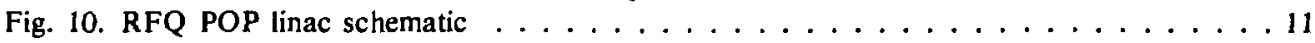

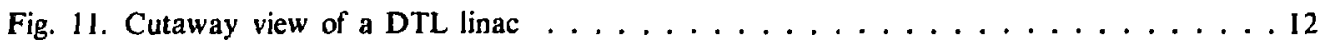

Fig. 12. DTL permanent-magnet quadrupole geometry $\ldots \ldots \ldots \ldots \ldots$

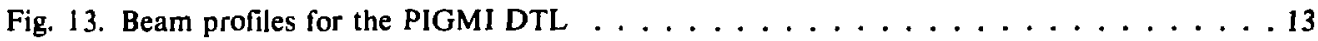

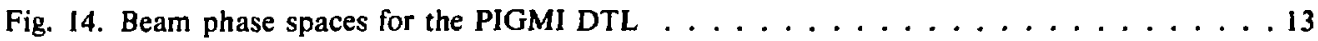

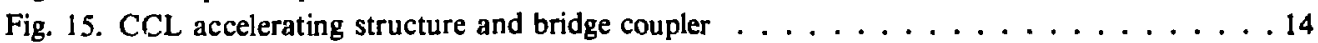

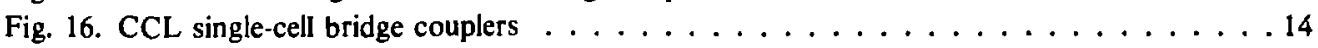




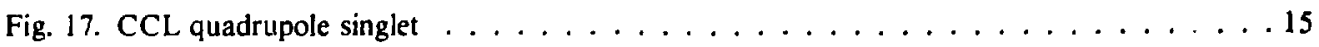

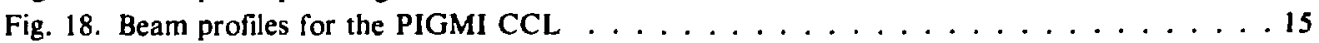

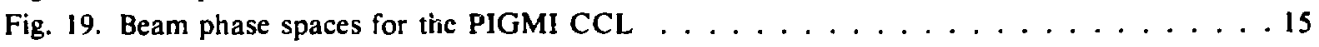

Fig. 20. PIGMI control-system configuration $\ldots \ldots \ldots \ldots \ldots$

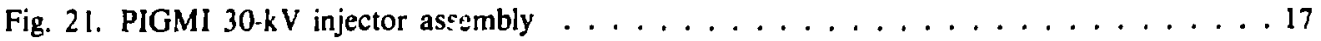

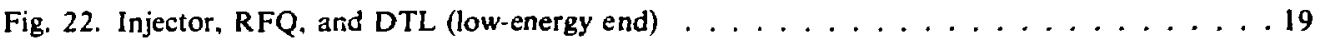

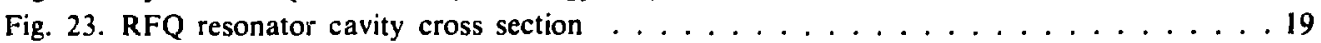

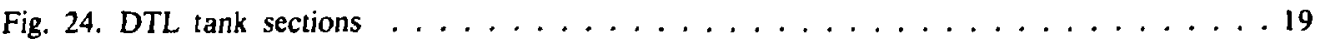

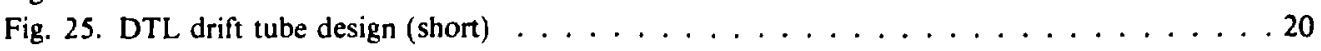

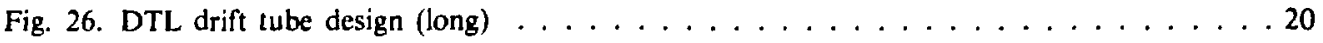

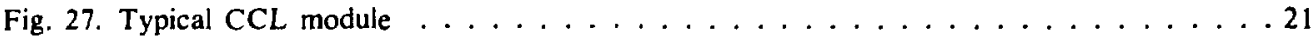

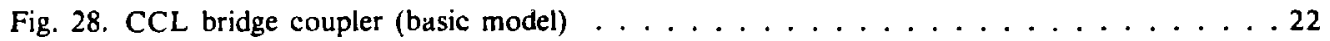

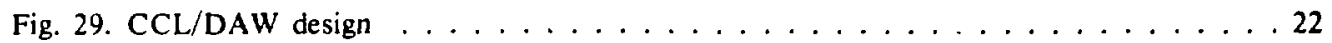

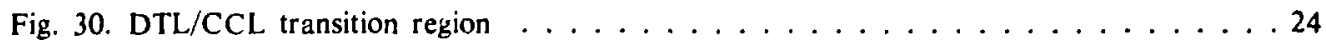

Fig. 31. CCL bridge coupler (with vacuum pumping) $\ldots \ldots \ldots \ldots \ldots$

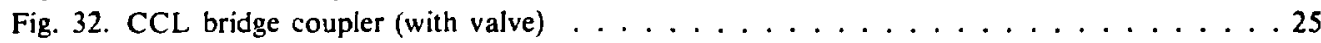

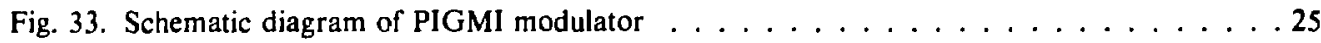

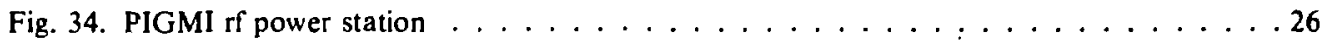

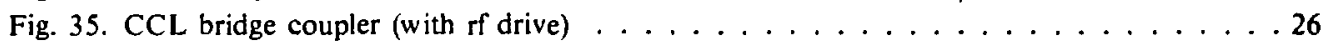

Fig. 36. Straight PIGMI with distributed $\mathrm{rf}$ system $\ldots \ldots \ldots \ldots \ldots \ldots$

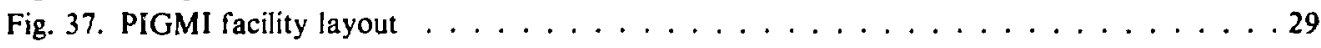

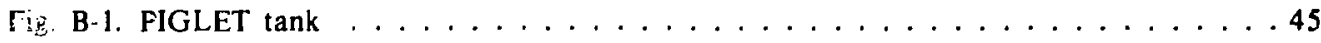

Fig. B-2. PIGLET drift tube (front view) $\ldots \ldots \ldots \ldots \ldots \ldots \ldots \ldots$

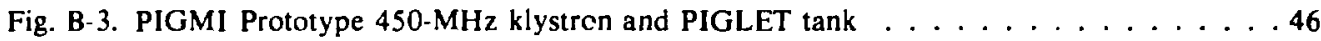

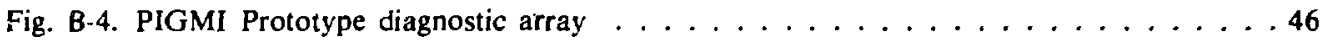

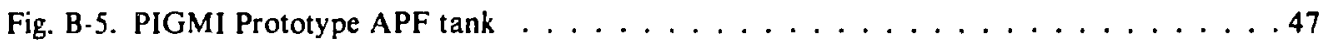

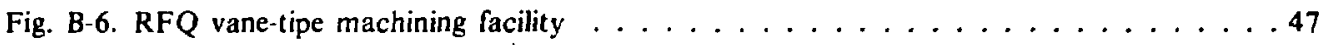

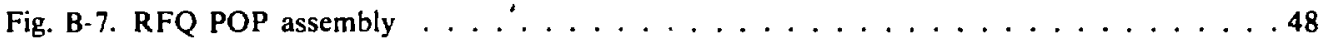

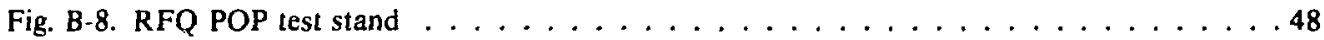

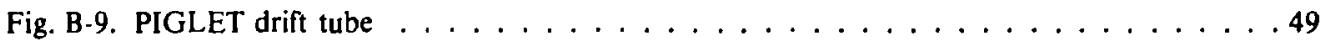

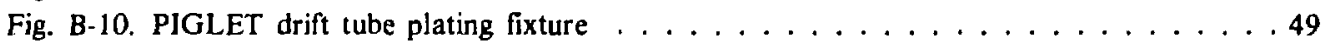

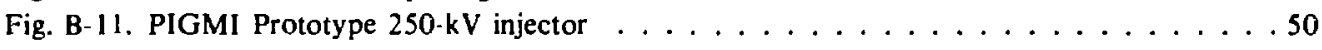

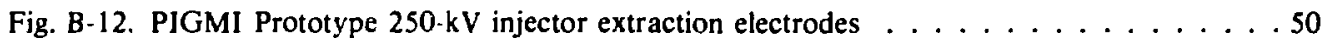

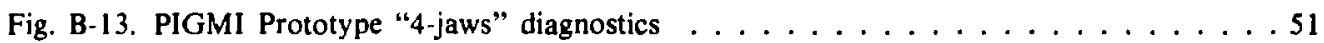

Fig. B-14. PIGMI Prototype focusing magnet $\ldots \ldots \ldots \ldots \ldots \ldots \ldots \ldots \ldots \ldots$

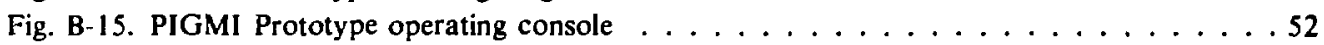

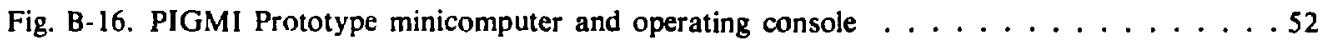

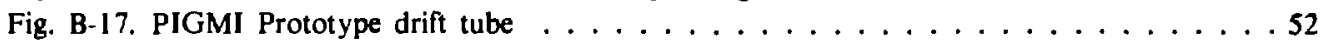

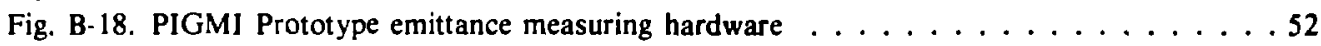

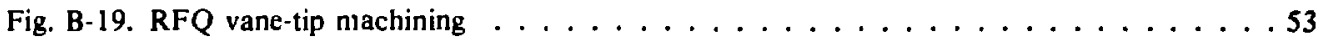

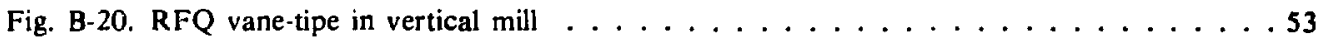

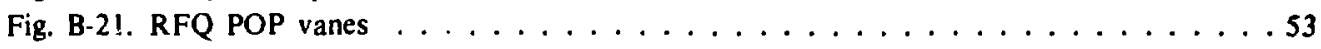

Fig. B-22. The 2380-MHz DAW test cavities for $\beta=0.5, \beta=0.6$, and $\beta=0.8 \ldots \ldots$. . . 54

Fig. B-23. DAW test cavities $(2380-\mathrm{MHz}$ size) $\ldots \ldots \ldots \ldots \ldots \ldots \ldots$

Fig. B-24. DAW assembly $(2380-\mathrm{MHz}$ size $) \ldots \ldots \ldots \ldots \ldots \ldots$ 


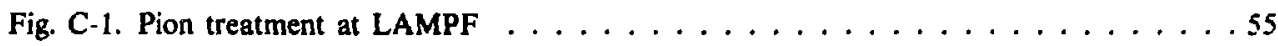

Fig. C-2. Geometrical configuration of the current sheet and solenoid pion channel. The z-axis is taken along the axis of symmetry. . . . . . . . . . . . . 56

Fig. C-3. Los Alamos concept for a PIGMI pion collection system . . . . . . . . . . . 56

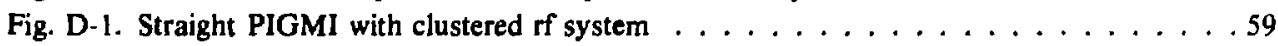

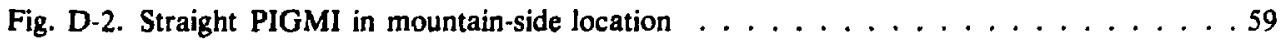

Fig. D-3. Folded PIGMI with clustered of system . . . . . . . . . . . . . . 59

Fig. E-1. An achromatic and isochronous bending system. (The bend radius of each

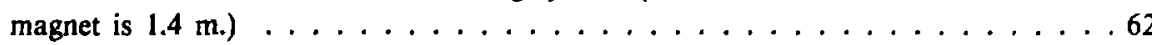

Fig. E-2. Particle trajectories of special interest. (The solid line and the dotted line show trajectories of particles of central momentum. The solid line labeled $\delta=0.2 \%$ is that of an off-momentum particle.) ............... 62

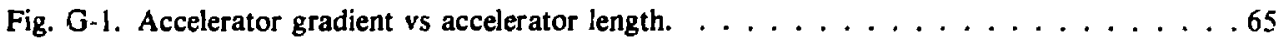

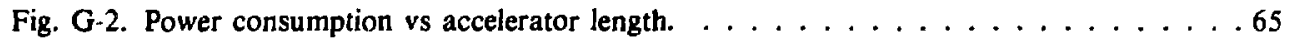

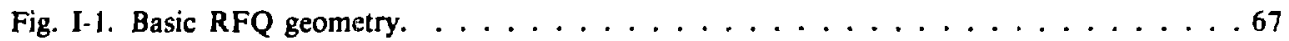

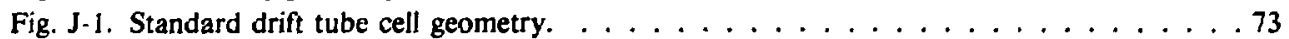

Fig. J-2. Standard drift tube "face contour." $\left(R_{D}=3.00 \mathrm{~cm} ; R_{C}=1.50 \mathrm{~cm} ; R_{N}=0.50 \mathrm{~cm}\right.$;

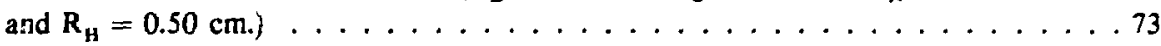

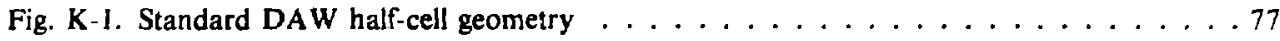




\section{SUMMAPY}

PIGMI is a compact linear accelerator used for pion (negative $\pi$-meson, a subatomic particle) production and cancer treatment in a hospital environment. In the PIGMI program, and elsewhere, technology has been developed that allows the construction of smaller, less expensive, and more reliable proton linacs (linear particle accelerators). This report summarizes the design of the PIGMI accelerator in its present state.

The major tecri.'urogical innovations resulting from the PIGMI program are listed in Fig. 1. The choice of protons over electrons as the accelerated particles is a particularly important advance, making the goal of $100 \mathrm{rads} / \mathrm{min}$ in $1 \mathrm{f}$ feasible within the costs described without further substantial development of the accelerator structure and the pion production target that would be necessary for an equivalent electron machine. (An electron machine with equivalent target or wall-plug power ratings would have considerably reduced performance-by more than a factor of ten.) Also, the proton machine allows a multipurpose facility with the added capability for radioisotope production and direct proton radiotherapy. Neutrons could be produced from a stub-out beam line.

Choosing $440 \mathrm{MHz}$ as the fundamental frequency (about twice the frequency of older machines) reduces the size of the structures and increases the achievable accelerating gradients. Because field gradients in a drift tube linac (DTL) structure of over $9 \mathrm{MV} / \mathrm{m}$ are achievable, the linac can be shorter. A new type of low-energy accelerating structure (the radio-frequency quadrupole, or RFQ), which allows the use of a very simple injector that operates at only $30 \mathrm{kV}$ and produces a beam of exceptionally good quality, has been tested. Experimental work in progress will partially determine the performance of a new type of high-energy accelerating struc ${ }^{4}$ ure, the disk and washer (DAW) structure, to be used in the coupled-cavity linac (CCL).

Sufficient experimental and developmental progress has been made to define in considerable detail an actual PIGMI facility. It will consist of a 30-kV injector, an RFQ linac to a 2.5-MeV proton energy, a DTL to $125 \mathrm{MeV}$, and a CCL to the final $650-\mathrm{MeV}$ energy, achieved in $\sim 134 \mathrm{~m}$. The RFQ and DTL will be driven by a single $440-\mathrm{MHz}$ klystron, a radio-frequency (rf) power-generating device; the CCL will be driven by six $1320-\mathrm{MHz}$ klystrons. The peak beam current will be $28 \mathrm{~mA}$. The beam's $60-\mu$ s pulse length and $60-\mathrm{Hz}$ repetition rate result in a $0.36 \%$ duty factor and a $100-\mu \mathrm{A}$ average proton beam current.

A detailed base-case PIGMI accelerator design is presented in the text of the report. The length and shape of the PIGMI accelerator would allow the machine to be installed under the parking lot of a hospital facility. Alternate configurations are presented in the appendices to indicate that some flexibility is available for siting. A complete PIGMI facility could be built in $\sim 2-3$ yr. Operation for $16 \mathrm{~h}$ per day would require a staff of eight. Maintenance would be done during the remaining eight hours per day and during a yearly maintenance shut-down of about 2 weeks.

Several options for the pion channel are being studied at various institutions. Channel efficiency, ease of tuning, and the characteristics of the delivered beam (parallel vs focused) are all factors under examination. Because selection of the preferred pion channel will be accomplished through clinical trials, 
the pion channel is not discussed in this report. The base-case PIGMI 100- $\mu$ S average proton current easily encompasses the range of present designs in terms of providing the desired pion production.

A cost estimate, based on the present level of the PIGMI design, is detailed in Appendix $A$. The fabrication and assembly cost of the accelerator only is estimated to be $\$ 10$ million in 1980 dollars. Site preparation (highly site-dependent) is estimated to be $\$ 5$ million. The cost of a treatment facility served by the accelerator (based on an incomplete design) is estimated to be $\$ 10$ million. Thus, the cost of a complete PIGMI facility is estimated to be $\$ 25$ million, of which the accelerator itself is $\sim 40 \%$.

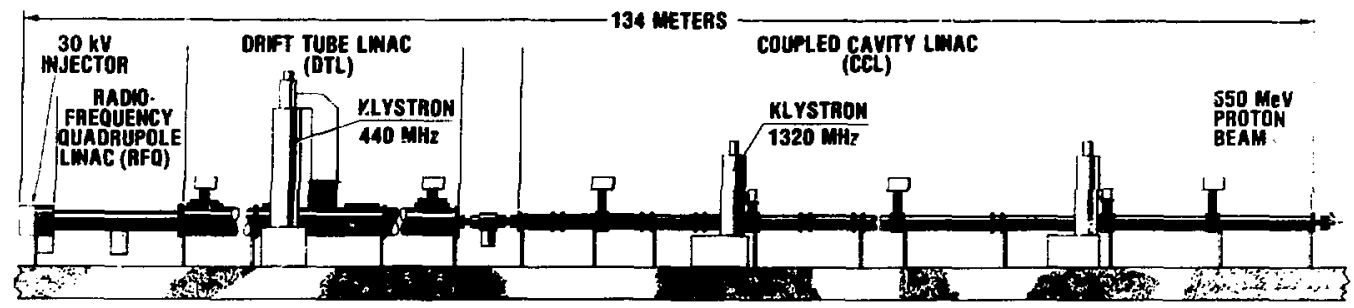

MAJOR TECHNICAL INNOVATIONS

HIGHER FREQUENCIES

HIGHER GRADIENTS

LOWER INJECTION ENERGY

RFO LINAC STRUCTUAE

POST-COUPLED DTL STRUCTURE

PERMANENT MAGNET OUAORUPOLE LENSES

DISK AND WASHER CCL STRUCTURE

COAXIAL BRIDGE COUPLERS

DISTRIBUTEO MICROFAOCESSOA CONTROL

\section{PROTON BEAM PARAMETERS}

INJECTION ENERGY

$30 \mathrm{keV}$

RFO/DTL TRANSITION ENERGY $2.5 \mathrm{MeV}$

DTL/CCL TRANSITION ENERGY $125 \mathrm{MeV}$

FINAL ENERGY

PEAK BEAM CURRENT

PULSE LENGTH

REPETITION RATE

AVERAGE BEAM CURRENT

$650 \mathrm{MeV}$

$28 \mathrm{~mA}$

$60 \mu \mathrm{s}$

$60 \mathrm{~Hz}$

$100 \mu \mathrm{A}$

PROTON LINAC PARAMETERS

$\begin{array}{lccc} & \text { FAEOUENCY } & \text { KLYSTRONS } & \text { GRADIENT } \\ \text { RFO \& DTL SECTION } & 440 \mathrm{MHz} & 1 & 6 \mathrm{mV} / \mathrm{m} \\ \text { CCL SECTION } & 1320 \mathrm{MHz} & 6 & 8 \mathrm{mV} / \mathrm{m}\end{array}$

Fig. 1.

Plon generator for medical Irradiation (PIOMI). 
PIGMI:

A Design Report

for

a Plon Generator for Medical Irradiations

Compiled by

Lash D. Haneborough

\begin{abstract}
PIGMI (Plon Generator for Medical Irradiations) is an integrated linear accelerator (linac) system developed under the auspices of the National Cancer Institute for specific application to cancer treatment in a hospital environment. In its full contiguation, PIGMI is a proton linac that is far smaller, leas expensive, and more reliable than previous machines that produce pions. Subsets of PICMI technology can be used with equal advantage to generate beams of other partisles (such as neutrons, protons, or heavy ions) that may be of interest for radiotherapy, radioisotope production, or other applications. The dramatic performance and cost advantages of this new breed of accelerator reault from a number of improvements. In the low-energy portion of the machine, a new type of low-energy linac (the radio-frequency quadrupole [RFO]) produces an exceptionally good quality beam, and uses a very simple $30-k V$ injector. In the second part of the machine (the drift-tube linac [DTL]), high accelerating gradients are now achievable with consequent reductions in machine length. Another new structure (the diak and washer (DAW]) will be used in the third and final section of the accelerator; this portion will also be relatively short and require few power amplifiers. The entire machine is designed for ease of operation and high reliability. The pion-production machine, discussed in this report, accelerates a 100- $\mathrm{A}$ average proton-beam current to $650 \mathrm{MeV}$; use of an efficient pion-collection channel would result in an average pion flux of over $100 \mathrm{rad} / \mathrm{min}$ in a volume of about $1 \mathrm{t}$. Pionchannel design is not treated in this report. Accelerator construction cost is estimated at $\$ 10$ million ( 1980 dollars); site preparation and treatment facility costs would bring the cost of a complete facility to an estimated $\$ 25$ million.
\end{abstract}




\section{SUMMARY BY SECTIONS}

\section{A. Accelerator Systems}

The accelerator portion of the PIGMI facility consists of an injector, and RFQ linac structure, a DTL structure, a CCL structure, a 440-MHz rf system, six $1320-\mathrm{MHz}$ rf systems, and a control and instrumentation system (Fig. 2). All of these components have been designed, fabricated, and tested in the PIGMI program at Los Alamos National Laboratory. The accelerator is $\sim 134 \mathrm{~m}$ long and is suitable for installation underground in a tunnel of modest cross section.

The 440-MHz AFQ linac, which dramatically simplifies the initial sections of the accelerator, can accept a proton beam with an energy of only $30 \mathrm{keV}$ and can bunch and accelerate it to a $2.5-\mathrm{MeV}$ energy in $\sim 1.8 \mathrm{~m}$, at which point the beam is ideally suited for injection into the DTL. The RFQ does this essential task better than any other known structure. Furthermore, it eliminates the need for a large and costly Cockcroft-Walton (a high-voltage dc generating device) power supply, a complex multicavity buncher system, a low-energy beam-transport system, and the associated control and instrumentation. The average accelerating gradient of the RFQ is $\sim 1.4 \mathrm{MeV} / \mathrm{m}$.

The DTL is a $440-\mathrm{MHz}$, single-cavity, post coupled, $\sim 30-\mathrm{m}$-long structure that accelerates the beam from 2.5 to $125 \mathrm{MeV}$. Inside are $150 \mathrm{drift}$ tubes, each containing a small permanent-magnet quadrupole lens to focus the beam. The DTL is driven by a single klystron coupled to the structure through an iris near the center of the DTL whose average axial electric-field gradient is $6 \mathrm{MV} / \mathrm{m}$.

The CCL, the longest part of the PIGMI accelerator, accepts the $125-\mathrm{MeV}$ beam from the $\mathrm{DTL}$ and accelerates it to $650 \mathrm{MeV}$ in $\sim 99 \mathrm{~m}$. The structure is composed of 108 tanks of 11 cells each, with the cell geometry of each tank optimized for the energy range it spans. The entire structure is connected by $10 ?$ single-cell coaxial jridge couplers into a single resor:ant unit. Each bridge coupler contains a permanent-magnet quadrupole singlet to focus the beam. The entire $C C L$ is driven by six klystrons couped to the CCL through an iris in six of the bridge couplers, periodically located aiong the structure. The average axial electric-fieid gradient is $8 \mathrm{MV} / \mathrm{m}$.

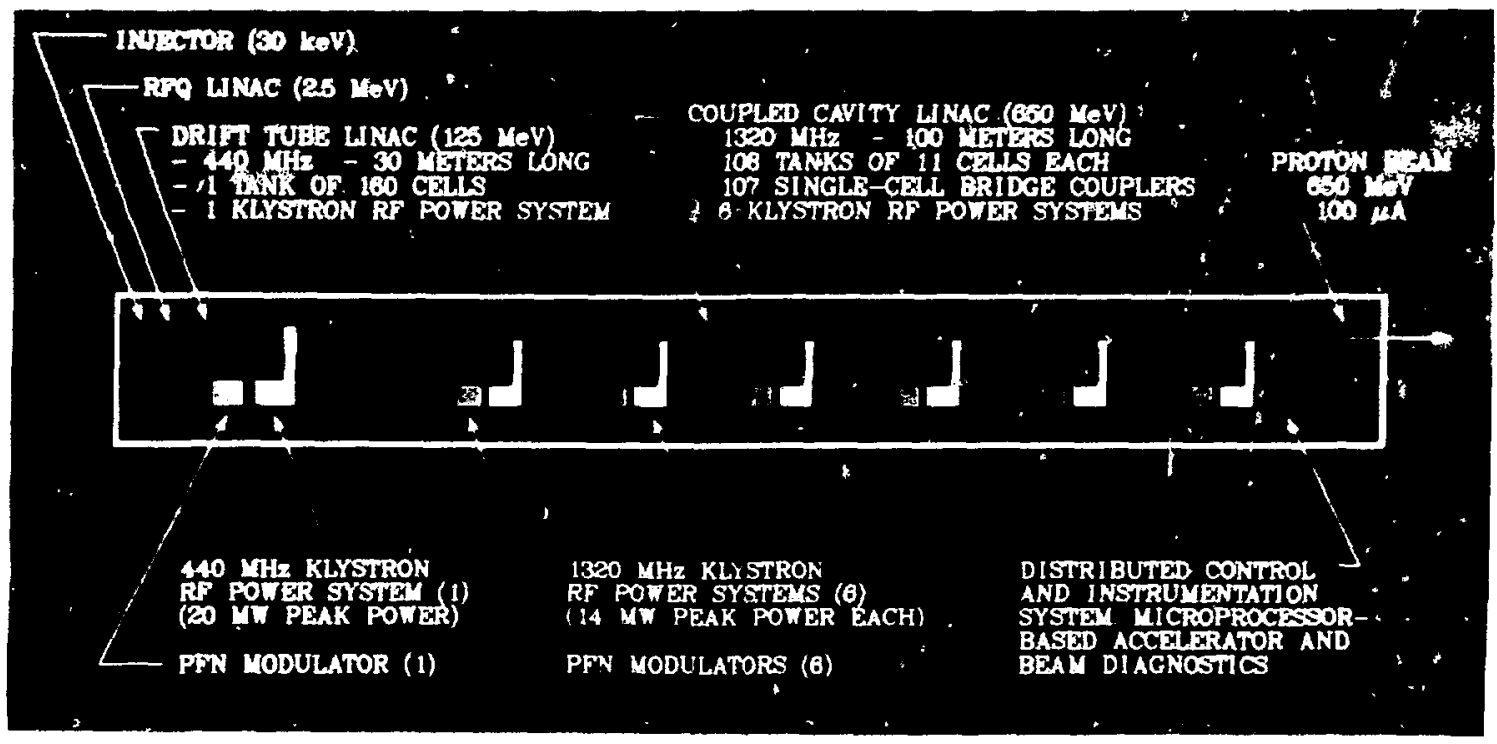

Fig. 2.

Principat componente of PICMI. 


\section{B. Accelerator Engineering Deaign}

A very attractive feature of the PIGMI accelerator is its simplicity. The injector operates at only $30 \mathrm{kV}$. Its power supply is shielded within a standard control rack, and voltage protection around the injector is provided by Lucite covers. The ion source is physically small but is based on conventional duoplasmation technology. Only one extraction gap is necessary with the extraction electrode beginning at ground potential. A simple einzal lens, operating at $30 \mathrm{kV}$, electrostatically focuses the beam into the RFQ. The distance from the extraction aperture to the RFQ is $16 \mathrm{~cm}$.

The 440-MHz RFQ accepts the 30-keV beam and focuses, bunches, and accelerates this beam to 2.5 $\mathrm{MeV}$ in $1.78 \mathrm{~m}$. Once tuned, the RFQ requires no further adjustments. It consists of a set of four specially machined vanes contained within a smalldiameter rf cavity. This RFO cavity is coupled through slots to the RFQ manifold, which in turn is resonantly coupled to the DTL structure.

The DTL is a refinement of the familiar post coupled Alvarez DTL structure. The structure, designed to resonant at $440 \mathrm{MHz}$, is fabricated from copper-plated steel. It accepts the $2.5-\mathrm{MeV}$ beam from the RFQ and accelerates it to $125 \mathrm{MeV}$ in $30.06 \mathrm{~m}$. One klystron feeds the DTL structure through a single iris. The drift tubes are small $(6-\mathrm{cm}$ diam) to reduce power consumption, and each one contains a quadrupole magnet made from permanent-magnet material. These permanent-magnet quadrupoles aliow a small drift tube diameter and require no cooling, power supply, nor active control. Experience has shown the DTL structure to be very reliable, requiring a minimuin of control once properly tuned.

The if systerns are relaiively simple, with one 440-MHz klystron required for the AFQ/DTL, and six $1320-\mathrm{MHz}$ klystrons required for the $\mathrm{CCL}$. The accelerator may continue to be operated at a slightly reduced beam current if one of the 1320 $\mathrm{MHz}$ klystrons must be turned off.

Except from some small steering magnets near the injector ion source, the transition region between the DTL and CCL contains the only electromagnets in PIGMI. Four electromagnetic quadrupoles and two steering magnets are located in this $1.50-\mathrm{m}$ region, which also contains vacuum isolation valves and beam-diagnostic equipment.

The CCL is a $1320-\mathrm{MHz}$ structure of the DAW type; it accelerates the beam from 125 to $650 \mathrm{MeV}$ in $98.93 \mathrm{~m}$. The CCL is divided into six modules, each fed through an iris by a $1320-\mathrm{MHz}$ klystron. A module consists of 18 accelerating tanks (each containing 11 DAW accelerating cells) and 18 coaxial bridge couplers. Each briage coupler contains a permanent-magnet singlet; some bridge couplers also contain other components. Because the entire $\mathrm{CCL}$ is electrically coupled as a resonant unit, the $\mathrm{rf}$ control is simple, requiring only one amplitude and one phase to be set.

The accelerator vacuum is maintained by a system of turbomolecular vacuum pumps and ion pumps. Turbomolecular vacuum pumps require periodic maintenance but may be valved off from the accelerator. Ion pumps are extremely re":able and are connected directly to the accelerator with no isolation valves.

A modest, distributed, MULTIBUS-based control system of the type being developed for other projects at Los Alamos and Fermi Nationai Accelerator Laboratory (Fermilab) can handle the control and diagnostic requirements of this facility. In all, there are very few power supplies and active control parameters. PIGMI is designed to incorporate the minimum number of the most reliable components.

\section{Facility Design}

There are many alternatives for the ultimate configuration of PIGMI. A straight PIGMI with a distributed $r$ system is considered to be the basecase configuration that most easily describes the system; other accelerator configurations (discussed in Appendix D) show that the design can be site specific. The $440-\mathrm{MHz}$ klystron (located in an above-ground service building) delivers if power through a vertical waveguide to the DTL located in a rectangular tunnel. The width of the DTL tunriel is dictated by the requirement for a minimum 1-mwide aisle, so that equipment can be moved down the tunnel alongside the accelerator. The 1320$\mathrm{MHz}$ klystrons and pulse-forming network (PFN) cabinets are located in the CCL portion of the tunnel, whose required width and height allow removal of a klystron tube or tank section intact. These designs are based on the desire to arrange the accelerator part of a PIGMI facility to fit, for example, under the parking lot of a typical hospital complex. 


\section{Facility Construction and Operation}

A complete PIGMI facility will require a construction time of $\sim 2-3 \mathrm{yr}$ from the beginning of site preparation to the production of pions in the treatment facility. Site preparation requires $\sim 1 \mathrm{yr}$, accelerator installation and checkout require 6 months, and treatment facility checkout requires an additional 6 months.

Two-shift (16 hours per day) operation can be done with a staff of eight. A yearly maintenance shutdown of approximately two weeks is required; routine weekly maintenance can be done during the 8-hours-per-day shutdown time.

\section{E. Facility Costs}

The accelerator portion of PIGMI is estimated to cost $\$ 10$ million, excluding site preparation, architectural considerations, service building/office space, cooling costs, accelerator tunnel construction costs, patient handling facilities, and contingency funds. These costs, which will add $\sim \$ 5$ million to the total, will be dictated by the needs or location of the medical facility where a PIGMI will be located. The pion treatment facility is estimated to cost another $\$ 10$ million, bringing the total cost of a complete PIGMI facility to approximateiy $\$ 25$ million in 1980 dollars. 


\section{INTAODUCTION}

\section{A. Background}

Since its inception, cancer radiotherapy has become increasingly dependent upon particle accelerators for the generation of radiation. Most of these accelerators were first developed by physicists conducting research directed toward understanding the structure of matter. During the last three decades, accelerator technology has grown rapidly, leading to the ability to produce various kinds of particle beams in different energy and iniensity regimes. The radiotherapeutic potential of some of these particles (including protons, neutrons, pions, and heavy ions) is, or soon will be, evaluated at several institutions, both clinically and through the accumulation of radiobiological data. Some beams also are being used for the production of medically useful radioisotopes and for charged-particle radiographic studies.

The potential advantages of using protons, neutrons, pions, and heavy ions for cancer radiotherapy have been extensively discussed. These particle beams possess one or more of the following characteristics that may make them superior to conventional radiations: (1) rapid, flexible beam shaping and energy variation by magnetic delivery system; (2) well defined range, with increased dose delivered near the end of the range, implying considerable sparing of normal tissue anterior and posterior to the tumor; and (3) a significant fraction of the dose to the tumor in the medium and high linear-energy transfer (LET) region. Negative pions and heavy ions possess all three advantages, protons both (1) and (2), and neutrons only (3). However, proton accelerators for producing therapeutically useful pion beams are considerably larger and more expensive than those for producing neutrons and protons. If current biomedical studies with these particles indicate that dose localization is much more important than high LET, then proton-therapy beams may suffice for many clinical applications. Conversely, if the destruction of hypoxic cells is of paramount importance, then neutrons may be the most practical radiation. If all the advantages prove worthwhile, pion generators may be justified and required.

Pions can be produced efficiently by impinging proton or electron beams (in the energy range of 600 to $800 \mathrm{MeV}$ ) upor: appropriate targets. These energies can be atta:ned in linear or circuler accelerator systems, but at the required currents. linear machines are necessary. For equivalent cion production, the required electron current is $\sim 30$ times larger than the required proton current; a beam-power penalty of 30 is very serious in these times of high energy.costs. Also the desired level of $\sim 100 \mathrm{rad} / \mathrm{min}$ in a $1 . /$ volume places an electron accelerator beyond the performance limit ever produced by electron-linac technology. An electron linac with pion-production capability equal to that of the base-case PIGMI design is outside present design capability by about a factor of six. Extremely high average-beam power also makes pion-production target fabrication and cooling very difficult. By reducing performance, an electron-beambased facility is possible, but considerable costs associated with more complex pion delivery systems are added. In addition, a proton-linac-based facility gives access to medically useful radioisotope production capabilities and allows direct proton radiotherapy to be implementec. A truly multipurpose facility can be designed around a PIGMI-based facility.

In addition to negative pions, other particles (such as neutral and positive pions, scattered protons, electrons, and neutrons) emanate from the target. The medical pion generator must incorporate an efficient channel for collecting and transporting the negative pions to the treatment area. This channel must accept and deliver as many of the negative pions as possible to the treatment area to minimize primary proton currents, reduce facility cost, and avoid serious problems from induced radioactivity. The channel must efficiently reject unwanted particles yet be reasonably short so that most of the unstable negative pions are delivered for treatment before decaying. The desired dose rate for pion radiotherapy is $\sim 100$ rads/min in a volume of $\sim 1 i$. To achieve such dose rates, the average primary proton currents range from $\sim \mathbf{3 0} \mu \mathrm{A}$ (with a high-efficiency pion-collection system) to $\sim 200 \mu \mathrm{A}$ (with a more conventional pion-collection system).

Present day clinical and biological experiments with pions, neutrons, and protons are carried out with particle accelerators that were constructed primarily for basic physics research. Such accelerators were designed with criteria (for example, duty factor) that are not necessarily relevant to medical application. Effective research capability was emphasized rather than cost, size, and complexity, all of which must be minimized for widespread medical use. However, considerable advances in linac technology pertinent to medical linacs were made at Los Alamos during the successful development of a high-intensity $800-\mathrm{MeV}$ 
proton linac that serves as the heart of the Clinton P. Anderson Los Alamos Meson Physics Facility (LAMPF). Linear accelerators are attractive as medical pion generators for several reasons. Linacs can accelerate large currents with very low beam loss ar. $\mathrm{J}$ generally exhibit high ac-power-to-beam-power conversion efficiencies. In contrast to most ciicular machines, beam extraction in linacs is not difficult. Commercially available medical electron linacs in the 4- to $35-\mathrm{MeV}$ range are simple, reliable, and economical to operate. Most of these use the type of accelerator structure developed for LAMPF.

The goai of the ongoing PIGMI program is to provide the design for a medically practical generator of pion beams of sulficient intensity and quality for therapeutic applications. The necessary work of designing a medical proton linac entails evaluating a number of options for each of the major subsystems of a linac beam-deiivery system. Such subsystems include the injector; the low-energy, medium-energy, and high-energy linac sections; rfpower systems; control system; target assembly; and the pion-collection and transport systems. Detailed beam-dynamics studies have been done to assess innovative configurations that could result in major accelerator subsystem simplification or cost reduction. Prototype fabrication and testing of these subsystems have been an essential part of the elfort. The research program for component development of the pion generator has emphasized the constraints inhererit in providing extensively useful medical equipment. These constraints are compactness, reasonable construction and operating costs, reliability, and simplicity of operation. The result of these studies is a medical pion-generator design compatible with typical hospital facilties and with well established operating parameters and cost.

Briefly, the proton linac for producing therapeutic pion beams as now envisioned in the PIGMI design will corisist of a suitable low-voltage injector (30 kV) feeding a low-energy RFQ linac section to $2.5 \mathrm{MeV}$, followed by a post coupled DTL section to $125 \mathrm{MeV}$, and then a DAW/CCL high-energy section to the final $650-\mathrm{MeV}$ energy. Electric field gradients up to $8 \mathrm{MV} / \mathrm{m}$ keep accelerator sizes within acceptable limits for most major hospital sites. High-frequency operation provides a smaller system than standard pruton-linac design and allows use of more conventional rl-power-generation devices. Permanent-magnet beam focusing, extensively used, provides inexpensive and compact focusing elements.
New technological concepts evaluated in the PIGMI program include (1) post coupled linac structures at low energies, (2) permanent-magnet focusing systems, (3) high electric-field-gradient operation, (4) RFO accelerator for very low particle energies, (5) accelertor resonators engineered for ultrahigh vacuum, (6) cathode-puised klystron systems for high-power operation, (7) coupled-cavity DAW linac structure for economical fabrication costs of the accelerator's high-energy section, (8) leveling, bright-acid, copper-plated accelerator components, (9) resonantly coupled accelerating structures to reduce the complexity and cost of the If system, and (10) relatively low energy (and voltage) injection systems to simplify design and operation.

Experiments and studies are continuing, and further design refinements will probably occur during 1981. This work is the product of many individuals who have contributed to the development of PIGMI technology; these contributors are listed in Appendix L.

\section{B. Pion Requirement for Cancer Treatment}

Pions are produced by nuciear interactions when sufficient free energy is available to materialize the particle (the pion) responsible for the strong nuclear force. This conversion of energy into mass (the pion has a rest mass corresponding to 140 $\mathrm{MeV}$ ) is, in some ways, the inverse of a nuclear explosion, where particle mass is converted into energy. The final capture of a pion restits in the conversion of mass back into energy, this time within the human body. As one might expect, the production of pions depends on (1) the incident projectile type, energy, and intensity; (2) the target material and size; and (3) the emerging pion charge state, energy, and direction with respect to the incident projectile begm. Unfortunately, a complete set of data is not avanlable for precisely defining the optimal projectile energy, pion energy, and pioncollector type; however, pion production is known to te a vieak function of proton energy above 650 MeV. Although SIN* and TRIUMF* operate at energies lower than $600 \mathrm{MeV}$ to prevent dissociation of the $\mathrm{H}^{-}$, this energy is considered too low for PIGMI. Design of the pion channel is important in determining the energy and current of ihe primary beam. Typical pion doses of $100 \mathrm{rad} / / /$ treatment are desirable for average treatment volumes of 2.7 . Dose ra:es of $50 \mathrm{rad} / \mathrm{min}$ into a iter volume

\footnotetext{
- See glossary.
} 
(resulting in 5-10 min per treatment) are considered the minimum acceptable. To satisfy the dose-rate requirement for pion therapy, a 50- to $100-\mu \mathrm{A}$ proton beam at $\sim 650 \mathrm{MeV}$ is required. Many costs are a strong function of proton energy (power, transport-system complexity, shielding, remote handing, etc.), but the duty factor is not important for medical applications. For economic reasons, the duty facior should be made as low as practical, but if beam losses are kept low, pion dose rates could be increased by increasing accelerator duty.

The number of target cells, collector channels, and treatment rooms depends partly on the number of required patient treatments per day. Beam-off times as short as 3-min-per-patient setup have been achieved at LAMPF. Assuming singletarget operation, only three treatment rooms may be necessary, two with vertical ports and one with a horizontal port.

\section{Accelerator Design Philosophy}

The design philosophy of PIGMI is to provide a linac tailored to the need's of the medical community by extending existing technology and by developing new technology. Such a linac must be relatively inexpensive and small, provide the required beam irtensity and energy, be simple and econorrical to operate, and be extremely reliable.

A primary design concern was minimizing the length of the machine; this was done by increasing the electric field gradients in the accelerators. To simplify (and reduce the cost of) the low-energy end of the accelerator, the injector voltage was reduced to a minimum. Fabrication costs were minimized by using inexpensive materials, simple designs, and uncomplicated (but not necessarily conventional) fabrication techniques. Simple, reliable operation was a major goal, achieved by highly coupled accelerator structures that require a minimum number of knobs to control or alter their performance. Operating cost was reduced by the use of computer controls (which minimize the number of, and demands on, the operating staff), by simple and relatively efficient if systems, by permanent-magnet technology (which requires no power supplies and no cooling), by some redundance of essential components, and by an emphasis on the development of reliable hardware and software.
With these general guidelines, the PIGMI design has been developed. For this report a base-case accelerator facility has been chosen as the design that most clearly illusirates the features of the PIGMI accelerator. It is an $\sim 134-m$-long proton linac with a distributed rf-power system located in a horizontal, rectangular-cross-section underground tunnel that contains the six $1320-\mathrm{MHz}$ klystron systems. The $440-\mathrm{MHz}$ klystron system is located above ground in a service building with a short vertical run of waveguide to the DTL. Options to this base-case PIGMI accelerator facility are presented in Appendices $D, E, F, G$, and $H$.

\section{ACCELERATOR SYSTEMS}

\section{A. Injector Syalem}

The injertor system has t:aditionally been an expensive and complicated component of proton linacs. The conventional injection energy of $\sim 750$ $\mathrm{keV}$ was reduced to $250 \mathrm{keV}$ by the alternatingphase-focused (APF) structure in the PIGMI Prototype. It was further reduced to $100 \mathrm{keV}$ in the RFQ proof-of-principle (POP) experiment, and was firially reduced to $30 \mathrm{keV}$ for PIGMI. Injector operation at $30 \mathrm{kV}$ dramatically simplifies the design, allowing the ion source and associated electronics to be enclosed in a small vacuum housing and a single equipment cabinet (Fig. 3).

The 30-keV injection energy satisfies the RFQ requirement for efficient bunching in a minimum distance and the requirement for reliable operation of the single-gap high-brightness extraction system. Because of this low energy, electrostatic focusing of the ion beam is more effective than the magnetic focusing used in the PIGMI Prototype. A three-element unipotential einzel lens was designed to provide this electrostatic focusing; the calculated beam profile for a 32-mA proton beam extracted from the ion source and transported through this system is shown in Fig. 4.

The einzel lens was selected because it is simple to fabricate, requires minimal space, and requiles no power and no cooling in comparison with mignetic focusing. The excitation of this lens can be derived from a high-voltage divider system on the injector power supply. Calculations of this lens and extraction system have shown that ion currents $\sim 20$ to $35 \mathrm{~mA}$ can be focused into the RFQ with a lens voltage of $\sim 20$ to $30 \mathrm{kV}$. Below $20 \mathrm{~mA}$ of extracted 
beam current, the divergnce of the beam is toc large to allow all of the beam to enter the einzel-lens aperture, although most of the beam entering the lens is focused into the RFQ.

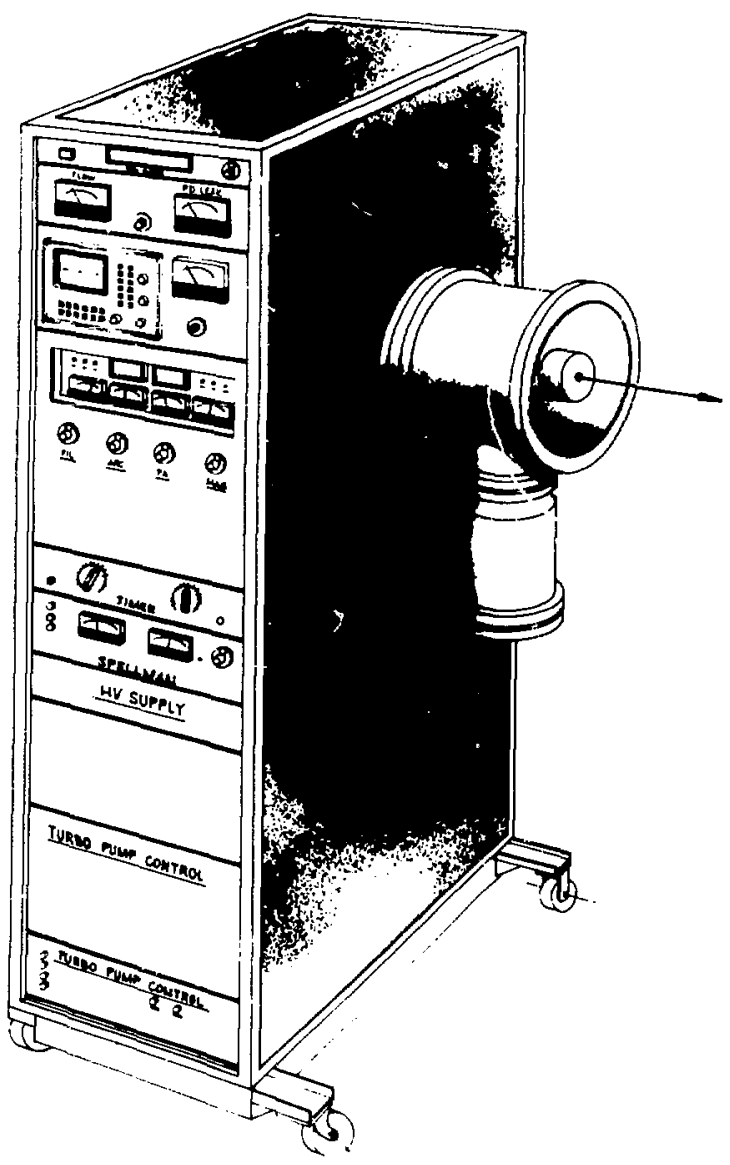

Fig. 3.

Ion source and associated equipment.

\section{B. AFO Linac}

The RFQ linac represents a revolutionary new - focusing, bunching, and accelerating structure that promises to be an important part of many future proton, light ion, and heavy ion iacilities. The first RFQ structure outside the USSR was tested in the Los Alamos PIGMI laboratory in Feburary 1980. A series of highly successful tests confirmed the general properties of the RFQ structure and gave excellent agreement between the measured properties of the beam and the predicted performance. These tests also confirmed the RFQ's stable operation, which is remarkably insensitive to errors in injection energy, if excitation, and structural fabrication.

The RFQ is considered by many to be a superb answer to one of the last remaining questions of how to build simple, reliable, and inexpensive proton or ion linacs. The RFQ offers the lowest injection energy of any kiown linac structure; it is the best buncher ever conceived because it bunches and accelerates the beam with less emittance growth than any other system. It represents the best transformation ever developed between the continuous beams that come from ion sources and the bunched and accelerated beams required by conventional linacs. The RFQ eliminates the need for large and costly Cockcroft-Walton power supplies, complex multicavity buncher systems, and lengthy beam-transport systems.

Essentially, the RFQ is a varie-loaded cylinder excited in a modified $\mathrm{TE}_{210}$ cavity mode that produces a strong electric quadrupole field near the axis (Fig. 5). The transverse components of this field (uniform in space and alternating in time) give rise to strong, alternating-gradient focusing effects that can focus particle beams traveling along the axis of the structure. By scalloping the vane-tip geometry, a longitudinal component is introduced

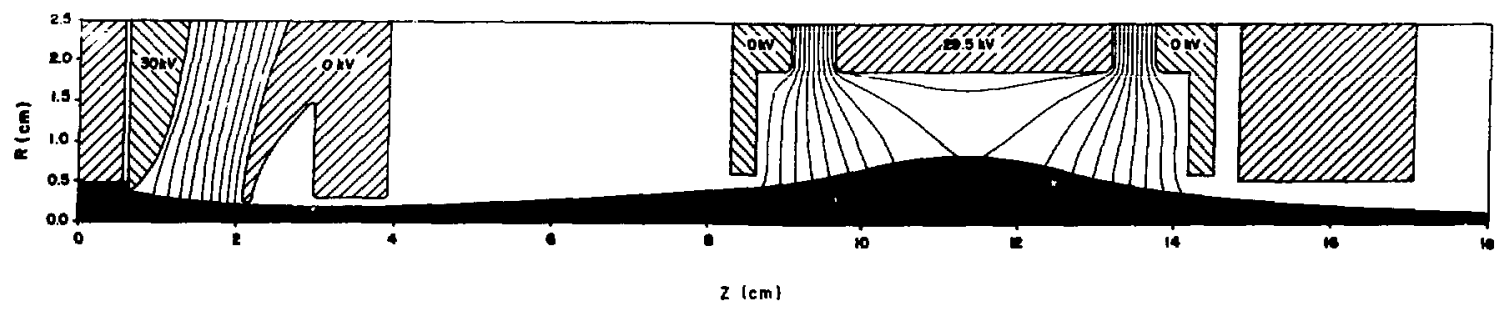

Fig. 4.

Beam protile for the PICMI injection syatem. 


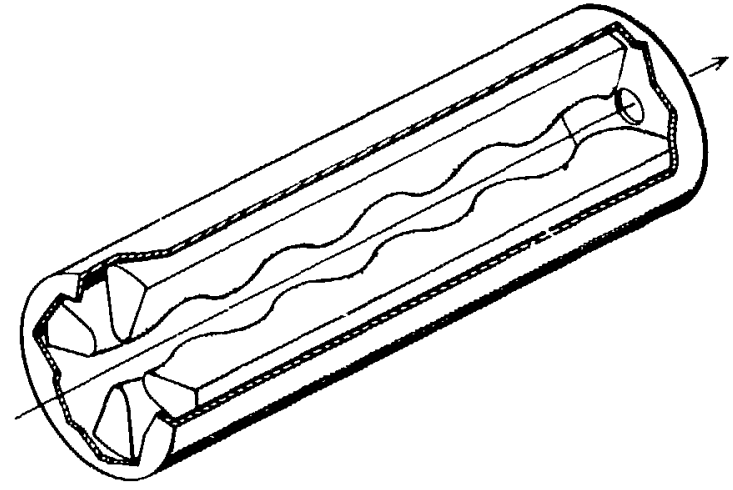

Fig. 5.

General configuration of the RFO.

into the rf electric field near the axis that can be used to bunch and accelerate the beams. Thus, the RFQ structure can focus, bunch, and accelerate beams of charged particles. For the first time, a linac can be configured for adiabatic capture of continuous beams at low energy. The configuration introduces the scallops slowly so that the structure acts primarily as a buncher at the beginning and primarily as an accelerator at the end. A computergenerated picture of such a vane tip is shown in Fig. 6 , and a cutaway view of the RFQ structure is shown in Fig. 7.

The RFQ contains four regions: the radialmatching section, the shaper, the gentle buncher, and the accelerating section. In the radial-matching region, the vane aperture is tapered to adjust the focusing strength from almost zero to its full value in a very short distance; this allows the dc injected beam to be matched into the time-dependent focusing. In the next two regions (shaper and gentle buncher), the beam is adiabatically bunched as it is accelerated. At the end of the gentle buncher, the beam's synchronous phase angle reaches its final value, and the bunched beam is then accelerated in the final accelerating section. In this section, the vane radius, vane modulation, and phase angle are held constant to obtain the maximum possible acceleration gradient.

The PIGMI RFO was designed and its performance analyzed with the RFQ-linac design and simulation computer code PARMTEQ. The RFQ, having an operating frequency of $440 \mathrm{MHz}$, is designed to accept a $30-\mathrm{keV}$ proton beam from the ion source, then to focus, bunch, and accelerate that beam to a $2.5-\mathrm{MeV}$ energy in $1.78 \mathrm{~m}$. Each vane tip has 135 scailops varying in length from $0.27 \mathrm{~cm}$ at the beginning to $2.47 \mathrm{~cm}$ at the end. The minimum radial aperture of the structure is $1.9 \mathrm{~mm}$. The RFQ is designed to capture $92 \%$ of a 30-mA beam to yield the PIGMI 28-mA design current. The size, phase, and energy profiles of the beam are shown in Fig. 8. The normalized emittance $[($ area $/ \pi) \cdot \beta \gamma]$ of the input beam was taken to be $0.048 \pi \mathrm{cm} \cdot \mathrm{mrad}$. The input and output phase spaces of the beam are shown in Fig. 9. The transverse emittance growth (for the $90 \%$ contour) is a factor of $\sim 1.4$, which is better than can be achieved by any known buncher/linac combination.

A coaxial if manifold was developed for the RFQ POP experiment (shown schematically in Fig. 10) to provide a symmetrical. multislot driving arrangement for an RFQ cavity. Surrounding the RFQ cavity, the coaxial if cavity is excited in a coaxial TEM mode. The magnetic fields in the TEM mode are orthogonal to the magnetic fields in the RFQ mode. These fields can be coupled by diagonal slots, where the slot angles are determined by the magnitude and direction of the magnetic fields near the slots. A technique for resonating these slots to provide resonant coupling between the RFQ manifold and the RFQ cavity is under investigation. Coupling the RFQ manifold to the DTL so the RFQ can derive its if power from the DTL eliminates the necessity for a separate if power source and drive line for the RFQ. This technique is scheduled to be tested at the PIGMI laboratory in 1981 in the 4.2-MeV PIGMI Primie acceleratcr.

\section{Drift Tube Linac}

Because the vast majority of the proton linacs are of the DTL type, and because most of the linacs designed in the last $10 \mathrm{yr}$ use post couplers (developed at Los Alamos) to stabilize the distribution of the electromagnetic fields within the structure, the properties and performance of these structures are well known.

The PIGMI DTL (Fig. 11) differs from conventional DTLs primarily in scale, being more than twice the frequency, and hence less than half the crosssection diameter of conventional linacs. PIGMI's high frequency and low duty factor make its optimum accelerating gradient higher than normal for conventional linacs: therefore, the PIGMI DTL is significantly shorter. 


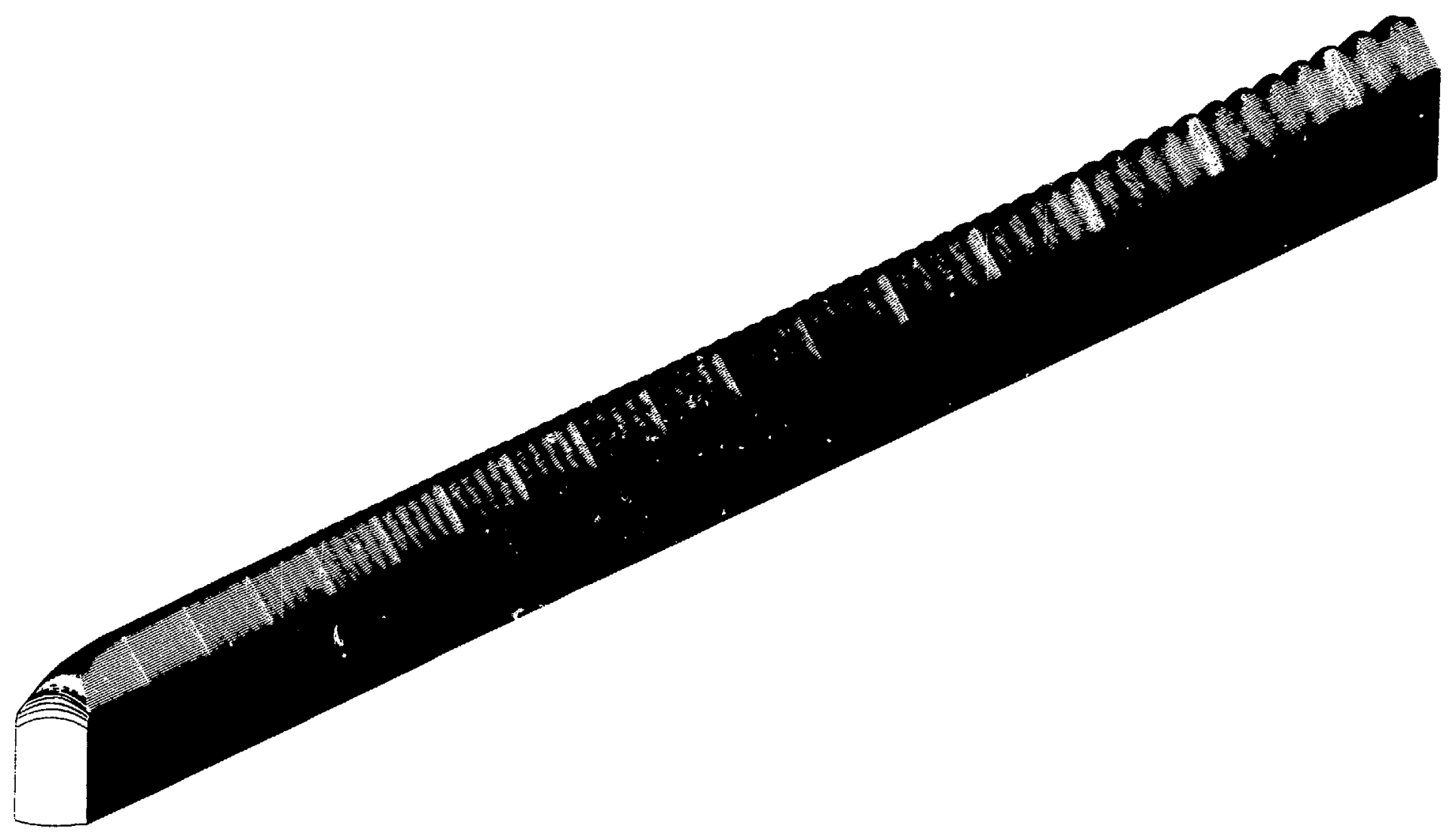

Fig. 6.

Computer-generated viow of the RFO vane tip. 


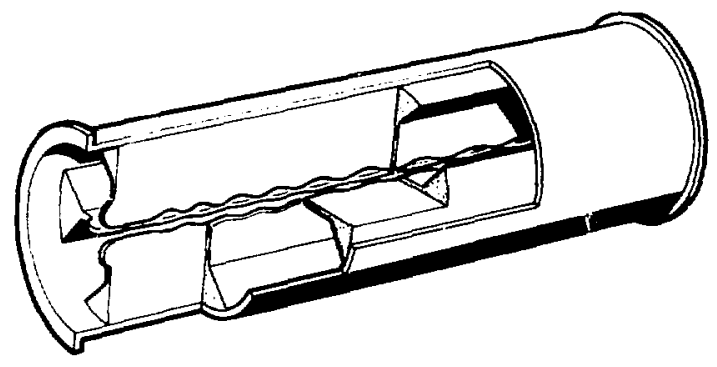

Fig. 7.

Cutaway viow of the RFO structure.
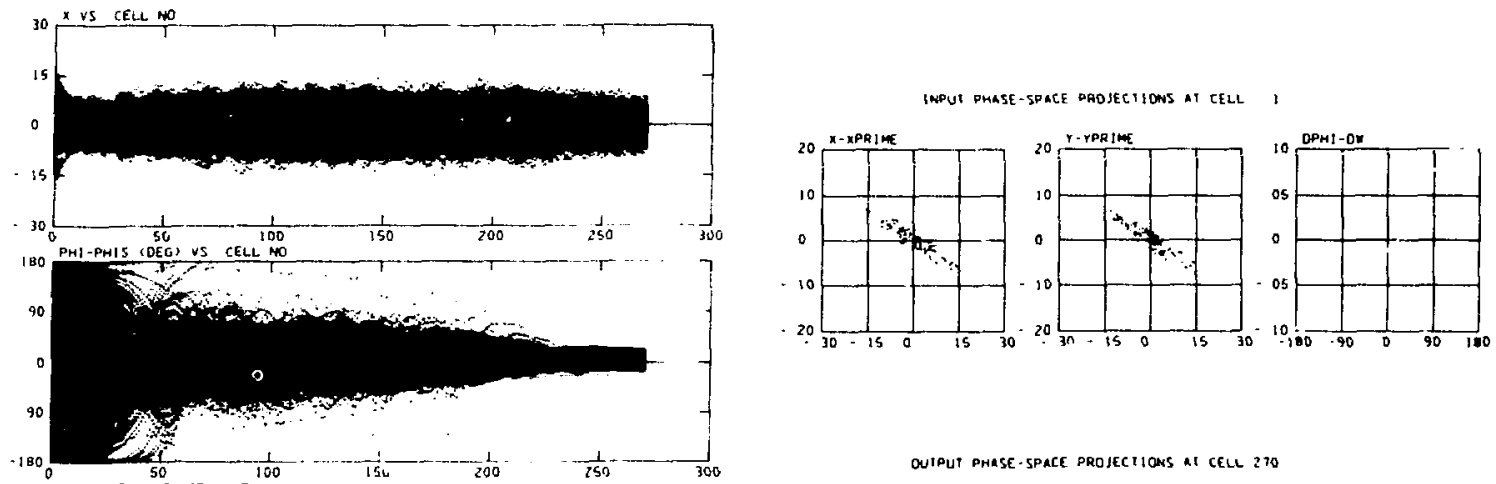

OutPut pHase.space projections at cell 270
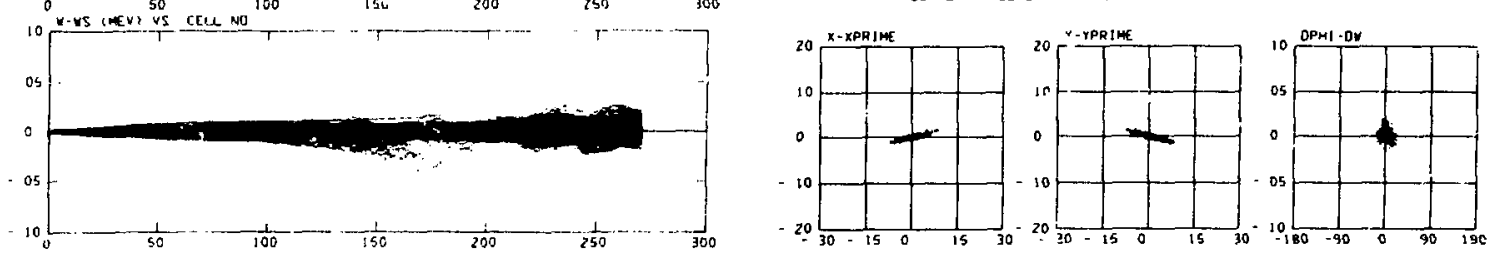

Fig. 8.

Beam profiles for the PICMI RFQ.

Fig. 9.

Beam phase epaces tor the PIOMI RFQ.

Fig. 10.

ARO POP linue echematic. 


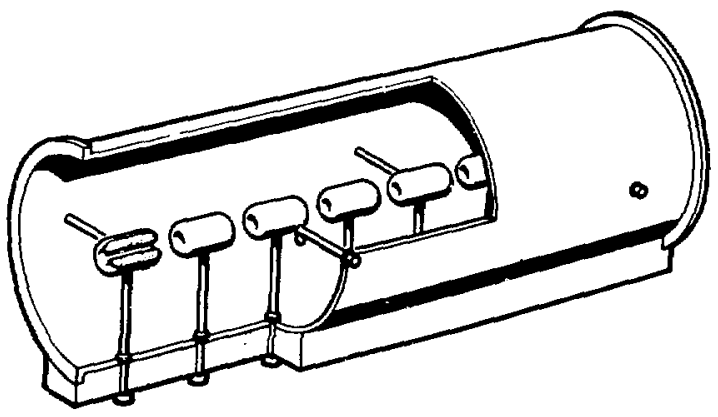

Fig. 11.

Cutaway view of a DTL linac.

Since the PIGMI drift tubes also are considerably smaller than those in conventional DTLs, electromagnetic quadrupole lenses are too large for beam focusing. The PIGMI approach uses modern permanent-magnet material in a geometrical configuration (Fig. 12) that results in very compact magnetic quadrupole lenses of sufficient strength. The design is further simplified by quadrupoles of the same length and strength throughout the structure.

The PIGMI DTL is a single-tank, post coupled structure $\sim 30 \mathrm{~m}$ long and $0.4 \mathrm{~m}$ in diameter. it sperates at $440 \mathrm{MHz}$ (the same frequency as the RFO) and accelerates the proton beam from 2.5 to $125 \mathrm{MeV}$, with an average axial electric field of 6 $\mathrm{MV} / \mathrm{m}$. The structure's peak-power dissipation is 14.2 MW, and the peak beam power is $3.4 \mathrm{MW}$. which results in a total 17.6-MW peak-power requirement. The average power dissipated in the structure is $51 \mathrm{~kW}$, or $1.7 \mathrm{~kW} / \mathrm{m}$.

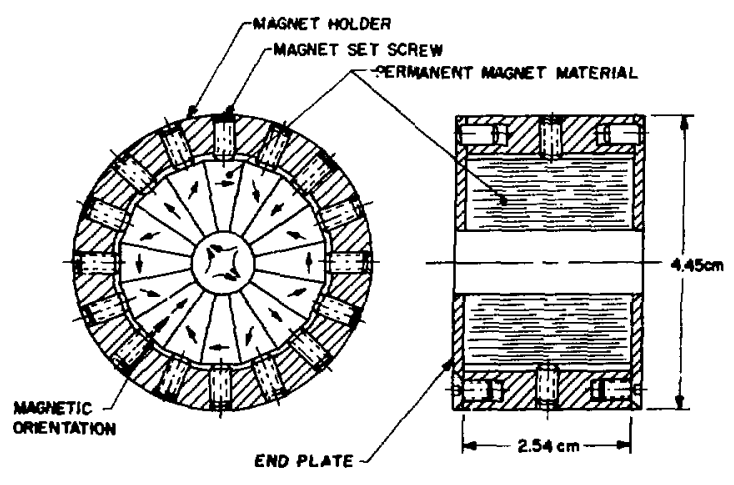

Fig. 12.

DTL permanent-magnet quadropole geometry.
The DTL structure was designed and analyzed with PARMILA, a linac design and simulation code. The structure accepts essentially $100 \%$ of the accelerated beam from the RFQ and accelerates it to $125 \mathrm{MeV}$. Figure 13 shows the beami's size, phase, and energy profiles, and Fig. 14 shows the input and output phase spaces. The beam suffers essentially no emittance growth in the DTL.

\section{Coupled-Cavity Linac}

Significant discoveries at !os Alamos during the development of LAMPF in the 1960s led tiie way to development of practical structures for acceieration of protons at energies $>200 \mathrm{MeV}$. The major advance was the recognition of the importance of using biperiodic standing-wave structures excited in the $\pi / 2$ cavity mode. The structure developed is called the side-coupled structure, which, when properly tuned, offers ligh efficiency in the conversion of $r f$ power to eam power and exceptional stability in the distribution of the accelerating fields, an essential feature for reliable operation.

Soviet scientists, in their interest in building a L.AMPF-type machine, considered the LAMPF sidecoupled structure and two oiner structures: namely, the ring-coupled structure and a DAW structure. They selected the DAW structure because of its large intercavity coupling constant and potential for simple fabrication.

At the start of the PIGMI program, Los Alamos researchers assumed that the high- $\beta$ portion of PIGMI would use a scaled-down version of the LAMPF side-coupled structure; the only developments envisioned were methods to increase the intercavity coupling and to simplify the fabrication. It was realized quickly that the outstanding properties of the DAW structure satisfied both goals. A cutaway view of the DAW structure is shown in Fig. 15.

SUPERFISH, a powerful rf-cavity calculational program developed at Los Alamos (partly in response to the needs of the PIGMI program), was used to analyze the DAW structure in detail. Exhaustive computer studies with this program, and test-cavity experiments, have led to a good understanding of the performance of this structure with an optimized set of parameters for the PIGMI application.

In long linac structures, the structure must be broken into shorter sections to allow introduction of auxiliary apparatus such as beam-focusing quadrupoles, beam-diagnostic equipment, vacuum isolation valves, etc. In many cases, coupling these 


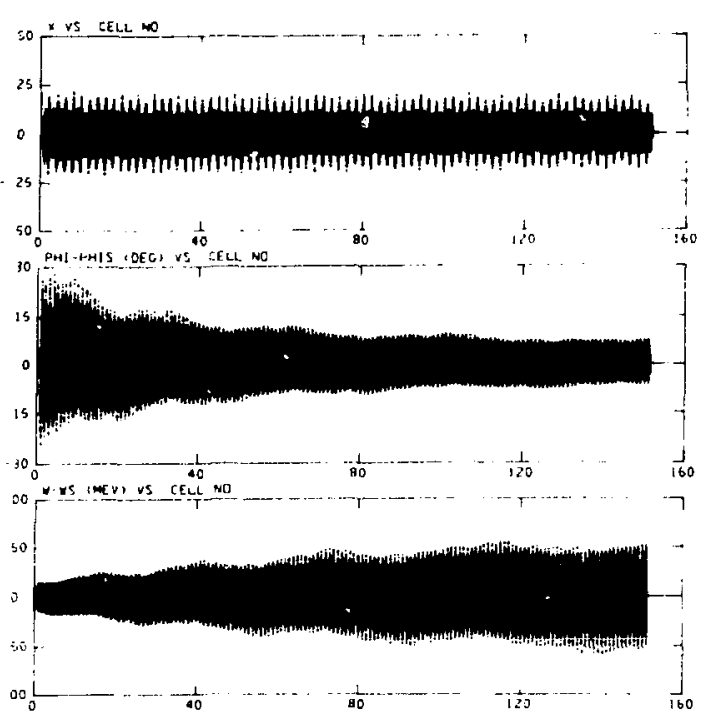

Fig. 13.

Beam protiles for the PIGMI DTL.

sections into longer resonant units reduces the required number of rf-power drive points and locks the relative phase and amplitude of the fields in adjacent sections. To take advantage of the superior properties of this structure, the if couplers should also be of the resonantly coupled type with large coupling constants; for practica! reasons of structure tuning, the if coupling of linac structures should represent a minimum distortion of the field patterns in either element. Such couplers in LAMPF have been called bridge couplers because they bridge the resonant properties of the linac structure around the auxiliary apparatus.

Single-cell bridge couplers adequate to house required apparatus within the linac structure have been developed for the PIGMI application. Figure 16 shows the general geometry of these bridge couplers for the values of $\beta$ (particle velocity as a fraction of the speed of light) equal to $0.5,0.6,0.7$, and 0.8 . In the center of each bridge coupler is a region of high magnetic field and zero electric field. Conducting radial supports in this plane have a negligible effect on the accelerating mode and a tolerable effect on the coupiing mode.

The PIGMI CCL is $\sim 99 \mathrm{~m}$ long and $0.34 \mathrm{~m}$ in diameter. The $1320-\mathrm{MHz}$ operating frequency, three times that of the DTL, accelerates the proton
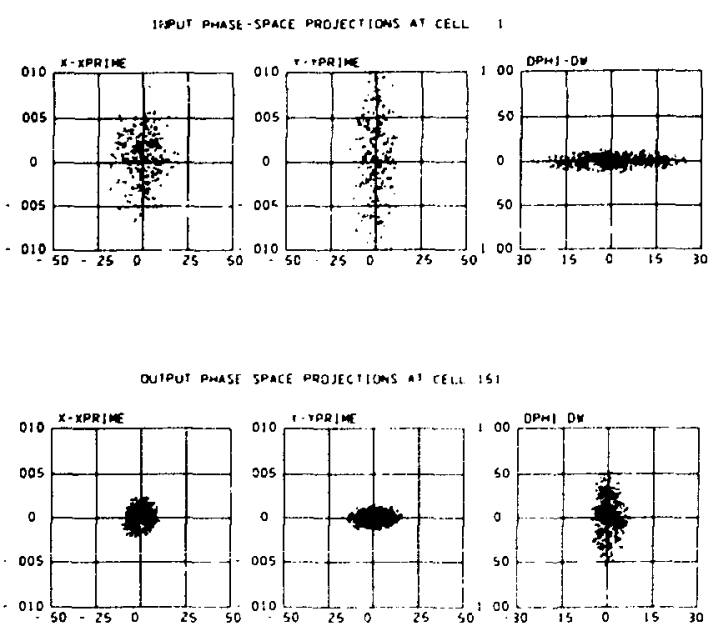

Fig. 14.

Beam phase spaces for the PIGMI DTL.

beam from 125 to $650 \mathrm{MeV}$ with an average axial electric field gradient of $8 \mathrm{MV} / \mathrm{m}$. The $\mathrm{CCL}$ is composed of 108 accelerating tanks of 11 cells each, whose lengths vary from 0.6 to $: .0 \mathrm{~m}$. The cell geometries are uniform throughout each accelerating tank but differ from tank ${ }^{+}$) tank. Thie tanks are resonantly coupled by 107 single-cell bridge couplers, each containing a permanent-magnet quadrupole singlet for focusing the beam. The geometry of all 107 quadrupole singlets is identical (Fig. 17). They are made of a ceramic material, magnetized to produce a quadrupole gradient of 5 $\mathrm{kG} / \mathrm{cm}$ over the $2-\mathrm{cm}$-diam bore. The bore-hole diameter of toth the structure and the bridge coupler is $2 \mathrm{~cm}$. The structure's peak-power dissipation is $66.8 \mathrm{MW}$, and its peak beam nower is 14.6 MW, a total 81.4-MW peak-pow'er requirement. The average power dissipated in the structure is only $250 \mathrm{~kW}$, or about $2.5 \mathrm{~kW} / \mathrm{m}$.

The CCL structure was designed and analyzed with the aid of the linac design program DAWDSN and the linac simulation program DAWLIN. The structure accepts essentially $100 \%$ of the accelerated beam from the DTL and accelerates it to $650 \mathrm{MeV}$. The size, phase, and energy profiles for the beam are shown in Fig. 18; its input and output phase spaces are shown in Fig. 19. The beam suffers virtually no emittance growth in this portion of the PIGMI facility. 


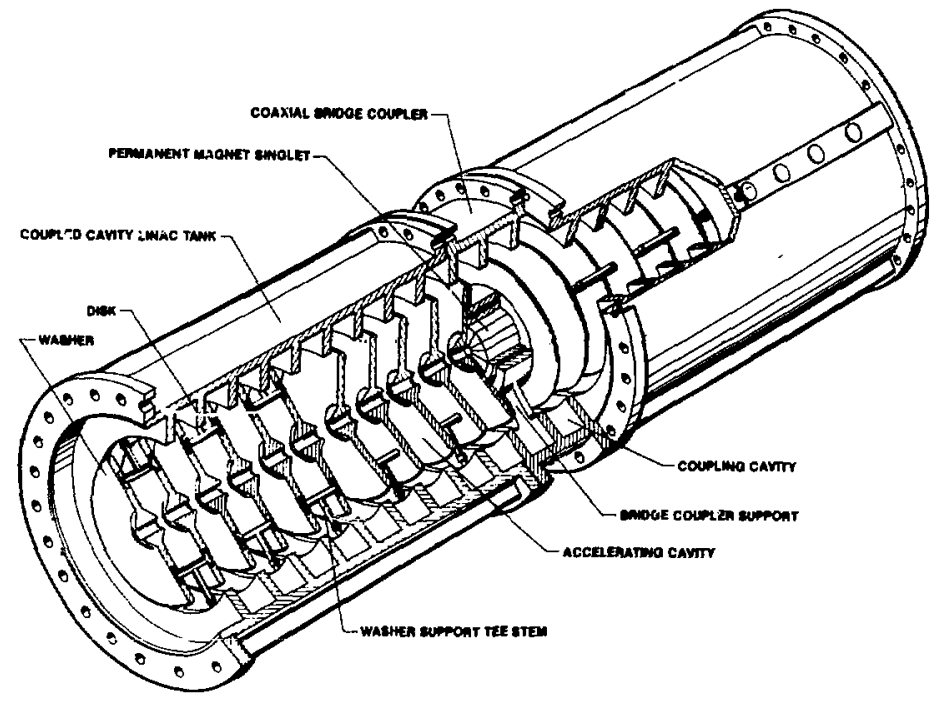

Fig. 15.

CCL accelerating structure and bridge coupler.
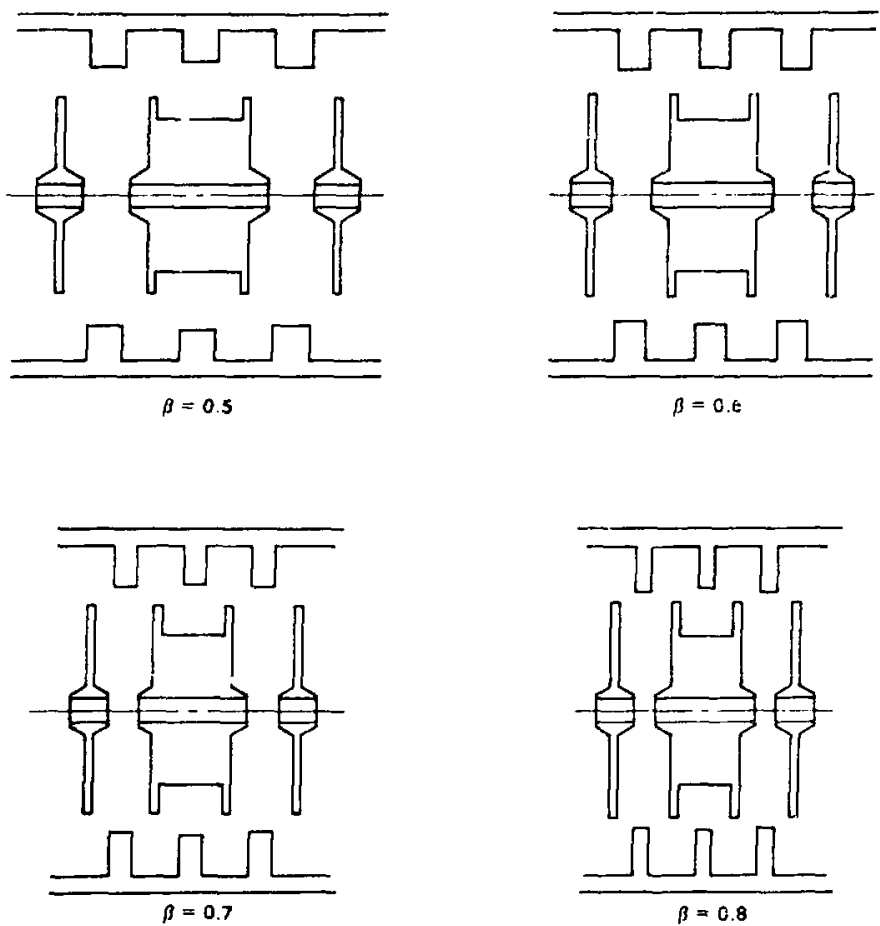

Fig. 16.

CCL single-cell bridge couplers. 


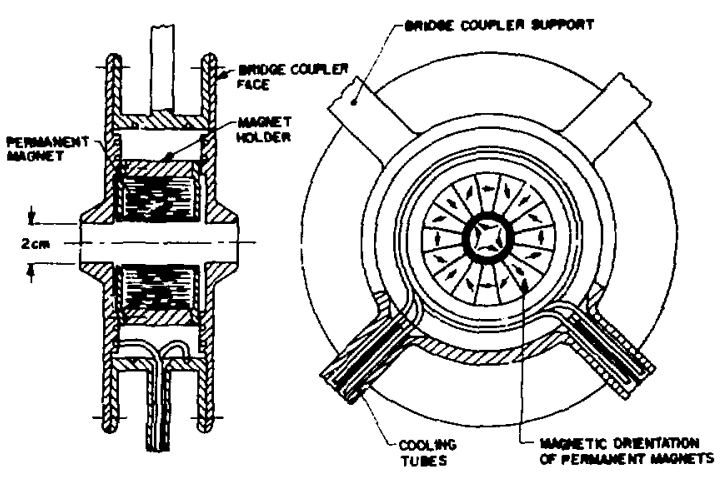

Fig. 17.

CCL quadropole sirglet.

\section{E. The if Power Systems}

The PIGMI frequencies of $440 \mathrm{MHz}$ and $1320 \mathrm{MHz}$ were chosen partly on beam-dynamics considerations and partly on the availability of suitable klystrons. Many military radar klystrons have been designed to operate in either the $400-$ to $450-\mathrm{MHz}$ frequency band or the next-higher band of 1250 to $1350 \mathrm{MHz}$. The PIGMI frequencies, which must be harmonically related, were chosen to fall in these ranges.

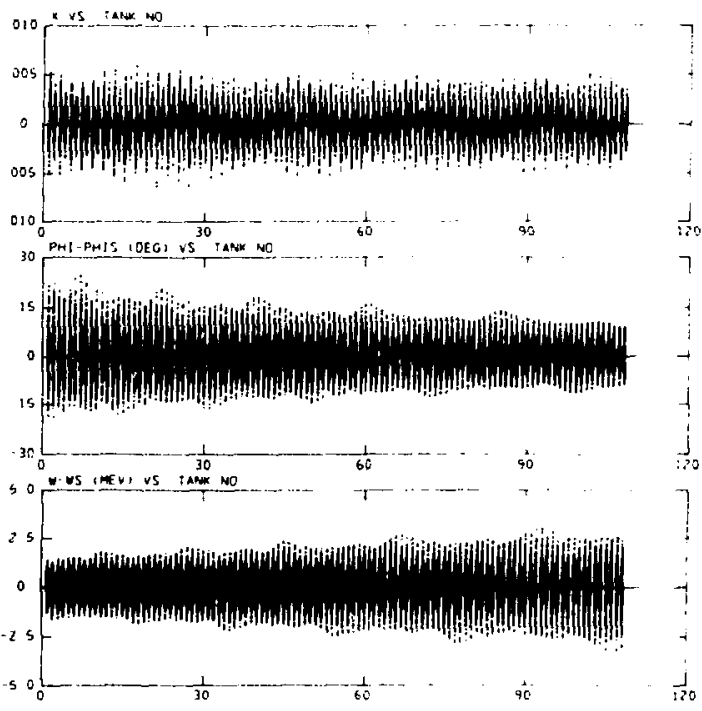

Fiq. 18.

Desm profiles for the FicMl CCL.
The costs of the PIGMI if systems were compared for three different beam-pulse patterns having the same duty factor: $10-\mu$ s beam pulses at a $360-\mathrm{Hz}$ repetition rate, $30-\mu \mathrm{s}$ beam pulses at a $120-\mathrm{Hz}$ repetition rate, and $60-\mu \mathrm{s}$ beam pulses at a $60-\mathrm{Hz}$ repetition rate. The shorter beam pulse and higher repetition rate reduce the cost of the PFN r.nodulator; however. these beam-pulse patterns consume more average power because of the larger number of cavity fill times. The longer beam pulse and lower repetition rate result in a 100-kW power savings over the medium-pulse alternative, and a 240-kW power savings over the short-pulse alternative. The $60-\mu \mathrm{s}, 60-\mathrm{Hz}$ option was adopted for PIGMI because the power savings resulting from the lower rejpetition rate overrides the additional cost of the PFN modulators associated with the longer pulse length.

The cavity power dissipation for the $440-\mathrm{MHz}$ portions of PIGMI (RFO and DTL) are estimated to be $16.2 \mathrm{MW}$, and bean loading for this same region corresponds to $3.5 \mathrm{MW}$. The if pulse length must exceed the beam puise length by the cavity fill time of $\sim 15.6 \mu \mathrm{s}$. The $\mathrm{rf}$ duty factor is $(60 \mathrm{pps}) \cdot(75.6 \mathrm{x}$ $10 \% \cdot(100 \%)$ or $0.4536 \%$. The total peak-power requirement at $440 \mathrm{MHz}$ is $19.7 \mathrm{MW}$, and the average-power requirement is $89.4 \mathrm{~kW}$. A single Varian VA-812E klystron can satisfy both the peakand average-power requirements of the $440-\mathrm{MHz}$ portion of PIGMI.
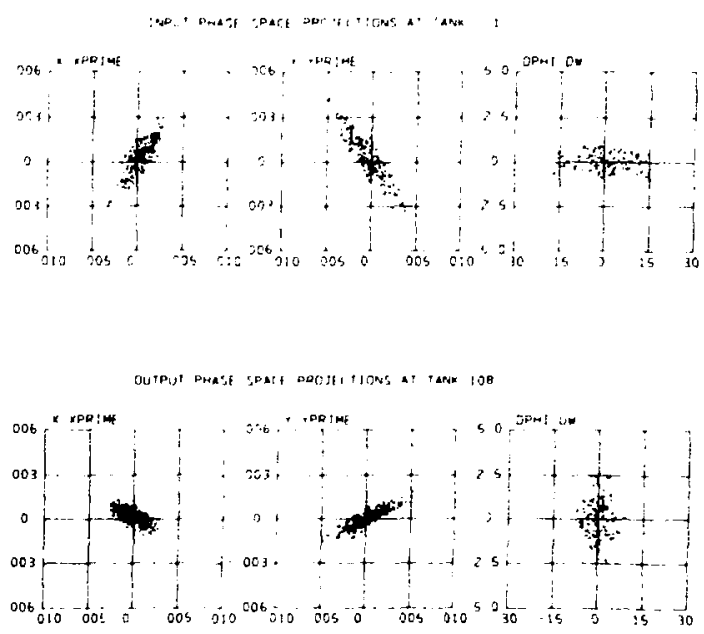

Fig. 19.

Beam phese epaces for the PUGH CCL. 
The cavity fill time of the $1320-\mathrm{MHz}$ structure is $3.6 \mu \mathrm{S}$, and the rf duty factor is $0.3816 \%$. The total peak-power requirement at $1320 \mathrm{MHz}$ is $81.4 \mathrm{MW}$ and the average-power requirement is $310.6 \mathrm{~kW}$. Five Litton L-5081 klystrons can satisfy both the peak- and average-power requirements of the 1320-MHz portion of PIGMI; however, the PIGMI design is based on six such klystrons operating at a reduced level, making continued operation possible even with the failure of one klyston.

\section{F. Computer Control and Instrumentation System}

Once turned on and tuned up, a PIGMI accelerator is designed to run reliably unattended. Therefore, the major role of the accelerator controi system is a passive one; its primary tasks are to monitor all facets of routine machine operation, to detect faults, and to alent the operator to abnormal or soon-to-be abnormal situations. When necessary, corrective action can be automatic. The PIGMI control system is composed of a minicomputer, a control console, and a distributed array of small, modular, and intelligent control stations (Fig. 20). This general configuration soon will control several new accelerator facilities (including the injector linac and the antiproton accumulator ring at Fermilab); the PIGMI system will benefit from these related applications. Data can be collected automatically and regularly, and the system will support accelerator maintenance by effective diagnostic testing. This control system provides straightforward and, in some cases, automatic procedures for machine turn-on, tune-up, and fault recovery.

The PIGMI control and instrumentation system could provide the operator with a three-state control: namely, OFF, STANDBY, and ON. The STAND$B Y$ and $O N$ states are identical in that all equipment is on arid running within tolerance, except that in the STANDBY state the beam is inhibited at the ion source and certain beam stops are inserted. In either the STANDBY or ON states, the operator can monitor the detailed performance of every system in the facility. Ali set points that influence the machine's performance are available to the operator through the control systerri; these set points can

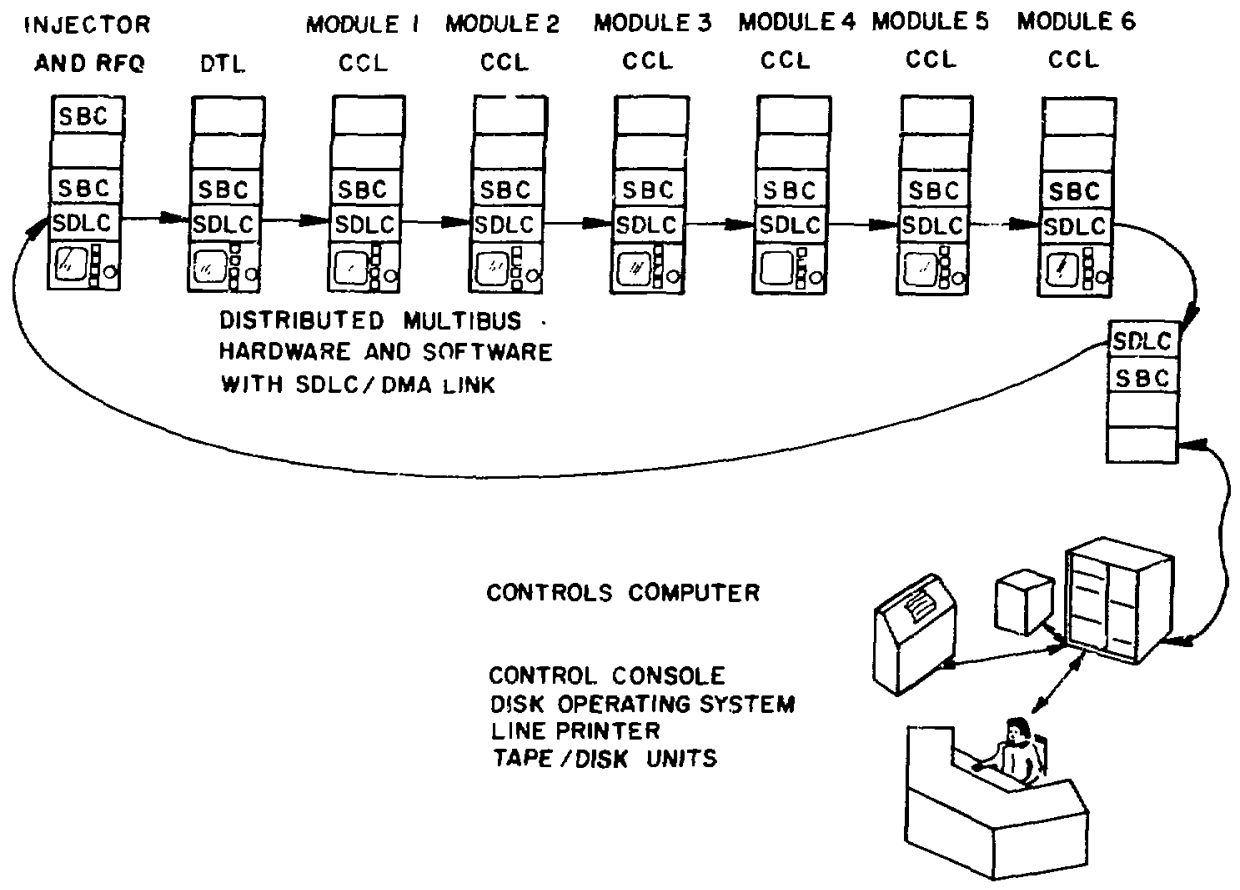

Fig. 20.

PICMI control-system configuration. 
be set up, monitored, and/or recorded for future setup purposes by convenient parameter-management procedures.

When the controls are in the ON state, the operator can monitor the beam properties, the evidence of any beam loss, and the effects of beam loading on the accelerator equiment systems. Certain tuning procgdures will be avaliable to the operator for fine-tuning of the performance. If equipment fails, the coritrol and diagnostic system identifies the faulty equipment and notifies the operator. in some cases, additional diagnostics may be available to pinpoint a faulty unit that should be replaced. Most repairs to the PIGMI control and instrumentation system will be by unit replacement.

All critical parameters will be monitored periodically and compared with their current set-point values and tolerance limits. The operator will be notified of out-of-tolerance conditions, and corrective action will be automated in some cases. Selected data wil! be collected regularly for general and specialized logs to support accelerator records and statistical studies of machine performance.

\section{ACCELERATOA ENGINEERING DESION}

\section{A. Injector Design}

In the cutaway view of the proton injector (Fig. 21), the ion source is a conventional duoplasmatron of the Von Ardenne type, with a 1 cm-diam iron plasma expansion cup, covered inside with a boron-nitride insulator. Because of the low-beam duty factor of the PIGMI design, cooling water need be provided only for the intermediate electrode arid arc magnet coil. The filament is a bifilar, oxide-coated, nickel-screen cathode. The plasma aperture is $0.63 \mathrm{~mm}$ in diameter, and a grounded focus electrode is mounted in front of the plasma expansion cup, which has an 8-mm-diam extraction aperture. The single-gap, convergent, extraction geometry will extract a $32-\mathrm{mA}$ beam at $30 \mathrm{keV}$. Tests on this ion-source geometry have shown that the bearn will be $90 \% \mathrm{H}^{+}$ions, with ihe remainder being $\mathrm{H}_{2}^{+}$ions and heavy ion contaminants.

The converget ion beam from the ion source is allowed to diverge beyond the extraction electrode

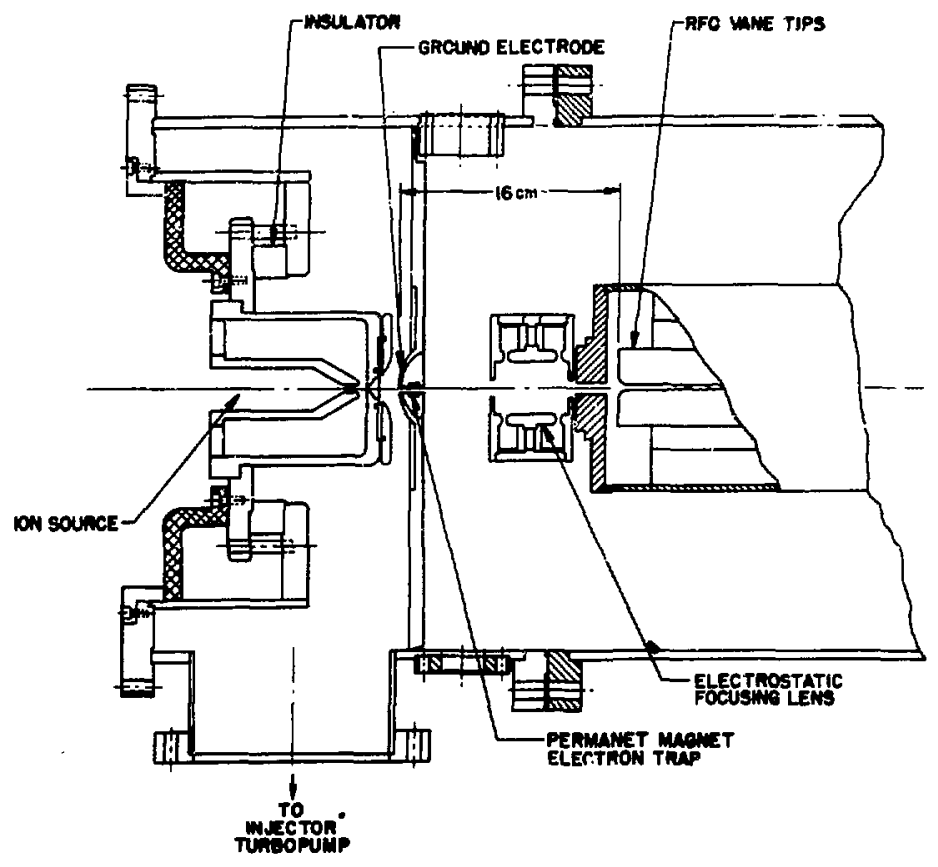

Fig. 21.

PIGMI 30-kV injector aseembly. 
and is then focused into the RFQ structure by a three-element, unipotential einzel lens. The extraction electrode is $16 \mathrm{~cm}$ from the RFQ structure, and a small amount of steering for the beam is available near the waist, just beyond the extractor. A small built-in valve, similar to one at LAMPF, is also provided in this region so that the ion source can be removed for servicing without disturbing the accelerator vacuum. In the space before the einzel lens, a minimal amount of beam-diagnostics equipment is provided, including a biased Faraday cup, a wire scanner, and a small beam-current monitor.

The ion source and acceleration gap are mounted horizontally in a grounded vacuum manifold that is pumped by a $450-1 / \mathrm{s}$ turbomolecular pump. The small aperture in the extraction electrode and the small entrance aperture of the RFQ allow the gas load between the two limiting apertures in the low-energy beam-transport region to be differentially pumped with a second, 200- $/ / 5$ turbomolecular pump. This arrangement will allow the vacuum in the RFQ to be in the $10^{-7}$ torr region while maintaining a gas i.ow of $\sim 1 \mathrm{~cm}^{3} / \mathrm{min}$ of hydregen in the ion source. The vacuum in the lowenergy einzel-lens system should be $\sim 10^{-6}$ torr, which is good enough to neglect space-charge compensation in the transport system.

The calculated profile of a 32-mA proton beam extracted from the ion source and transported through the einzel lens to the entrance aperture of the RFO (Fig. 4) was done with SNOW. an injector extraction optics computer code that solves the plasma extraction problem and transports the ion beam through the system, including the spacecharge and neutralization effects. The potential of the einzel lens for the correct match of the beam into the RFQ is somewhat less than $30 \mathrm{kV}$. Because this voltage is the same polarity as the biased 30 $k V$ injector, it can be obtained from a divider placed on the 30-kV power supply and can be tuned easily with a multiturn potentiometer.

The ion-source electronic equipment operates at $30 \mathrm{kV}$ and is located within a small equipment cabinet, as shown in Fig. 3. The necessary electrical operating power is supplied by a small 1-kVA isolation transformer, which is in the same equipment cabinet. The hydrogen gas flow and water cooling are provided from ground through nonconducting tubes. The 30-kV power-supply control is provided locally by nonconducting rods, located through the high-voltage shield surrounding the ion-source equipment in the cabinet. Minimal control and monitoring are provided through a fiberoptics link to a microprocessor-based system lo- cated at ground potential, and the time pulse to the ion source also is provided through this fiber-optic link.

\section{B. AFO Linac Design}

The general configuration of the RFQ linac structure, in relation to the ion source and the DTL, is shown in Fig. 22. The PIGMI AFQ resonator cavity is shown in Fig. 23 and bears some resemblance to the all-copper RFQ POP cavity shown in Fig. B-20. However, the mechanical design is considerably improved. The PIGMI RFO resonator cavity is $\sim 0.151 \mathrm{~m}$ in diameter, and the RFQ linac vanes are $1.78 \mathrm{~m}$ long. The RFQ operating at $440 \mathrm{MHz}$ accelerates the proton beam from the $30-k e V$ injection energy to a final $2.5-\mathrm{MeV}$ energy. The maximum surface field is $40.6 \mathrm{MV} / \mathrm{m}$, which corresponds to 2 times the Kilpatrick sparking limit. The total estimated if power for the RFO linac (including the resonator cavity, power manifold, and beam) is $1.8 \mathrm{~kW}$. of which the beam power is $0.34 \mathrm{~kW}$.

The PIGMI RFQ resonator cavity is fabricated from mild steel. The end flanges are weided, and the cylinder is then stress-relieved and machined by turning the inside diameter to the proper dimension, cutting the coupling siots, and providing other necessary features. It is then completely copper plated.

The RFO POP vane tips were bolted to the vanes: this creates a potentially troublesome mechanical rf joint between the vane and the vane tip. The PIGMI RFQ's copper vane tips will be first furnace brazed to a copper-plated mild-steel vane base, then profile-machined in a numerically controlled (NC) mill. The four vane assemblies then will be aligned in a jig and the outside diameter machined to match the cylinder's inside diameter. Following the mounting of the vanes in the cylinder. the vaneto-cylinder joint will be made, and the RFQ is ready for tuning.

The RFQ tuning is done by means of small tuners (Fig. 23), which decouple the mechanical alignment requirements from the requirements to balance the electric fields. These small tuners in the cylinder wall adjust the cavity frequency. level the fields, and provide the fine-tuning adjustments.

The RFQ resenator cavity is surrounded by the RFO power manifold, which is resonantly coupled to the DTL through an unexcited coaxial coupling cell $(\pi / 2$ mode); therefore, the DTL furnishes all the if power required by the RFQ. 


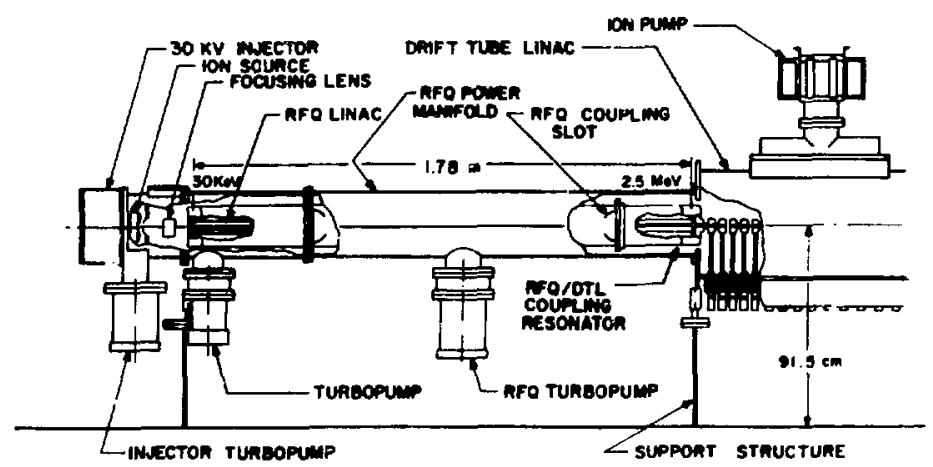

Fig. 22.

Ir ;ector, RFa, and DTL (low-energy end).

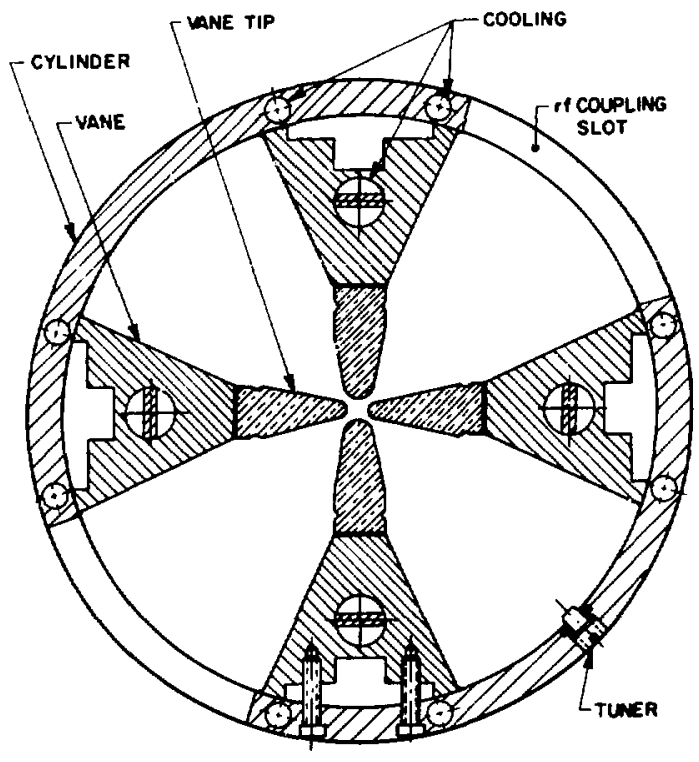

Fig. 23.

RFO resonator cavity croses section.

\section{DTL Design}

The small size of the PIGMI DTL precludes normal fabrication and assembly techniques and prevents personnel entry within the structure for assembly and alignment. The PIGMI scheme is based on the preassembly of short linac tank sections, into which the drift tubes can be introduced from the ends or through slots in the top. The 30.06-m linac structure is fabricated in 12 tank sections, each $\sim 2.5 \mathrm{~m}$ long, as shown in Fig. 24 .
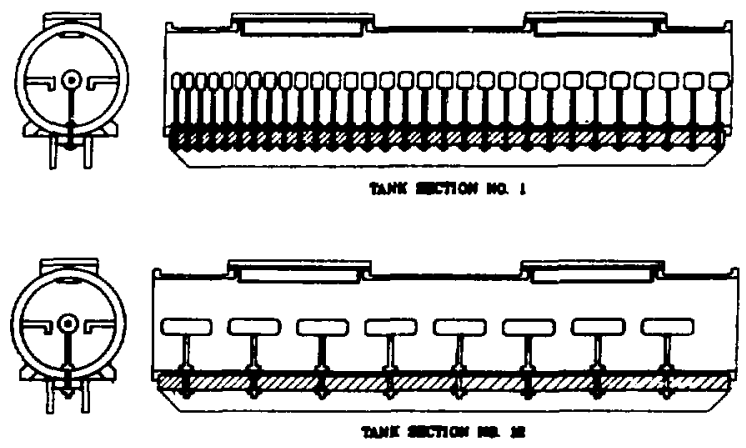

Fig. 24.

DTL tank sections.

The ends of the tank sections are located in points corresponding to the midplane of a drift tube gap. Each tank section will be assembled, tuned. aligned, leak checked, and sealed before transport to the medical facility site. Installation at the site then becomes a simple assembly operation.

The length, number of drift tubes, and maximum energy associated with each of the tank sections are given in Table I. The general mechanical features of the first and last tank sections are shown in Fig. 24. The saddle approach, developed for the PIGMI Prototype, is used in the construction of the tank sections. Each tank section is stiffened along the bottom by a structural member that also is used to support and align the drift tubes. The drift tube mounting holes are precision bored through this structural member and tank wall. Post coupler 
TABLE I

PIGMI DRIFT TUBE LINAC TANK SECTIONS

\begin{tabular}{cccr} 
Section & $\begin{array}{c}\text { Length } \\
(\mathbf{m})\end{array}$ & $\begin{array}{c}\text { Number of } \\
\text { Drilt Tubes }\end{array}$ & $\begin{array}{c}\text { Energy } \\
(\mathbf{M e V})\end{array}$ \\
\hline & & & \\
1 & 2.502 & 30 & 13.4 \\
2 & 2.570 & 19 & 25.0 \\
3 & 2.375 & 14 & 35.7 \\
4 & 2.556 & 13 & 47.2 \\
5 & 2.411 & 11 & 57.5 \\
6 & 2.624 & 11 & 68.5 \\
7 & 2.557 & 10 & 78.7 \\
8 & 2.433 & 9 & 88.2 \\
9 & 2.550 & 9 & 97.8 \\
10 & 2.350 & 8 & 108.5 \\
11 & 2.443 & 8 & 115.2 \\
12 & 2.680 & 8 & 125.0 \\
\hline TOTAL & $\mathbf{3 0 . 0 6 1}$ & $\mathbf{1 5 0}$ & $\mathbf{1 2 5 . 0}$
\end{tabular}

mounting holes are bored along the side of the tank at locations corresponding to the midplane of every other drift tube, alternating side to side along the structure. Each tank section has two 1/2-m slots in the top s:ırface for access to the interior and for mounting vacuum pumps, fixed tuners, variable tuners, etc. Wall-cooling tubes are attached by epoxy to the tank sections; this is considered acceptable because of the very low heat deposition on the walls. The tank sections are fabricated from mild-steel (1010-1020) tubing with a copper-plated interior, and elastomer seals are used for most vacuum joints.

The DTL structure has 150 drift tubes and 74 post couplers. The drift tubes are fabricated from Type 304 stainless steel, then copper plated. Each drift tube contains a permanent-magnet quadrupole lens to focus the beam, but the length of the drift tubes varies from $3.8 \mathrm{~cm}$ to $23.9 \mathrm{~cm}$. All 150 quadrupole magnets are identical in size and strength, made of samarium cobalt magnetized to produce a quadrupole gradient of $20 \mathrm{kG} / \mathrm{cm}$ over the 1-cm-diam bore. Designs for short and long dritt tubes are shown in Figs. 25 and 26. Each drift tube has a $6.0-\mathrm{cm}$ 0.d. and a 1.0-cm-bore diameter. Values for the drift tube face angle begin at $4^{\circ}$ in

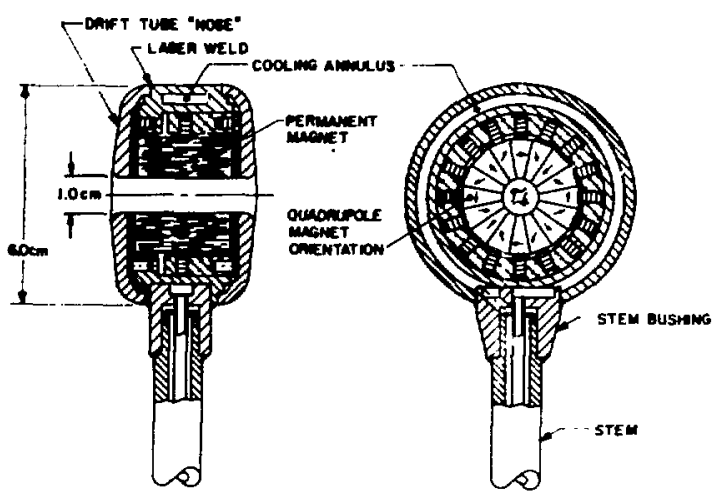

Fig. 28.

DTL diff tube deaign (chort).

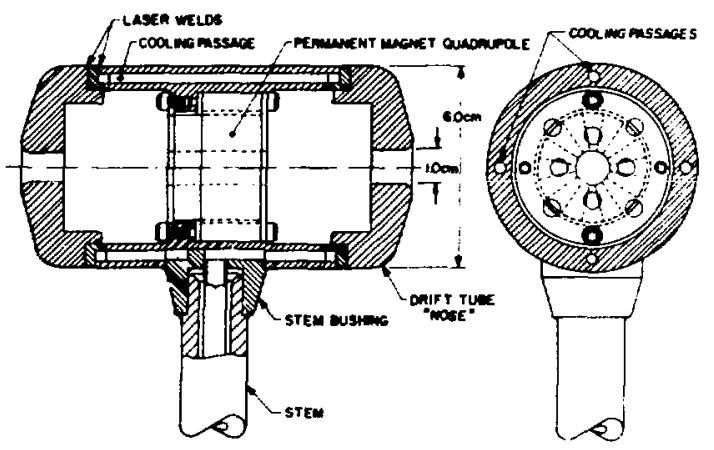

Fig. 28.

DTL drift tube design (long).

the low-energy end and change to $10^{\circ}$ at $\sim 40 \mathrm{MeV}$ for the rest of the DTL. Drift tube ends (noses) are attached to the cooling jacket by laser welds. Short drift tubes use a $1.27-\mathrm{cm}$-diam stem, whereas long drift tubes use a $1.91-\mathrm{cm}$-diam stem. The cooling jacket in the short drift tube uses annular cooling passages; the cooling jacket in the long drift tube uses axial coc.u1g pessages, with an annular distribution :ing at each end. The drift tube of joint and vacuum seal are accomplished by the "controlled crush" copper seal developed for the PIGMI prototype program.

The tuning-slug design is based on that tested in the PIGMI prototype program. A copper surface is furnace brazed to the bottom of the tuning slug. and frequency tuning of each tank section is accomplished by machining this slug. A few movable 
tuners similar to the LAMPF design may be necessary in the DTL assembly. Post couplers and monitor loops are similar to the LAMPF designs; however, the post couplers need not be water cooled because of the low duty factor.

Before assembly of the entire structure, each tank section is fully assembled, complete with drift tubes, post couplers, tuners, monitor loops, etc. The drift tubes are aligned with the centers of the end flanges. The tank sections can be terminated by a conducting plane at each end and the fine tuning on the resonant frequency and the post coupler adjustments can be made.

For final assembly, the tank sections are joined, aligned, and supported by their end flanges. At this point, only minor tuning is needed to obtain the desired resonant frequency and field distribution. The end flanges are supported directly from the floor by structures that have good transverse but poor longitudinal rigidity, allowing for minor thermal flexing. The DTL structure is fastened to a rigid longitudinal support at the DTL-CCL transition region.

\section{CCL Design}

For facility organization, the $98.93-\mathrm{m} \mathrm{CCL}$ is subdivided into 6 modules, each similar with regard to distribution of the necessary auxiliary features such as if drive points, beam accelerator diagnostic instrumentation, and vacuum equipment. Each module consists of 18 accelerating tanks and 18 coaxial bridge couplers that separate the accelerating tanks. Figure 27 shows a typical module, and Table $\|$ gives the length and maximum energy of each module. A center bridge coupler in each module accommodates a $1320-\mathrm{MHz}$ ri-drive point; the end bridge couplers are equipped with a coaxial ceramic windows and
TABLE \|

\section{PIGMI CCL MODULES}

\begin{tabular}{cccc} 
Modules & $\begin{array}{c}\text { Length } \\
(\mathbf{m})\end{array}$ & $\begin{array}{c}\text { Number of } \\
\text { Tanks }\end{array}$ & $\begin{array}{c}\text { Energy } \\
(\mathrm{MeV})\end{array}$ \\
\hline & & 18 & 193 \\
1 & 12.60 & 18 & 271 \\
2 & 14.61 & 18 & 357 \\
3 & 16.22 & 18 & 450 \\
4 & 17.52 & 18 & 548 \\
5 & 18.58 & $\mathbf{6 5 0}$ \\
6 & 19.42 & 18 & $\mathbf{6 5 0}$ \\
\cline { 1 - 1 } & $\mathbf{9 8 . 9 3}$ & $\mathbf{1 0 8}$ & \\
\hline
\end{tabular}

compact beamline valve to provide vacuum isolation between modules for maintenance purposes. The remaining bridge couplers accommodate an array of vacuum pumps and diagnostic gear.

Each of the $108 \mathrm{CCL}$ accelerating tanks is fabricated as a multicell unit of 10 identical washers that are supported in pairs by T-shaped supports. A bridge coupler, located between two accelerating tanks, is shown in Fig. 15. Detail of a basic CCL bridge coupler is shown in Fig. 28. Hollow, radial supports provide suitable channels for services required by the auxiliary apparatus, such as cooling water for the bridge coupler parts, signal leads for beam diagnostic devices, and control rods for mechanical devices. The permanent-magnet singlet assembly is rigidly supported by radial supports in its midplane. The exposed end of the bridge coupler is removable for access to the auxiliary apparatus.

The $\mathrm{CCL}$ accelerating tanks are fabricated by machining the outer portions of the structure, including the disks, from a thick-walled mild-steel

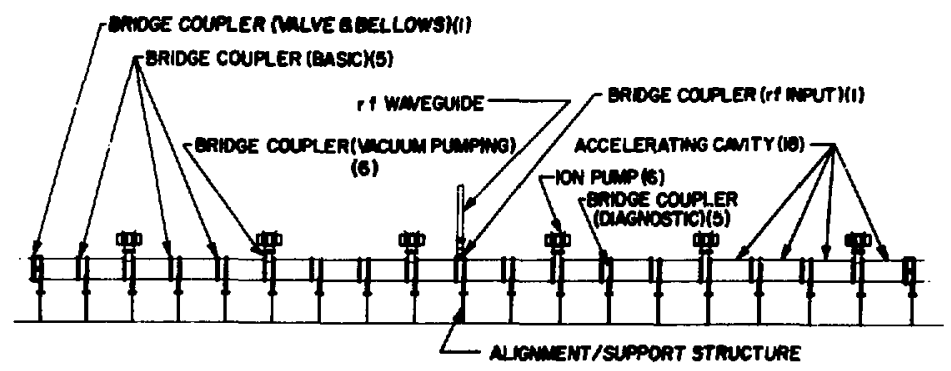

Fig. 27.

Typical CCL module. 


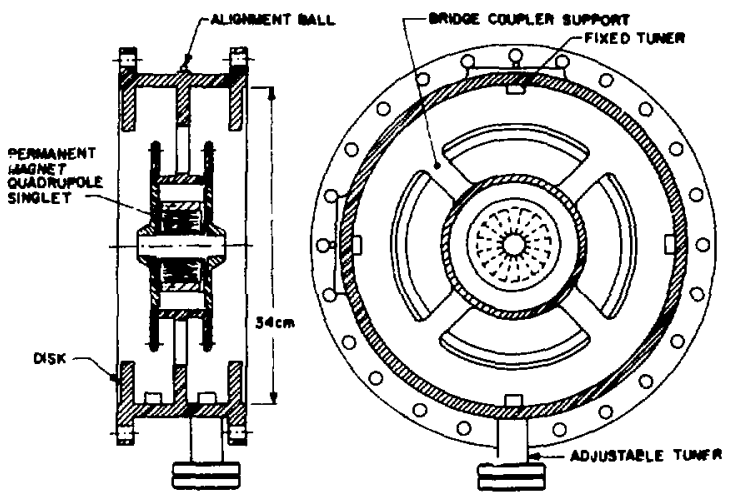

Fig. 28.

CCL bridge coupler (basic model).

cylinder. This assembly is then copper plated, with four short tubes protruding from every other disk to which the washers will be mounted (Fig. 29). About $90 \%$ of the rather modest structure heating ( 2.16 $\mathrm{kW} / \mathrm{m}$ ) occurs on the washer. The washers are fabricated from copper then furnace brazed to the copper-plated Type 304 stainless steel tee-stems, forming a two-washer unit. For assembly, a washer unit is placed inside the cylinder, and the copper steam bushings are slipped over each of the four washer stem-to-disk tube joints. During assembly of each CCL tank, the internal parts are temporarily assembled to check the resonant frequency and the stopband between the accelerating and coupling modes. If required, changes may be made to the individual washers. After these measurements and any necessary tuning adjustments, the washer units are soldered with a low-temperature solder, one at a time, to the outer cylinder. The joint is made by inserting into the stem tube a special heat source that supplies a short but intense burst of heat. This assembly technique also allows for in situ repair of any joints that might fail during accelerator operation. Finally, the plugs in the external cooling passages (that allow access to the stems) are soldered into place and leak checked. The accelerating tanks then are joined in small groups to test the properties of the bridge couplers. Minor changes required in the bridge couplers can be made at this time. Finally, the entire CCL structure is assembled at its final destination, with only minor tuning required for the desired resonant frequency and field distribution. All vacuum seals in the $\mathrm{CCL}$ are made of metal so their construction is not affected by the radiation environment in the high-energy portion of the operating accelerator. The CCL fabrication techniques will be verified by a $1300-\mathrm{MHz}$ field-gradient power assembly proposed for testing in 1981 .

\section{E. Vacuum Systems}

The six vacuum systems required for PIGMI are the injector, the RFQ, the DTL, the transition region, the CCL (six identical systems), and the target area/pion channel. The first five have been studied in some detail; only general comments will be made about the nonaccelerator-related vacuum system.

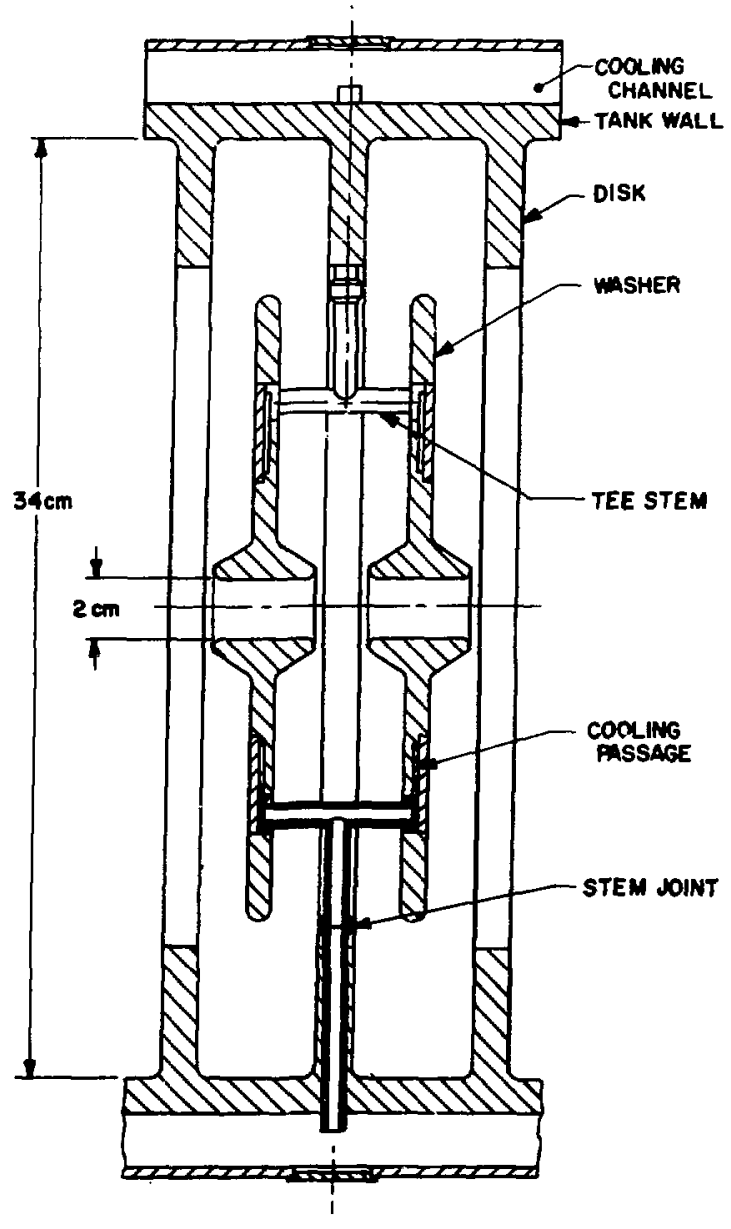

Fin. 29. CCLIOAW demign. 
1. Injector Vacuum System. The injector has the hydrogen gas that is boiled off from the ion source as the major gas load; the other gas load is normal outgassing from structural materials. A turbomolecular vacuum pump with oil-lubricated bearings works quite well in this application. Experience with the PIGMI Prototype has shown that a $450-1 / \mathrm{s}$ pump can maintain the desired $1 \times 10^{-3}$-torr vacuum in the injector, and an isolation valve is not required for this turbopump. If the injector must be brought up to atmospheric pressure (to change the ion-source filament, for instance), the rest of the accelerator is isolated by a small valve near the first waist in the beam, and this turbopump is turned off.

The major gas loads in the short region between the injector extraction-electrode aperture and the entrance aperture into the RFQ are hydrogen gas from the injector region and organic gases from diagnostic equipment and the einzel-lens insulators. The other gas load is the normal outgassing from structural materials. Because the organic gases are undesirable in an rf region (to which they would migrate through the RFQ entrance aperture), they must be exhausted from the system by a smali turbopump $(\sim 200 \mathrm{~d} / \mathrm{s})$ provided with an isolation valve. The vacuum in this region will be $\sim 1 \times 10^{-6}$ torr, which provides a buffer between the $1 \times$ $10^{-15}$-torr injector vacuum and the $1 \times 10^{7}$-torr accelerator vacuum. A common forepump system for the injector turbopump and the diagnostics-region turbopump has worked very well on the PIGMi prototype. The forepump system must be fitted with systems to eliminate oil backflow from the forepump. A molecular sieve is inexpensive but should be combined with either a pneumatically operated valve that closes automatically on loss of electrical power, a mechanically refrigerated cold trap, or both. Experience with the mechanically refrigerated sold traps has been excellent.

2. RFQ Vacuum System. The RFQ vacuum system includes both the RFQ cavity and RFQ power manifold between the injector diagnostics region and the DTL. The major gas load for this system, is outgassing from structural materials and the copper $\mathrm{rf}$ surfaces. Although an ion pump couid be used, a $450 \mathrm{t} / \mathrm{s}$ turbomolecular vacuum pump is recommended with an isolation valve. The operating yacuum in the RFQ must be $\sim 1 \times 10^{-7}$ torr to accommodate the $\mathrm{rf}$ fields. The total gas load is calculated to be $\sim 46 \mathrm{t} / \mathrm{s}$. Because it is near the other turbopumps, a common forepump system for all three is desirable.
3. DTL Vacuum System. The DTL is $\sim 30 \mathrm{~m}$ long, and the major gas load is outgassing from copper if surfaces. Other gas loads include outgassing from structural materials and from the samarium-cobalt perinanent-magnet material in the drift tubes. The operating vacuum must be $\sim 1 \mathrm{x}$ $10^{-1}$ torr. Ion pumps, mounted on top of the DTL tank sections, $p:$ :mp past a copper tuning slug. This arrangement has worked very well on the PIGMI Prototype, and it moves the pump to an out-of-theway yet convenient location. lon pumps are extremely reliable, inexpensive to operate, and widely used for accelerator applications. The ion pumps are not provided with isolation valves, but their performance can be monitored by observing the required pump current. These pumps do not fail rapidly or massively; they just slowly decline in performance. Suspect oumps can be identified easily and early and can be replaced during regularly scheduled shutdowns.

Each 2.5-m DTL tank section is equipped with two 0.5-m-long fixed tuning slugs. These tuning slugs serve serveral purposes. They allow tuning of the cavity frequency and provide a port for vacuum pumping; when removed, they provide access to the DTL interior. The total gas load, calculated to be $\sim 491$ //s, requires twelve $300-/ / s$ ion pumps, or one ion pump per tank section. The tuning slugs not equipped with ion pumps can be equipped with vacuum gauges or other auxiliary equipment.

For initial pumpdown, the turbopumps at either end of the DTL (the RFQ turbopump and the iransition-region turbopump) plus temporarily mounted cryopumps must be used. The cryopumps can be mounted on the vacuum portion at the $\mathrm{rf}$ waveguide to pump through the if iris or can be mounted on some tuning-slug housirigs. Once the ion pumps are started, the cryopumps can be isolated and removed. A pumpdown time of several hours may be required. Such a time period is acceptable because it will not often be necessary.

\section{The Transition-Region Vacuum System. The} transition region between the DTL and $\mathrm{CCL}$ is $1.5 \mathrm{~m}$ long (Fig. 30). The major gas load in this region is outgassing of organic gasses from diagnostic equipment, which must be exhausted. The total gas load is estimated to be $18 \mathrm{~d} / \mathrm{s}$; therefore, a $\sim 200-1$ turbopump can maintain the $1 \times 10^{-7}$ torr vacuum. 


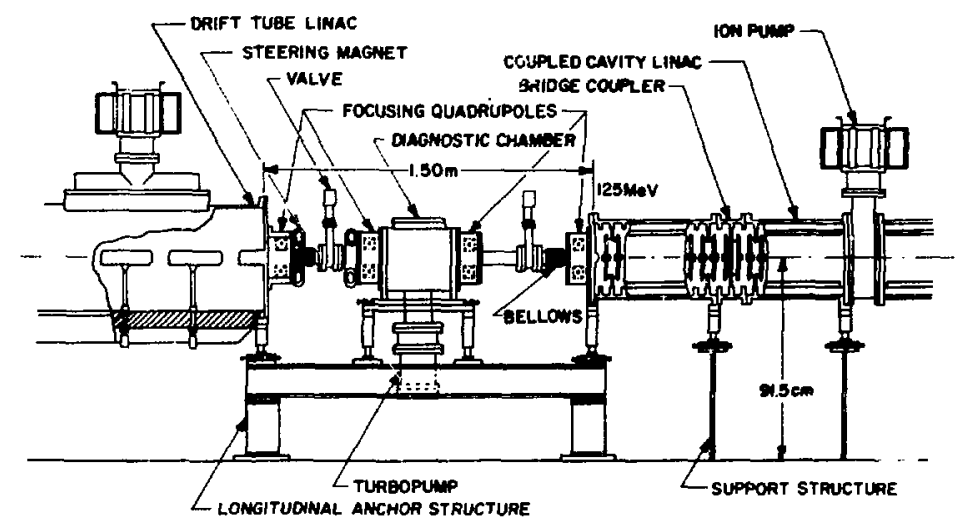

Fig. 30.

DTL/CCL transition region.

5. The CCL Vacuum Systems. The CCL is $99 \mathrm{~m}$ long and is divided into 6 modules, each consisting of 18 accelerating tanks containing 11 DAW cells. Between each tank is a coaxial bridge coupler. The length of each module varies from between $12.6 \mathrm{~m}$ at the low-energy end to $19.4 \mathrm{~m}$ at the high-energy end; however, the vacuum system for each module is tre same. The major gas load is outgassing from the copper if surfaces. Other loads include outgassing from ceramic permanent-magnet material in the quadrupole singlets, from structural materials, and from some other nonmetallic materials. The operating vacuum must be $\sim 1 \times 10^{\text {? }}$. Each module contains six bridge couplers on which $500-1 / \mathrm{s}$ ion pumps can be mounted. The ion pumps, mounted on top of these bridye couplers, pump through a grill, as shown in Fig. 31. Ion pumps in this location are used for the same reasons they are used on the OTL, and they also are not equipped with isolation valves. The total gas load is calculated to be $23467 \mathrm{c} / \mathrm{s}$.

Modules can be isolated by valves contained within the bridge couplers at each end (Fig. 32). These valves contain elastomer seals, which may be degraded by the radiation, but they are considered to be a maintenance convenience rather than an essential accelerator component. For initial pumpdown, one bridge coupler in each module contains a port on which a cryopump can be temporarily mounted. The cryopump can pump through the of iris in the same manner as in the DTL.

6. The Target Area/Pion-Channel Lines. The target will have a large outgassing rate, and experience has shown that periodic maintenance is

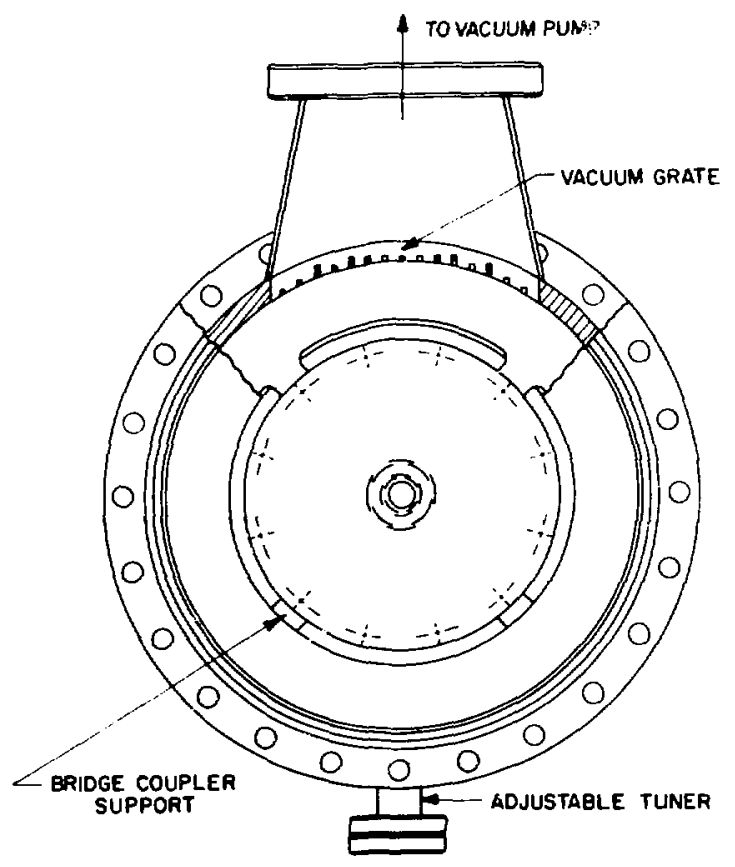

Fig. 31.

CCL bridge coupler (with vacuum pumping).

necessary; therefore, the target area should be isolable and equipped with turbomolecular vacuum pumps. Other parts of the pion channels will probably be pumped by cryopumps or turbomolecular pumps. Although some preliminary designs have been considered (see Appendix $C$ ), the exact size and shape of the pion channels have not yet been determined. 


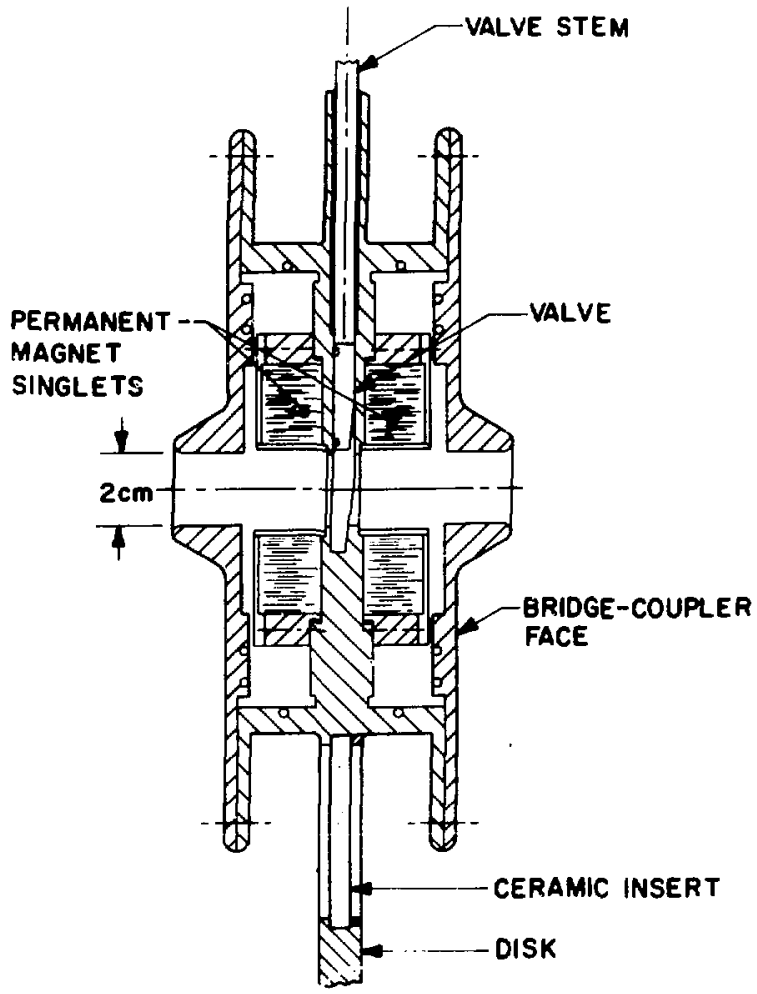

Fig. 32.

CCL bridge coupler (with valve).

\section{F. The if Systems}

1. 440-MHz System. The beam pulse length selected for the 440-MHz system (which drives the DTL and RFQ) is $60 \mu \mathrm{s}$, with a repetition rate of 60 $\mathrm{Hz}$. The kylstron for the $440-\mathrm{MHz}$ system requires a control margin of $\sim 15$, and the if system must deliver 22.7 MW of peak power. The DTL cavity's fill time is $15.6 \mu \mathrm{s}$, with a $Q$ of 44000 ; therefore, the total rf pulse length is $7.56 \mu \mathrm{s}$. An appropriate PFN modulator has been designed and is being fabricated for the PIGMI-component test program. Figure 33 shows a schematic of the modulator, which is essentially the same for both the 440 and 1320$\mathrm{MHz}$ systems. The risetime of a PFN and pulse transformer is $\sim 2 \mu s$ for this type of long-pulse

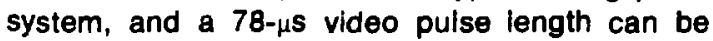
assumed. The average if power then required is $103 \mathrm{~kW}$; the Varian VA-812E klystron is a good choice for this application. Because it is rated at 20MW nominal peak-output power and $300-k W$ aver-

age-power output, a single VA-812E can supply both the peak and average power required by PIGMI. The kylstron is relatively tall, standing 4.1 $\mathrm{m}$ including the oil tank. The vendor's data indicate that a single tube can supply up to $25 \mathrm{MW}$ of peak power, but it is guaranteed only for pulse lengths up to $25 \mu \mathrm{S}$. The VA-812E should operate well at $60 \mu \mathrm{s}$; however, it has not yet been actually tested to such long pulses.

The VA-812E klystron has an efficiency of $33 \%$ and a microperveance of 2.81 , which dictate that the pulse applied to the cathode be $226.7 \mathrm{kV}$. The peak current is $303.4 \mathrm{~A}$, and the klystron impedance is $747 \Omega$. A PFN and step-up transformer are required to cathode pulse the VA-812E. The PFN total capacity is $5.2 \times 10^{-6} \mathrm{~F}$. The transformer, whose core will weigh $\sim 100 \mathrm{~kg}$, will be fairly large. The turns ratio of 10:1 will keep the low-voltage side to $\sim 45 \mathrm{kV}$. and the pulse transformer will share the oil tank with the high-voltage end of the klystron.

The primary if source is a voltage-contolled crystal oscillator. This high-stability oscillator is the phase and frequency reference for the entire machine. The cavity fields are sampled, and an analog feedback loop controls the phase and amplitude to $\pm^{\circ}$ and $\pm 1 \%$. The $\mathrm{rf}$ system is controlled at the 0.1 to 1.0 level, and the set points may be computer controlled. The complete modulator will fit into an enclosure $0.61 \mathrm{~m}$ wide by $2.74 \mathrm{~m}$ long by $2.13 \mathrm{~m}$ deep. In addition, four racks of electronic equipment are required to house the high-voltage controls, interlocks, and low-level rf system.

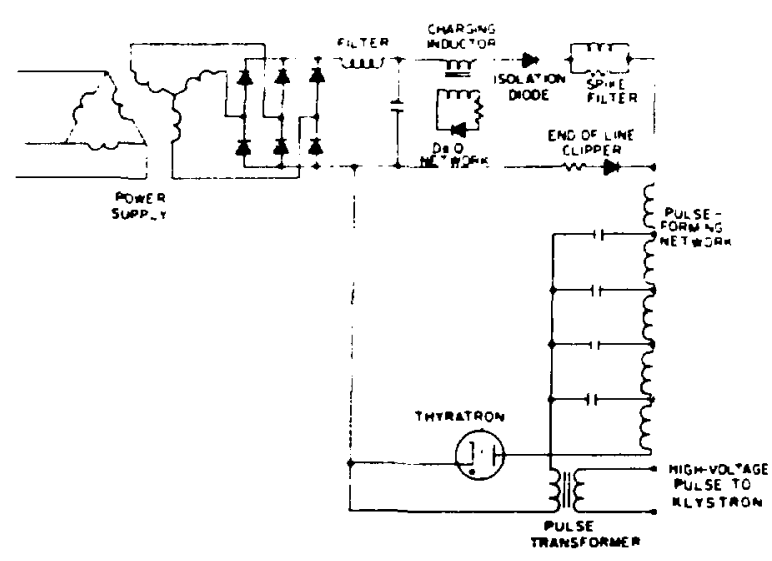

Fig. 33.

Schematic diagram of PICMI modulator. 
2. 1320-MHz of Syatem. One of the general physical properties of the $1320-\mathrm{MHz}$ rf-power system (Fig. 34) is delivery of if power to the CCL through an iris in six bridge couplers that have a slightly different internal shape from the other bridge couplers (one is shown in Fig. 35). The CCL system requires $66.8 \mathrm{MW}$ to supply the copper power and 81.4 MW for the total peak if power. Because a saturated if system cannot be controlled, an additional 15-MW power capability is required for a control margin. This brings the total of power capability to $93.6 \mathrm{MW}$. The $\mathrm{Q}$ of the 1320 $\mathrm{MHz}$ if system is 24000 ; therefore, the fill time becomes $\sim 3.6 \mu \mathrm{s}$. Thus, the total rf pulse length is $63.6 \mu \mathrm{s}$, and the average $\mathrm{rf}$ power is $357 \mathrm{~kW}$. The modulator risetime is $\sim 2.4 \mu \mathrm{s}$ with a total video pulse length of $66 \mu \mathrm{s}$.

The Litton Industries L-5081 klystron is an excellent choice for driving the $1320-\mathrm{MHz}$ system. It is a cathode-pulsed klystron that can deliver $75 \mathrm{~kW}$ of

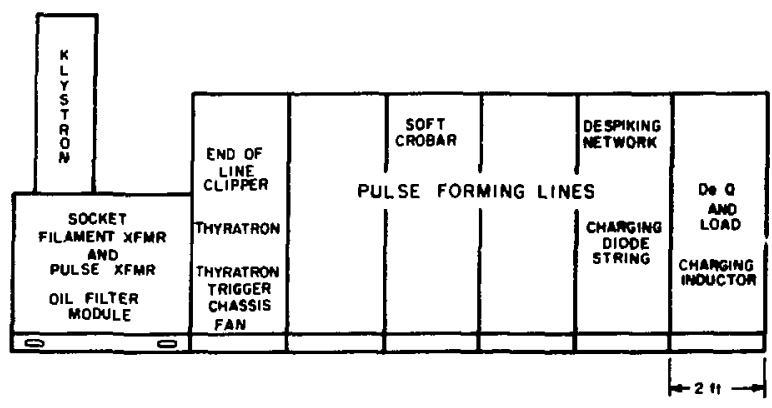

Fig. 3.

PIOMI if power stotion.

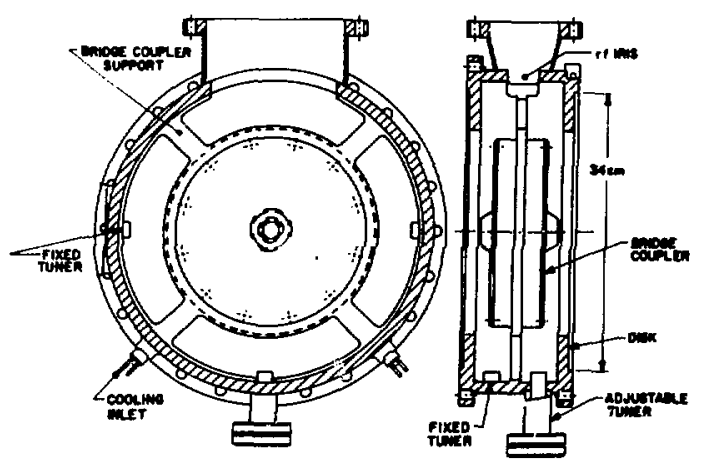

Fig. 35.

CCL bridge coupler (with if drive). average power and $30 \mathrm{MW}$ of peak power. Its microperveance is 2.12 and its efficiency is $38 \%$. Although this klystron is usually operated at $10 \mu \mathrm{s}$, it will probably operate at longer $(60-\mu s)$ pulse lengths. The average-power limitations require a minimum of five L-5081 klystrons, but because the CCL structure operates as its own rf manifold, an extra klystron would allow the system to operate with one L-5081 out of service. The PFN step-up transformer modulator wou!d have essentially the same schematic as the $440-\mathrm{MHz}$ system. The lowlevel electronics and control system for the 1320$\mathrm{MHz} \mathrm{CCL}$ is almost idential to the $440-\mathrm{MHz}$ DTL system diagram, although the detailed components are different. The klystrons would operate at 18.7 MW, $222.0 \mathrm{kV}$, and 221.7 A in the 5-klystron mode. When all 6 klystrons are operating, each would produce 15.6 MW at 206.4 kV and 198.9 A. The modulator and pulse transformer would be simitiar in size to the $440-\mathrm{MHz}$ components, but the klystron tube would be smaller because of the shorter wavelength at $1320 \mathrm{MHz}$.

\section{G. Control and Diagnostic System}

The equipment systems under the surveillance of the control system include injec:or parameters, cavity field parameters, temperature control systems, forward and reflected powers, PFN modulator parameters, beam diagnostics, beam-spu! radiation monitors, and a few electromagnetic quadrupoles and steering magnets. A few protection systems, such as the personnel safety systems. the run-permit system, and the fast-protect system, are implemented independently of the control system and provide their status (but no control) to the computer control system.

The control system will experience its greatest demands for good response and heaviest use during commissioning, routine accelerator-maintenance periods, and subsequent turn-on. The system will be expected to support accelerator maintenance with effective diagnostic tesiing and exercising of all subsystems. It will provide straightforward ar,d, in some cases, automatic procedures for all machine operations. Effective and responsive control, including visual displays and timely execution of operato instructions will be provided at the operator's console. During the initial commissioning period and subsequent machine development periods, the contol system will support a variety of beam-diagnostic measurements. 
The control-system design envisioned for a PIGMI accelerator is based on an advanced architecture developed at Fermilab, and it benefits from their state-of-the-art engineering and years of experience in controlling an operating linac. The design is based on a collection of small, modular, intelligent, control statiors, each of which is associated with an accelerator module or logical collection of equipment requiring control and associated signal sources. Each control station includes a single-board computer, a small equipment-oriented console, and the analog-and-digital interface equipment. All of these components would be compatible with MULTIBUS, an industrystandard microcomputer-bus specification, which is currently supported by over 50 manufacturers of compatible equipment. Each local station would be assembled from a collection of commercially available cards, backplanes, and enclosure hardware.

The software associated with each local statio is stored Programmable Read-Only Memory (PROM) to insure long-term integrity and provide capability for automatic restart, if necessary. Channel table information, including device descriptors, calibration information, set point and tolerance values for accelerator parameters requiring infrequent updating, would reside in nonvolatile core memory.

Associated with each local control station is a miniconsole that supports local testing and maintenance of equipment. The miniconsole would contain a video display for equipment parameter values and channel table data. Parameters may be selected and modified by a single knob, and data can be entered by means of a pullout keyboard. The console is controlled by a single card, located in the MULTIBUS card cage, requiring only a threewire connection. If a station is inaccessible during operation, operators familiar with the local console could access any local station through an identical, remotely located console.

A schematic layout of the control system is shown in Fig. 20; the local control stations are secondary stations that communicate with a central minicomputer over fast serial link, under the control of the primary station. The communications link operates in a loop mode that uses the very efficient, bit-oriented SDLC protocol. This industy-standard protocol is supported by a variety of LSI circuits that facilitate rapid transfer of message with minimum software overhead.

The primary station, which is responsible only for the link operation and not for equipment control, retrieves data from secondary stations, makes the data readily available to the computer for display at the console, and continually polls the secondaries for requested service. Being intimately interfaced to the minicomputer, the primary (or link) controller forwards requests for data and control instruccions. initiated by the operator, to the appropriate secondary stations.

Secondary stations perform the task of data acquisition, monitoring, and control of the local hardware. During each control cycle $(\sim 15 \mathrm{~Hz})$, each secondary digitizes all its anaiog data, reads the digital status from the equipment, and makes it available as a current data pool, accessible either locally or through the link to the console. Based on a table of requested parameters, groups of data from the pool are transmitted to the primary following each control cycle. Next, the secondary proceeds to service the local console and executes any required application programs. Suitably locating secondary stations can keep the cable lengths short, reducing the chance that noise and ground loops could degrade the quality of the analog signals Likewise, the local consoles would be located close to the hardware that requires maintenance.

The minicomputer (Fig. 20) can be independent of the rest of the system in its hardware configuration. Its primary function is to provide a facility for high-level program development and execution of software, oriented toward interactive control. Because the bulk of the processing load is shared by an array of microprocessors in parallel, the task of accelerator control would represent a modest load for the computer. These excess resources could easily be exploited for other control functions associated with a PIGMI facility, such as targeting, secondary beam lines, and treatment rooms. In addition, the computer could be used to manage patient records and to facilitiate treatment planning.

The primary interface between the operator is at a small control console. Display equipment would include a color cathode ray tube (CRT) for status displays, interactive control, limited graphics, and a storage scope for general-purpose graphics. Knobs under operator control would facilitate most manual tuning operations. Buttons with assigned functions would be provided. A variety of software tools would be available, many of which could be executed concurrently, selected at a touch-panel from a computer-generated index. However, normal accelerator operation might be done by switching to OFF, STANDBY, or ON. 


\section{FACILITY DESIGN}

\section{A. Base-Case Accelerator Design}

The base-case PIGMI accelerator facility was chosen for detailed description in this report because it most clearly illustrates the features of the PIGMI accelerator. It is c. linac exactly $133.15 \mathrm{~m}$. long with a distributed if power system. The accelerator is horizontally positioned within an underground rectangular tunnel that contains the 1320$\mathrm{MHz}$ klystrons. The $440-\mathrm{MHz}$ klystron is located in an above-ground service building with a short vertical waveguide to the DTL.

The accelerator tunnel cross section (Fig. 36) is large enough for access to the accelerator by maintenance equipment and personnel. The $\mathrm{CCL}$ portion of the tunnel must be large enough so that a complete 1320-MHz klystron can be moved down the tunne' to an elevator, where it can be lifted to the service building. The accelerator tunnel must have sufficient overburden to reduce the radiation from the accelerator to meet statutory limits for public access. The accelerator produces radiation primarily in the form of "soft" $x$ rays, caused by the rf-induced electric currents on the accelerator interior surfaces. As the accelerator is operated, beam spill may cause minor activation of the accelerator structure that releases "harder" radiation. The PIGMI design minimizes any beam spill; the control and instrumentation would rapidly shut down the accelerator in case of an inadvertant beam spill that, if continued, would cause activation of structural materials. An average overburden of $\sim 4 \mathrm{~m}$ will be adequate to reduce any conceivable radiation to an acceptabie level at ground surface.
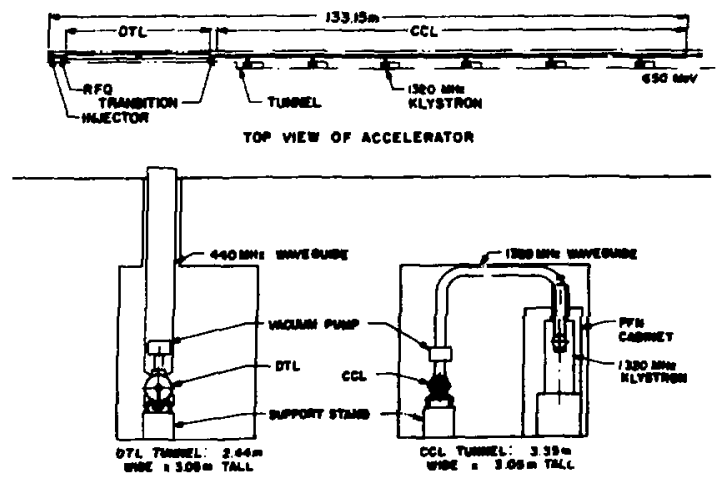

Fig. 38.

Straight PICNI with distribuled $\boldsymbol{A}$ syatem.

\section{B. Support Facility}

The PIGMI acceierator facility will require a service building or area, the exact size and location of which will be determined by the particular medical complex. If the service area is combined with the building housing the $440-\mathrm{MHz}$ klystron, the building would be situated over the DTL. A minimum ceiling height of $\sim 10 \mathrm{~m}$ would be needed to allow the 440-MHz klystron tube to be lifted from its oil tank. This could be reduced to $\sim 6 \mathrm{~m}$ if the klystron is placed at the same level as the accelerator. The requirements of the various accelerator support systems would determine any additional floor space needed. The service building also should contain an elevator and other access to the accelerator for personnel and equipment.

The minimum facilities considered necessary to operate and maintain the PIGMI accelerator are these:

Floor

Function Space

Vacuum laboratory $36 \mathrm{~m}^{2}$

Electronics laboratory $36 \mathrm{~m}^{2}$

Utilities room (electrical, cooling, ventilation)

$54 \mathrm{~m}^{2}$

Storage space $36 \mathrm{~m}^{2}$

Elevator to accelerator

$15 \mathrm{~m}^{2}$

440-MHz kJystron

$35 \mathrm{~m}^{2}$

Office space

$40 \mathrm{~m}^{2}$

Operating console area

$25 \mathrm{~m}^{2}$

Cooling tower/heat exchangers

(optional)

$30 \mathrm{~m}^{2}$

Total

$307 \mathrm{~m}^{2}$

\section{Treatment Facility}

A very important parameter in the pion generator design is the efficiency of the pion-collection channel. The pion collection system must operate with a maximum acceptance and energy spread to minimize residual radioactivity in the system's target regions. The higher the pion channel's acceptance, the less stringent are the accelerator current requirements. However, high solid-angle acceptance channels imply a difficult beam configuration at the output, whereas large solid-angle acceptance implies large emittance beams with attendant large. 
angula- spreads in the treatment region. Several possible configurations that might be suitable are being investigated; the treatment facility to be used with a PIGMI accelerator will be highly dependent on the needs and layout of the parent facility. A typical treatment facility is shown in Fig. 37. Because of the time requirement for patient setup, a minimum of two treatment rooms is considered necessary. Three treatment rooms may be the optimum number because more than three would create redundancy in the most restricted portion of the PIGMI facility.

\section{Utilities}

1. Electrical. With the injector voltage of only 30 $\mathrm{kV}$. the shielding of electronic components (by a Faraday cage) from the effects of high-voltage arcdowns is not necessary. Arc-downs will be minimized by conservative design of the high-voltage components. A carefully designed ground system should be adequate to cope with the effects of arcdowns if they occur.

Various kinds of electrical power will be required for the PIGMI accelerator. By far the greatest amount of power will be required by the klystrons. These require

\begin{tabular}{lll} 
System & $480 \mathrm{Vac} 30^{\circ}$ & $\frac{208 \mathrm{Vac} 10^{\circ}}{12.6 \mathrm{~kW} \text { at } 35 \mathrm{~A}}$ \\
\hline $440 \mathrm{MHz}$ & $28 \mathrm{~kW}$ at $33.7 \mathrm{~A}$ & \\
$1320 \mathrm{MHz}$ (Max/klystron) & $161.5 \mathrm{~kW}$ at $194.3 \mathrm{~A}$ & $12.6 \mathrm{~kW}$ at $35 \mathrm{~A}$ \\
\hline
\end{tabular}

\section{3-phase. \\ "single-phase.}

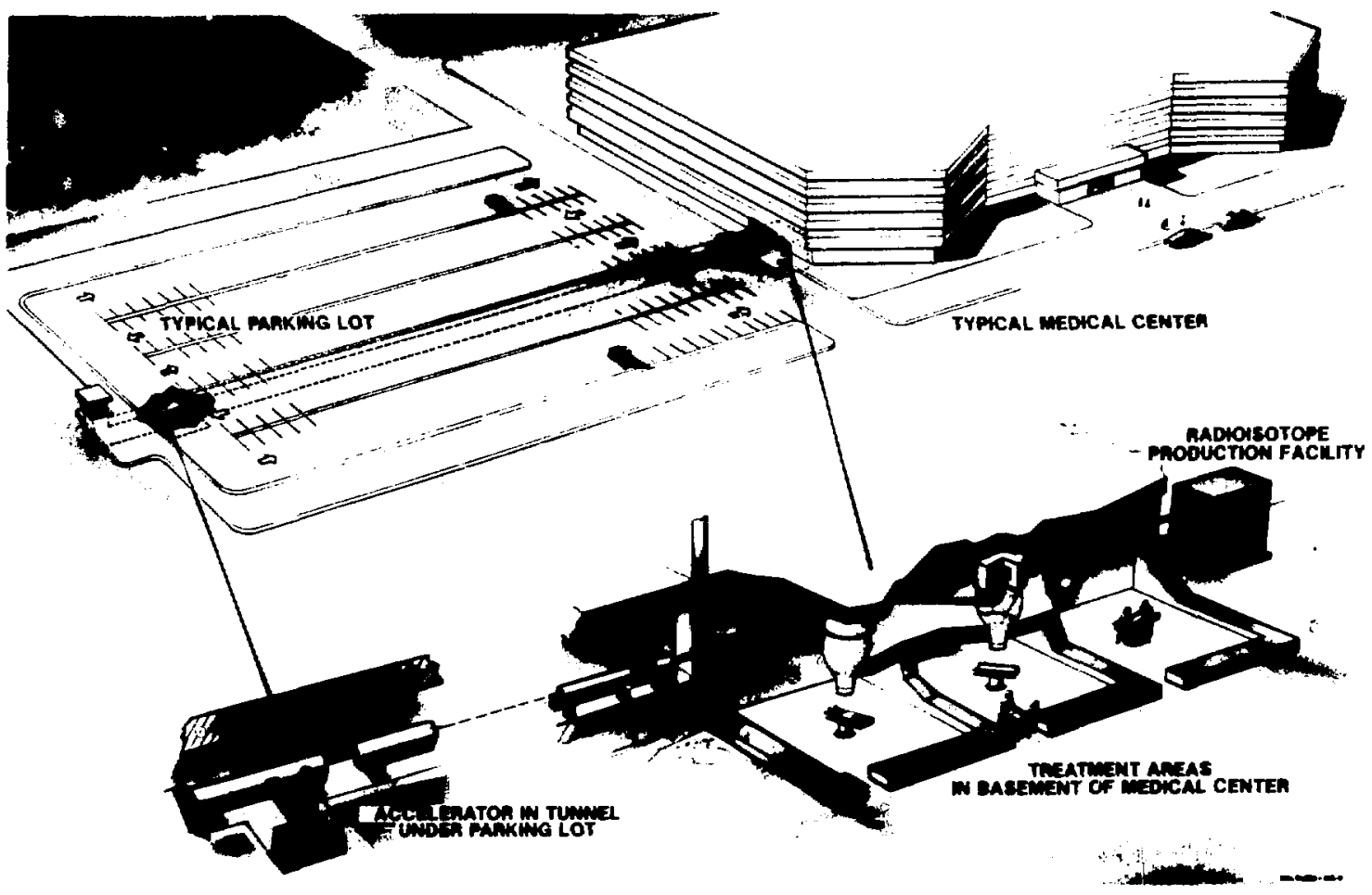

Fin. 37.

PICNI berity leyout. 
Because the six $1320-\mathrm{MHz}$ klystrons would actually operate at reduced power ( $\cong$ five $1320-\mathrm{MHz}$ klystrons at full power), the total power required would be $-835.5 \mathrm{~kW}$ of $480 \mathrm{Vac} 3 \phi$ and $\sim 75.6 \mathrm{~kW}$ of $208 \mathrm{Vac} 1 \phi$ power. Minor additional amounts of 110 Vac 1\$ and 110 Vac 10 "clean power" would be required.

2. Cooling Water. Cooling-water requirements for the PIGMI accelerator are modest. The injector and $R F Q$ require $\sim 5 \mathrm{~kW}$, the $D T L$ requires $\sim 50 \mathrm{~kW}$. and the $\mathrm{CCL}$ requires $-250 \mathrm{~kW}$. The $440-\mathrm{MHz}$ klystron requires $-250 \mathrm{~kW}$, and the $1320-\mathrm{MHz}$ klystrons require $-1200 \mathrm{~kW}$. Therefore, a total cooling capacity of $-1800 \mathrm{~kW}$ will be required. which is equivalent to $-77.9 \mathrm{l} / \mathrm{s}(\sim 1235 \mathrm{gpm})$ of cooling water, assuming a $4.5^{\circ} \mathrm{C}\left(10^{\circ} \mathrm{F}\right)$ temperature rise. This cooling water requirement could be met by various methods that will be gieatly site dependent. such as cooling tower. city-water cooling, or use of existing excess cooling capacity at the hospital.

\section{FACILITY CONSTRUCTION AND OPERA- TION}

\section{A. Construction}

Because the major accelerator components will be prepared for installation before shipment to the medical center, construction tims at the medical facility is governed by the preparation of the accelerator channel. Site preparation may take $\sim 1$ year. Because of the clean conditions necessary to assemble the accelerator, most site construction should be finished before the accelerator is installed. The electronics can be assembled and checked out before shipment but should be rechecked at the medical facility during installation. A service building may be used as an accelerator $\therefore$ aging and assembly area.

Following site preparation, accelerator assembly begins with the injector and RFQ installation, alignment, and checkout ( $\sim 4 \mathrm{wk}$ ). The DTL and transition section are then assembled, aligned, tuned, and the beam characteristics are verified ( $-6 \mathrm{wk}$ ). Then the CCL is assembled, aligned, tuned, and checked out (one module at a time) until the final module is installed ( -3 wk per module, or -24 wk for the entire $C C L$ ). The beam targets and pion channels can be assembled in parallel with accelerator assembly, but checkout and tuning must await a beam from the accelerator. The treatment facility checkout may be lengthy (perhaps up to 16 wk) because of the precision required; however, this time can be used for rf conditioning and any needied accelerator testing to bring it to full design performance. Therefore, a complete PIGMI facility could be in operation $2 \mathrm{yr}$ after the start of construction.

\section{B. Staffing}

Staffing requirements for the PIGMI facility are modest compared with those for research accelerators because of the design emphasis on simplicity and reliability. A mirimum staff of eight will be necessary to operate a two-shift operating schedule:

- six accelerator operators,

- one accelerator operations supervisor, and

- one administrator.

Of those six operators, two should be mechanical technicians and two should be electrical/electronic technicians.

\section{c. Operation}

The accelerator is operated from the control console described in Sec. II. The control-system computer directed by the console operator does the detailed operations, including startup of the accelerator. Once the accelerator is started, the console operator becomes an observer; therefore. it is desirable to combine the accelerator control console with the consoles that control the beam line, pion channels, and. perhaps. the treatment facility. For safety considerations. a minimum of two operators should be present during normal accelerator operation.

Besides actually operating the accelerator, the computer also can monitor the support and safety systems, so that any unsafe or deteriorating situation can be reported to the console operator. The computer can automatically place components and equipment in a safe condition if there are emergencies; also, it can produce any required data logs and periodic status reports.

\section{Mainlenence}

The PIGMI accelerator is designed to be extremely reliable: however, periodic maintenance will be 
required. Normal maintenance items required would be klystron maintenance (yearly), ion source filament replacement (yearly), ion pump rebuilding ( $10 \%$ of the pumps yearly), turbopump rebuilding (one pump a year, on the average), and turbopump bearing oil change (periodic). Therefore, a total shutdown for maintenance once a year for $\sim 2$ wk should be adequate.

\section{FACILITY COSTS}

\section{A. Accelerator Cost}

The PIGMI facility costs are summarized in Table III.

Engineering costs for most projects are astimated to be $30 \%$ of total project costs; the latter,

TABLE III

\section{PIGMI FACILITY COST SUMMARY}

Accelerator beam line
Injector
RFQ
DTL
Transition region
CCL

Cost (1980 dollars)
$\$ 105000$
68000
1140600
101000
10100
4452000
rf systems
$1320 \mathrm{MHz}$

$440 \mathrm{MHz} \quad \$ 849000$

1374000 however, includes costs for component development. When the ongoing PIGMI Prototype program is completed, every major component of the accelerator will have been designed or built, at least in a prototype form. Therefore, the major engineering costs associated with a PICMI accelerator will be the production of a complete set of fabrication drawings (most based directly on the PIGMI Prototype drawings) and the engineering time necessary to supervise the fabrication process. Furthernore, the cos. analysis assumes that two PIGMI accelerators would be buili concurrently and that the engireering costs would be shared. The cost analysis includes $\sim 10 \%$ overhead on some accelerator components to pay for engineering during the fabrication phase.

The total cost of the accelerator portion of PIGMI is estimated to be $\$ 5866600$. A detailed cost analysis of the PIGMI accelerator is presented in Appendix $A$. The injector is $-2 \%$ of the total cost of the accelerator, the RFQ $\sim 1 \%$, the DTL $\sim 19 \%$, and the transition region $\sim 1 \%$. The $\mathrm{CCL}$ is by far the largest cost item, $\sim 77 \%$ of the accelerator cost.

\section{B. The r!-System Cost}

The rf-svstem costs are based on estimated component costs from the vendors, plus cost data that have been generated for the PIGMI Prototype program. The 440-MHz system (Varian VA-812E rf tube) is estimated to cost $\$ 849000$. Each of the six $1320-\mathrm{MHz}$ klystrons (Litton L-5081 if tube) is estimated to cost $\$ 229000$; the total cost for the entire $1320-\mathrm{MHz}$ system is estimated to be $\$ 1374000$. The cost per major component of these systems is tabulated in Appendix A.

\section{Treatment-Facility Cost}

\section{Miscellaneous}

Vacuum equipment

Cooling

$\$ 428000$

70000

430000

310000
The treatment facility is not yet sufficiently defined to allow a detailed cost analysis. Based on the conceptual design presented in Appendix $C$, it is roughly estimated that the magnets, target, pion channels, shielding-treatment heads, and necessary auxiliary equipment will cost $\sim \$ 10$ million for a three-treatment-room facility. A major portion of the cost is the target and primary pion channel. Additional treatment rooms may be available at a relatively low cost.

\begin{tabular}{lrl} 
Total Coat of Accelerator & $\$ 9779600$ \\
Treatment Facility & $10000 \quad 000$ \\
Site Preparation & $5000 \quad 000$ \\
Total Facility Cost & 24779600 \\
\hline
\end{tabular}




\section{Miacellaneous Costs}

There are various miscellaneous systems required for the PIGMI accelerator. The control and instrumentation system is estimated to cost $\$ 452000$. The vacuum systems costs are treated in detail in Appendix $A$ and require $\sim \$ 428000$ for vacuum pumps and associated equipment. Cooling of the accelerator must be quite precise; $\sim \$ 70000$ will be required for the accelerator temperature control systems. Assembly and installation costs for accelerator system components is estimated to be $\$ 430000$, and initial startup cost is estimated to be $\$ 310000$. These costs are detailed in Appendix A.

\section{E. Operating Costs}

Operating costs are estimated to be $\$ 906000$ per year, assuming a staft of eight and electrical power available at $6 q / \mathrm{kWh}$. The payroll of the staff is $\sim 66 \%$ of the total operating cost.

\section{publications Relevant to the pigmi progham}

1. Boyd, T. J., Jr., K. R. Crandall, R. W. Hamm, L. D. Hansborough, F. F. Hoeberling, D. W. Mueller, J. M. Potter, R. H. Stokes, J. E. Stovall, R. G. Sturgess, D. A. Swenson, P. J. Tallerico, T. P. Wangler, and L. C. Wilkerson, "The PIGMI Technology," Los Alamos Scientific Laboratory MP/AT-Division Joint Colloquium, unclassified release document LA-UR-80-3561 (December $10,1980)$.

2. Bradbury, J. N., and D. A. Swenson, "Proposal for Development of a Pion Generator for Medicial Application," Los Alamos Scientific Laboratory proposal No. P-540 (September 1975).

3. Bradbury, J. N., E. A. Knapp, and D. E. Nagle, "Light Ion Linacs for Medical Application," Proc. 1975 Particle Accelerator Conf., Washington, DC, March 12-14, 1975, IEEE Trans. Nucl. Sci. 22. p. 1755 (1976).

4. Bush, E. D., Jr., "Permanent Quadrupole Magnets," Proc. 1976 Linac Conf., Chalk River, Ontario, September 14-17, 1976, Chalk River Nuclear Laboratories report AECL-5677, p. 363 (1) 7).

5. Crandall, K. R., R. H. Stokes, and T. P. Wangler, "RF Quadrupole Beam-Dynamics Design Studies," Proc. 10th Linear Accelerator Conf., Montauk, New York, Septemter 10-14, 1979, Brookhaven National Laboratory report BNL-51134, p. 205 (1980).

6. Goodwin, R. W., and M. F. Shea, "A Distributed Linac Control System Featuring SDLC Loop
Communications," Proc. 10th Linear ACcelerator Conf., Montauk, New York, September 10-14, 1979. Brookhaven National Laboratory report BNL-51134, p. 274 (1980).

7. Halbach, K., and R. F. Holsinger, "SUPERFISH-A Computer Program for Evaluation of if Cavities with Cylindrical Symmetry," Particle Accelerators 7, p. 213 (1976).

8. Halbach, K., R. F. Holsinger, W. E. Jule, and D. A. Swenson, "Properties of the Cylindrical if Cavity Evaluation Code SUPERFISH," Proc. of 1976 Proton Linac Conf., Chalk River, Ontario, September 14-17, 1976, Chalk River Nuclear Laboratories report AECL-5677, p. 230 (1977).

9. Halbig, J. K., S. F. Klosterbuer, and D. A. Swenson, "A General-Purpose MicroprocessorBased Control Chassis," Los Alamos Scientific Laboratory report LA-7898-MS (August 1979).

10. Halbig, J. K., S. F. Klosterbuer, and V. A. Martinez, Jr., "A Data Acquisition and Command System for Use with a MicroprocessorBased Control Chassis," Los Alamos Scientific Laboratory report LA-7894-MS (January 1980).

11. Hamm, R. W., "The Advantages of Combining an EBIS with the PIGMI Technology," Proc. 6th Conf. on the Applications of Accelerators in Research and Industry, Denton, Texas, November 3-5, 1980, IEEE Trans. Nucl. Sci. 28, p. 1515 (1.981). 
12. Hamm, R. W., "30-kV Injector for PIGMI Prime Prototype." Los Alamos Scientific Laboratory Accelerator Technology Division Group AT-1 memorandum No. AT-1-270 (September 11. 1980).

13. Hamm, R. W., K. R. Crandall, L. D. Hansborough, J. M. Potter, G. W. Rodenz, R. H. Stokes, J. E. Stovall, D. A. Swenson, T. P. Wangler, C. W. Fuller, M. D. Machalek, R. A. Jameson, E. A. Knapp, and S. W. Williams. "The if Quadrupole Linac: A New Low-Energy Accelerator," Intl. Conf. on Low-Energy Ion Beams 2, Bath, England, April 14-17, 1980 (Inst. Phys., Bristol, England, 1981), LowEnergy Ion Beams, 1980, Conf. Ser. 54, p. 54.

14. Hamm, R. W., R. R. Stevens, Jr., D. W. Mueller, and $H$. M. Lederer, "A Compact 250-kV Injector System for PIGMI," Proc. 5th Conf. on the Applications of Small Accelerators, Denton, Texas, November 6-8, 1978, IEEE Trans. Nucl. Sci. 26, p. 1493 (1979).

15. Hansborough, L. D., E. D. Bush, and V. E. Hart, "Mechanical Description of PIGMI," Proc. 5th Conf. on the Applications of Small ACcelerators, Denton, Texas, November E-8, 1978, IEEE Trans. Nucl. Sci. 26, p. 1464 (1979).

16. Hansborough, L. D., E. D. Bush, and V. E. Hart, "Mechanical Technologies for PIGMI," Proc. 1979 Particle Acjelerator Cont., San Francisco. California, March 12-14, 1979. IEEE Trans. Nucl. Sci. 26, p. 3770 (1979).

17. Hansborough, L. D., R. W. Hamm, J. E. Stovall, and D. A. Swenson, "An Optimized Dosign for PIGMI," Proc. 6th Conf. on the Applications of Accelerators in Research and Industry, Denton, Texas, November 3-5, 1980, IEEE Trans. Nucl. Sci. 28, p. 1511 (1981).

18. Hart, V. E., "PIGMI Mechanical Fabrication," Proc. 1976 Proton Linac Conf., Chalk River, Ontario, September 14-17, 1976, Chalk River Nuclear Laboratories report AECL-5677, p. 358 (1977).

19. Holsinger, R. F., "The Drift-Tube and Beamline Quadrupole Permanent Magnets for the NEN Proton Linac," Proc. 10th Linear Accelerator
Conf., Montauk, New York, September 10-14. 1979. Brookhaven National Laboratory report BNL-51134, p. 373 (1980).

20. Inagaki, S., "Space-Charge Limit for a DriftTube Linac from the Stability Point of View of Longitudinal Periodicity." Los Alamos Scientific Laboratory report LA-8288-MS (March 1980).

21. Inoue. $H$., and D. A. Swenson, 'Design Study for Achromatic and isochronous $180^{\circ}$ Bending Systems for PIGMI," Los Alamos Scientific Laboratory report LA-7406-MS (July 1978).

22. Jameson, R. A., and R. S. Mills. "On Emittance Growth in LInear Accelerators," Proc. 10th Linear Accelerator Conf., Montauk, New York. September 10-14, 1979. Brookhaven Nationat Laboratory report BNL-51134, p. 231 (1980).

23. Knapp, E. A., "Applications of Linear ACclerators." Proc. 1976 Linac Conf.. Chalk Aiver. Ontario. September 14-17, 1976. Chalk River Nuclear Laboratories report AECL-5677, $p$. 115 (1977).

24. Knapp, E. A., and J. N. Bradbury. "Medical Linac Design Possibilities." Proc. 3rd Conf. on Applications of Small Accelerators, Denton. Texas, November 6-8, 1974, (National Technical Information Service, Springfield, Virginia, 1975), Conf-741040-P1/P2, p. 304.

25. Knapp, E. A., B. C. Knapp, and J. M. Potiter. "Standing-Wave High-Energy Linear ACcelerator Structures," Rev. Sci. Instrum. 39. p. 979 (1968).

26. Knapp, E. A., and D. A. Swenson, "The PIGMI Program at LASL," Proc. 1976 Proton Linear Accelerator Conf., Chalk River, Ontario, September 14-17, 1976 Chalk River Nuclear Laboratories report AECL-5677, p. 230 (1977).

27. Lazarev, N. V., and V. S. Skachkov, "Tipless Permanent-Magnet Quadrupole Lenses," Proc. 10th Linear Accelerator Conf., Montauk, New York, September 10-14, 1979. Brookhaven National Laboratory report BNL-51134, p. 380 (1980). 
28. Manca, J. J., and E. A. Knapp, "Optimization of the Disk and Washer Accelerating Cavity." Los Alamos Scientific Laboratory report LA-7407 (September 1978).

29. Manca, J. J., and E. A. Knapp, "RF Coaxial Couplers for High-Intensity Linear ACcelerators," Los Alamos Scientific Laboratory report LA-8235-MS (February 1980).

30. Manca, J. J., and E. A. Knapp, "TM $M_{01}$ Mode Accelarating Cavity Optimization," Los Alamos Scieritilic Laboratory report LA-7323-MS (AUgust 1978).

31. Menca, J. J., E. A. Knapp, and D. A. Swenson, "High Energy Accelerating Structures for HighGradient Proton Linac Applications," IEEE Trans. Nucl. Sci. 24, p. 1087 (1977).

32. Nagle, D. E., E. A. Knapp, and B. C. Knapp, "Coupled Resonator Model for Standing-Wave Accelerator Tanks," Rev. Sci. Instrum. 38, p. 1583 (1967).

33. Potter, J. M., "An rf Power Manifold for the Radio-Frequency Quadrupole Linear ACcelerator," Proc. 10th Linear Accelerator Conf., Montauk, New York, September 10-14, 1979. Brookhaven National Laboratory report BNL-51134, p, 138 (1980).

34. Potter, J. M., S. W. Williams, F. J. Humphry, and G. W. Rodenz, "Radio-Frequency Quadrupole Accelerating Structure Research at Los Alamos," Proc. 1979 Particle Accelerator Conf., San Francisco, California, March 12-14. 1979, IEEE Trans. Nucl. Sci. 26, p. 3745 (1979).

35. Saito, N., E. D. Bush, and D. A. Swenson, "Development of Samarium-Cobalt Quadrupole Lenses for Particle Accelerator Applications," Los Alamos Scientific Laboratory report LA-7232-MS (June 1978).

36. Schriber, S. O.. "High-Bete Linac Structures," Proc. 10th Linear Accolerator Conf., Montauk, New York, September 10-14, 1979, Brookhaven National Laboratory report BNL-51134, p. 164 (1980).
37. Schriber, S.O., "Room-Temperature Cavities for High-Beta Accelerating Structures," Proc. Conf. on Future Possibilities for Electron ACcelerators, Charlottesville, Virginia, January 8-10, 1979, (University of Virginia, Charlottesville, Virginia), p. L-1 (1979).

38. Shriber, S. O., and J. M. Potter, "Limitations of the Disk-and-Washer Structure," Proc. 10th Linear Accelerator Conf., Montauk, New York. September 10-14, 1979. Brookhaven National Laboratory report BNL-51134, p. 176 (1980).

39. Stokes, R. H., K. R. Crandall, R. W. Hamm, F. J. Humphry, R. A. Jameson, E. A. Knapp, J. M. Potter, G. W. Rodenz, J. E. Stovall, D. A. Swenson, and T. P. Wangler, "The RadioFrequency Quadrupole: General Properties and Specific Applications," Proc. 11th Intl. Cont. on High-Energy Accelerators, CERN, Geneva, July 7-11, 1980, Experimentia: Supplement 40, p. 399 (1980).

40. Stovall, J. E. "Initial Performance of the PIGMI Prototype," Proc. 1979 Particle Accelerator Conf., San Francisco, California, March 12-14, 1979, IEEE Trans. Nucl. Sci. 26, p. 3767 (1979).

41. Stovall, J. E., S. F. Klosterbuer, and J. K. Halbig. "An Accelerator Control System for PIGMI," Proc. 5th Conf. on the Applications of Small Accelerators, Denton, Texas, November 6-8, 1978, IEEE Trans. Nucl. Sci. 26, p. 399 (1980).

42. Sugimitsu, T., and D. A. Swenson, "Investigation of Large Solid-Angle Pion Channel for a Medical Application Utilizing Current Sheets and Solenoid Elements," Los Alamos Scientific Laboratory report LA-8356-MS (May 1980).

43. Swenson, D. A., "Low-Beta Linac Structures," Proc. 10th Linear Accelerator Conf., Montauk, New York, September 10-14, 1979 Brookhaven National L.aboratory report BNL-51134, p. 129.

44. Swenson, D. A., and E. A. Knapp, "A Small Proton LInear Accelerator as a Source of Neutrons for Radiotherapy." Proc. 4th Conf. on the Scientific and Industrial Applications of Small 
Accelerators, Denton, iexas, October 27-29, 1976 (IEEE, Piscatiway. New Jersey, 1977), Pub. No. 76Ch-1175-9-NPS, p, 502.

45. Swenson, D. A., E. A. Knapp, J. M. Potter, and E. J. Schneider, "Stabilization of the Drift-Tube Linac by Operation in the $\pi / 2$ Cavity Mode," Proc. 6th Int. Conf. on High-Energy ACcelerators, Cambridge, Massachusetts, CEAL-2000, 167 (1967).

46. Wangler, T. P., and R. H. Stokes, "The RadioFrequency Quadrupole LInear Accelerator,"
Proc. 6th Conf. on the Applications of ACcelerators in Research and Industry, Denton, Texas, November 3-5, 1980, IEEE Trans. Nucl. Sci. 28, p. 1494 (1981).

47. Williams, S. W., G. W. Rodenz, F. J. Humphry, and J. M. Potter, "Voltage-Breakdown Testing for the Radio-Frequency Quadrupole Accelerator," Proc. 10th Linear Accelerator Conf., Montauk, New York, September 10-14, 1979. Brookhaven National Laboritory report BNL-51134, p. 144 (1980). 


\section{APPENDIX A}

\section{COMPONENT COSTS DETAILED COST ANALYSIS}

TABLE A-I

Engineering/Purchase/Fabrication Costs

\begin{tabular}{|c|c|c|c|c|}
\hline \multirow[b]{2}{*}{ Injector } & \multirow[t]{2}{*}{$\begin{array}{c}\text { Number } \\
\text { Reqd. }\end{array}$} & Unit Cost & \multicolumn{2}{|c|}{$\begin{array}{l}\text { Total Cost } \\
\text { (1980 Dollars) }\end{array}$} \\
\hline & & & & \\
\hline Ion source & 1 & --- & $\$$ & 30000 \\
\hline Vacuum manifold/structure & 1 & $\cdots$ & & 20000 \\
\hline Einzel lens & 1 & --- & & 3000 \\
\hline Power supplies & 1 & --. & & 10000 \\
\hline Equipment cabinet assembly &.- & -- & & 24000 \\
\hline Alignment/support structure & 1 & --- & & 2000 \\
\hline Engineering & -- & $\cdots$ & & 16000 \\
\hline Total cost & & & $\$$ & 105000 \\
\hline \multicolumn{5}{|l|}{$\mathbf{R F Q}$} \\
\hline RFQ manifold & 1 & $\cdots$ & $\$$ & 19000 \\
\hline RFQ resonator cavity & 1 & --. & & 14700 \\
\hline Vane tips & 4 & 4825 & & 19300 \\
\hline Resonator cavity spools & 2 & 2000 & & 4000 \\
\hline Alignment/support structure & 1 & -.. & & 1000 \\
\hline Engineering & $\cdots$ & -- & & 10000 \\
\hline Total cost & & & $\$$ & 68000 \\
\hline \multicolumn{5}{|l|}{ OTL } \\
\hline Tank sections & 11 & $\$ 53000$ & $\$$ & 583000 \\
\hline Tank section with rf input & 1 & -- & & 60000 \\
\hline Drift tubes (complete) & 150 & 2100 & & 315000 \\
\hline Post coupler & 74 & 400 & & 29600 \\
\hline Alignment/support structure & 12 & 1000 & & 12000 \\
\hline Cooling manifold & 12 & 3000 & & 36000 \\
\hline Engineering & $\ldots$ & -- & & 105000 \\
\hline Total cost & & & & 1140600 \\
\hline
\end{tabular}


TABLE A-1

Engineering/Purchase/Fabrication Costs

(Cont)

\begin{tabular}{|c|c|c|c|c|}
\hline Component/System & $\begin{array}{l}\text { Number } \\
\text { Peqd. }\end{array}$ & Unit Cost & $\begin{array}{l}\text { Tota } \\
\text { (198 }\end{array}$ & $\begin{array}{l}\text { I Cost } \\
10 \text { Dollars) }\end{array}$ \\
\hline \multicolumn{5}{|l|}{ CCL } \\
\hline $\begin{array}{l}\text { Accelerating tanks } \\
\text { Basic bridge coupler } \\
\text { Vacuum-pumping bridge }\end{array}$ & $\begin{array}{l}\text { 18/Mod. } \\
\text { 5/Mod. }\end{array}$ & $\begin{array}{r}\$ 26000 \\
6000\end{array}$ & $\$$ & $\begin{array}{r}468000 \\
30000\end{array}$ \\
\hline coupler & 6/Mod. & 8000 & & 48000 \\
\hline \multicolumn{5}{|l|}{ Diagnostic bridge } \\
\hline coupler & 5/Mod. & 8000 & & 40000 \\
\hline Valve-and-bellows bringe coupler & 1/Mod. &.-- & & 10000 \\
\hline rf-drive bridge couple $i$ & 1/Mod. & --- & & 10000 \\
\hline Alignment/support structure & $18 / \bmod$ & 1000 & & 18000 \\
\hline Cooling manifolds to linac & -.. & 4000 & & 18000 \\
\hline Engineering & --- & --- & & 100000 \\
\hline Total cost per module & & & & 742000 \\
\hline Total cost (6 Modules) & & & & 4452000 \\
\hline \multicolumn{5}{|l|}{ Transition Region } \\
\hline Diagnostic chamber/beam line & 1 & --- & $\$$ & 40000 \\
\hline Quadrupole electromagnets & 4 & $\$ 3000$ & & 12000 \\
\hline Power supplies & 4 & 5000 & & 20000 \\
\hline Cooling & 4 & 1000 & & 4000 \\
\hline Bellows/flanges & 2 & 1500 & & 3000 \\
\hline Valves & 2 & 1000 & & 2000 \\
\hline Alignment/support structure & 1 & --- & & 5000 \\
\hline Engineering & -- & --- & & 15000 \\
\hline Total cost & & & $\$$ & 101000 \\
\hline \multicolumn{5}{|l|}{ 100-MHz if System } \\
\hline Klystron and solenoid & 1 & -- & $\$$ & 640000 \\
\hline rf-module electronics (PFN) & 1 & $\cdots$ & & 117000 \\
\hline dc power supply & 1 & -- & & 69000 \\
\hline Waveguide & 1 & $\cdots$ & & 1000 \\
\hline rf window & 1 & -- & & 15000 \\
\hline Cooling & 1 & -- & & 3000 \\
\hline Engineering & $\cdots$ & -- & & 4000 \\
\hline Total cost & & & $\$$ & 849000 \\
\hline
\end{tabular}


TABLE A-I

Enginearing/Purchase/Fabrication Costs

(Cont)

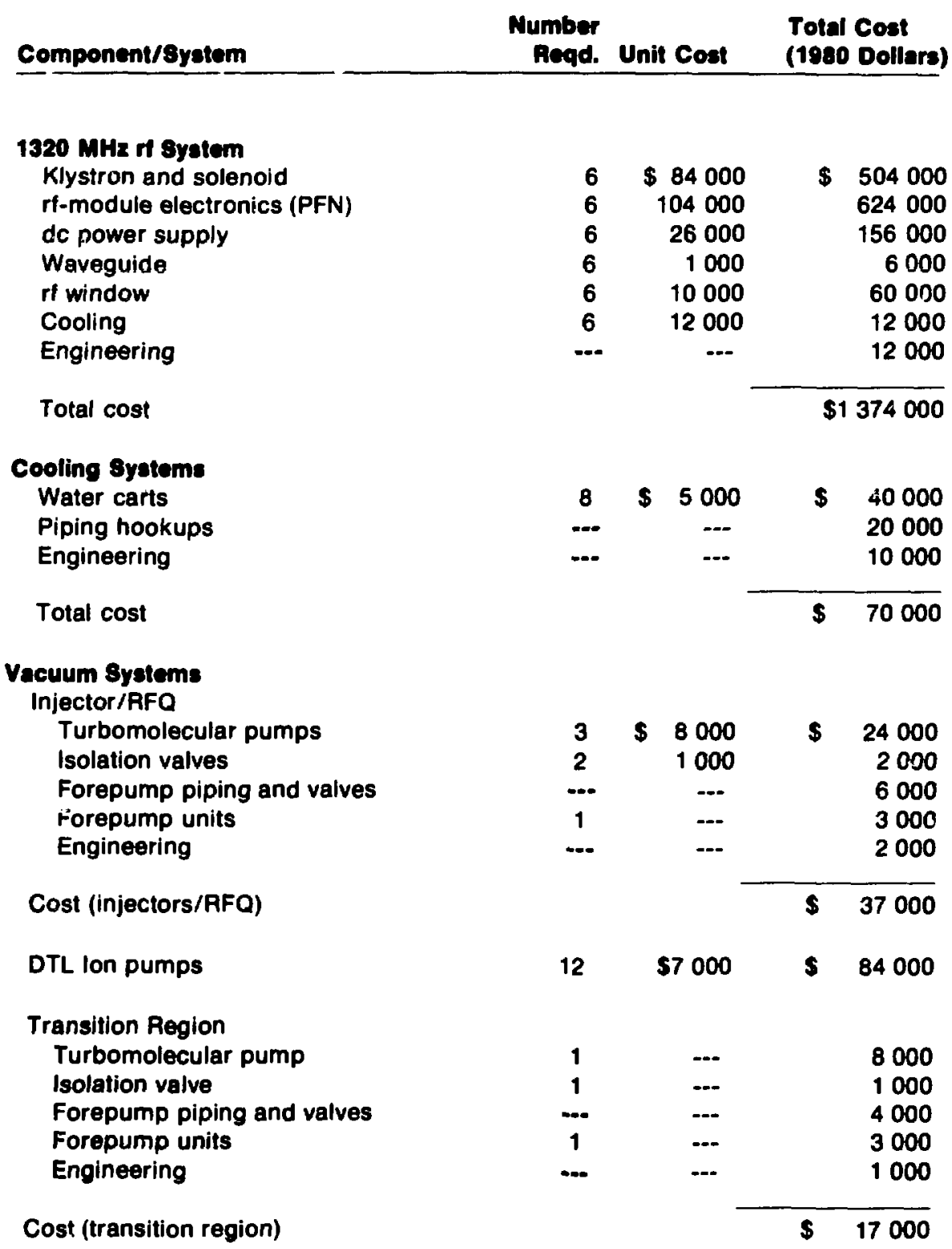


Tane at

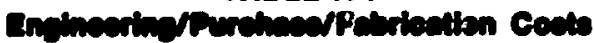

(Com)

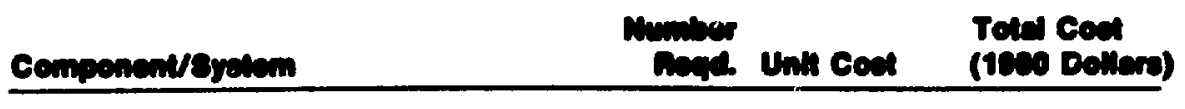

CCL ton pumpe

Initid pumpdown gystem

Cryopump

Roughing-pump unit

Plumbing and valves

Cart

Engineering

Cost (Initial pumpdown syotem)

Miscellaneous

lon gauges and velves

Total cost of vacuum syotems

\section{Contrel Syetion \\ Primary station \\ Secondary stations \\ Minlcomputor \\ Operating/control console \\ Wiring and ascombly \\ Safoty/hardware interlocke}

Total cost

Disgnembes and inotrumentalion

Injector

if oystems (4 algnals each)

Tranaition-reglon diegnoetice

CCL beam diagnoatice
$30 \$ 7000 \$ 252000$

\begin{tabular}{rrrr}
1 & $\ldots$. & & 7000 \\
1 & $\ldots$. & & 3000 \\
$\cdots$ & $\cdots$ & & 6000 \\
$\cdots-$ & & 4000 \\
-- & & 4000 \\
\hline & & & \\
\cline { 2 - 3 } & & 24000
\end{tabular}

$14 \leqslant 1000 \leqslant 14000$

$\$ 428000$

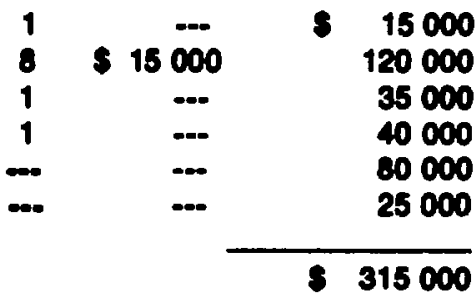

\begin{tabular}{rrrr}
$-\infty$ & 5000 & 5 & 10000 \\
7 & 2000 & 5600 \\
15000 \\
\hline 27 & 2000 & 56000 \\
& & 56 \\
& & 5137000
\end{tabular}

Totel cost 
TADLE A-II

Asecmbly/Inatellation Costs

\begin{tabular}{lrr} 
Componentrayatem & $\cdots$ & Conts \\
\hline Injector & 800 & $\$ 20000$ \\
AFQ & 800 & 20000 \\
DTL & 1600 & 40000 \\
Tranaition region & 800 & 20000 \\
CCL & 4000 & 100000 \\
440-fAHz rf system & 800 & 20000 \\
1320-MHz rf system & 3600 & 90000 \\
Cooling sysiems & 800 & 20000 \\
Support structures & 800 & 20000 \\
Dlagnostics & 800 & 20000 \\
Instrumentation & 800 & 20000 \\
Control system & 1600 & 40000 \\
Tolal cost & & \\
\hline
\end{tabular}

TABLE A-III

Initial start-up/Chock-out Costs

\begin{tabular}{lrr} 
Activity & Men-hours & Costs \\
\hline Injector & 600 & $\$ 15000$ \\
RFQ & 600 & $150 \mathrm{C}$ \\
DTL & 1600 & 40000 \\
Transition region & 600 & 15000 \\
CCL & 4800 & 120000 \\
Diagnostics & 600 & 15000 \\
Control system & 3600 & 90000 \\
& & \\
Tolal coat & & $\$ 310000$ \\
\hline
\end{tabular}

TADLE A-IV

Operating Coets

Irsm

Costrear

Staffing (8 full-time employees)

$\$ 600000$

if power ( $815 \mathrm{~kW}$ at $6 \mathrm{e} / \mathrm{kWh})$

220000

Cooling

24000

Other utilities

12000

Normal maintenance

50000

Total cont par year

$\operatorname{sens} 000$ 


\section{COST EQUATIOIIS}

\section{A. RFO Linac Cost Equation}

The RFQ linac consists of three primary components: the RFQ manifold, the RFQ resonator cavity. and the RFQ vanes. Other minor components ( $\mathrm{ft}$ probes, supports, etc.) are considered minor costs, compared with the primary components.

1. RFQ Resonator Manifold Cost. Based on experience with the fabrication costs of the PIGMIDTL tank, simplified as an RFQ manifold (no welded saddle or precision-bored drift-tube holes), the RFQ manifold would have an estimated base cost of $\$ 10000$ plus an additional cost of $\$ 5000$ per meter of length. This cost includes tank and RFQ support fabrication and copper plating of components.

2. AFQ Resonator Cavily Cost. The RFQ resonator cavity costs are estimated to be as follows (all costs on a per-meter basis).

\section{Material}

Welding and stress relief

$\$ 500$

500

Initial machining

Tuning machining

Cooling

Copper plating

Vane-tip installation

Ultrasonic cleaning

Total cost per meter

$\$ 6000$
1200

2000

400

800

500

100
Material

Stress relief

$\$ 100$

Vane-blank preparation

100

Vane-base machining

300

Vane brazing

400

First NC mill cut

Final NC mill cut

200

250

750

100

200

300

Total cost per vane per meter

$\$ 2700$

Therefore, the estimated total cost for a set of four . $1-m$-long vanes is $\$ 10800$.

4. RFQ-Linac Cost Equation. Below is the cost equation for the RFQ linac, based on the unit cost of the primary components.
RFQ cost per meter = RFQ manifold cost + RFQ resonator-cavity cost + RFQ vane-tip costs

$$
\begin{aligned}
\operatorname{RFQ}(\$ / \mathrm{m})= & \mid \$ 10000+(l)(\$ 5000)] \\
& +[\$ 4000+(l)(\$ 6000)] \\
& +[(l)(\$ 10400)] \\
= & \$ 16000+(l)(\$ 21400)
\end{aligned}
$$

where $t=$ RFQ length in meters. Therefore, the total fabrication cost of a $2.5-\mathrm{MeV}, 1.78-\mathrm{m}$-long RFQ would be about $\$ 54000$, having an average cost of $\$ 30337 / \mathrm{m}$ (or $\sim \$ 24500 / \mathrm{MeV}$ ).

\section{B. DTL Cost Equation}

In addition, at each end of the RFQ cavity there is an end plate, with tuners; these tuners are estimated to cost $\$ 2000$.

3.RFQ Vane-Tip Costs. From experience with the machining of the RFQ POP vanes, and assurning previous amortization of the development cost for computer programs necessary to control the numerically controlled mill (NC), the vane-tip costs (for a single 1-m-long vane tip) are estimated as follows.
The DTL linac consists of two major components: the DTL tank sections, and the drift tubes. In addition, one tank section that incorporates provision for of input must be installed in the accelerator.

1. DTL Tank-Section Cost. Based on experience with the fabrication of the PIGMI Prototype DTL tanks, and assuming that each tank section will be $\sim 2.5-\mathrm{m}$ long, the cost of a DTL tank section is estimated as follows. 
DTL tank fabrication

Vacuum box/tuning-slug fabrication

Copper plating

Tuning slug machining

Total cost per 2.5-m tank section

2. Drift Tube Cost. Every drift tube will contain a permanent-magnet quatrupole. Partly based on the known fabrication costs for single-stem drift tubes for the PIGMI Prototype, and partly on estimated costs from others for the assembly and tuning of these types of magnets, the cost per drift tube is estimated as follows.

Drift tube material

Drift tube preliminary machining

Cooling-channel welding

Drift tube nose profile machining

Machining of stem parts

Stem welding

Final stem machining

Permanent-magnet material

(for one 2.54-cm-long quadrupole)

Magnet yoke/holder fabrication

Magnet assembly/tuning cost

Laser welds

Copper plating

Stem vacuum seal

Stem termination

Total cost per drift tube
$\$ 100$

200

100

75

150

100

50

500

100

500

50

75

30

70

$\$ 2100$

This cost per drift tube should remain essentially constant for all drift tubes, despite varying length of the drift tubes.

3. DTL Tank Section with if Input. Based on experience with the PIGMI Prototype phase-ramp tank, which is very similar to this tank, the cost for a 2.5-m-long tank is estimated as follows:

rt-input flange fabrication

Tank fabrication

Vacuum box/tuning-slug fabrication

Tank copper plating

Tuning-slug machining

of iris machining

Total cost per 2.5-m tank

4. DTL Tank End Plate. The DTL low-energy end plate couples to the RFQ resonator cavity and contains two permanent-magnet quadrupoles, in addition to the half-drift tube profile. Based on the cost of the PIGMI Prototype DTL tank end plate, the cost of the DTL high-energy end plate is estimated to be $\$ 2000$, and the DTL low-energy end plate costs $\$ 8000$, including copper plating and cooling.

5. DTL Post Couplers. The PIGMI DTL post couplers should be quite small and simple in design; it may not be necessary to cool them actively. The post couplers can be fabricated for $-\$ 400$ each.

6. DTL Cost Equation. The cost equation for the DTL linac is the sum of the cost of the major components.

$$
\begin{aligned}
\text { DTL cost }= & \text { End plate costs } \\
& + \text { Cost of DTL tank section with } \mathrm{nt} \\
& \text { input } \\
& + \text { DTL tank section costs } \\
& + \text { Total cost of drift tubes } \\
& + \text { Total cost of post couplers }
\end{aligned}
$$

Using the numbers developed earlier in this appendix:

$$
\begin{aligned}
\text { DTL cost }= & \$ 8000+\$ 2000+\$ 64000 \\
& +(\$ 53000 / 2.5-m-\text { long tank } \\
& \text { section) (Number of tank } \\
& \text { sections }-1) \\
+ & (\$ 2100) \text { (Number of drift tubes) } \\
+ & (\$ 400) \text { (Number of post couplers) }
\end{aligned}
$$

Therefore, the PIGMI DTL is estimated to cost $\$ 1001600$ to fabricate, an average cost of $\$ 33320 / \mathrm{m}$ (or $\sim \$ 8 \quad 176 / \mathrm{MeV}$ ).

\section{CCL Cost Equation}

The CCL consists of two primary components: accelerating tanks of DAW structures, which vary between $0.6 \mathrm{~m}$ and $1.2 \mathrm{~m}$ in length, and bridge coupler sections, which include the singlet focusing magnet plus other features.

1. CCL Accelerating Tank Section Coat. The estimated cost of the CCL accelerating structure is based on the fabrication technique being developed for a $1300-\mathrm{MHz}$ DAW field-gradient test experiment. An outside cylinder (including the disks) is fabricated, and assemblies of two copper 
washers are attached with four stems to the outside cylinder. The cost per meter of a CCL accelerator tank is estimated as follows.

\section{Washer assembly \\ Copper washer (12 washers per tank) \\ Material \\ Contour machining \\ Water channel parts \\ Stem termination machining \\ Stainless steel stems (4 stems per washer) \\ Fabrication and copper plating \\ Braze costs (includes fixtures, alloy, and heat) \\ Washer-assembly braze}

300

\section{Cylinder assembly}

Cylinder machining (preliminary)

End flanges (machining and weiding)

Stress relief

Cylinder machining (final)

Cylinder flange facing

Stem fabrication and welding

Copper plating

Cooling channel fabrication

(4 per tank)

5500

800

200

5000

400

2400

1500

1200

Final Assembly

Stem brazes (24 per accelerating tank)

1200

Total cost per accelerating tank
2. CCL Driden-Coupler Cou. There is no fabrication experience with the type of bridge coupler envisioned for the PIGMI CCL; however, a bridge coupler with if drive (but no permanent-magnet singlet) will be fabricated as part of the $1300-\mathrm{MHz}$ DAW field-gradient-test experiment. The approximate costs are estimated as follows.

Basic bridge coupler

Vacuum-pumping bridge coupler

$\$ 6000$

8000

Diagnostic bridge coupler

8000

10000

Valve-and-bellows bridge coupler

rf-drive bridge coupler

3. CCL Coet Equation. The cost equation for the $\mathrm{CCL}$ linac is the sum of the costs of the accelerating tank and the bridge couplers.

$$
\begin{aligned}
& \text { CCL cost } \quad \text { (Cost of CCL accelerating } \\
& \text { tank) (Number of tanks) } \\
& + \text { (Cost of bridge couplers) } \\
& \text { (Number of bridge } \\
& \text { couplers) }
\end{aligned}
$$

Using numbers developed earlier in this appendix. and assuming the average cost of a bridge coupler to be $\$ 7600$ :

$$
\begin{aligned}
\text { CCL cost } & =(\$ 26000) \text { (Number of tanks) } \\
& +(\$ 7600) \text { (Number of tanks - 1) }
\end{aligned}
$$

Therefore, the PIGMI CCL is estimated to cost $\$ 3636000$ at an average cost of $\$ 36400 / \mathrm{m}$ (or $\sim \$ 7000 / \mathrm{MeV}$ ). 


\section{APPENDIX, \\ PIGMI PAOTOTYPE DEVELOPMENT ACHIEVEMENTS}

This appendix begins with a list of some of the major accelerator-development activities accomplished by the PIGMI program at Los Alamos. These include

- development and routine application of the computer program SUPERFISH, the most exciting and powerful tool for linac. klystron, and storage-ring cavity design of the last decade;

- development and routine application of a new general-purpose computer program. PANDIRA (a magnetostatic-analysis computer code), for solving two-dimensional, cylindrically symmetric, anisotropic, magnetostatic problems;

- development of an ajmorithm for determining all of the geometric properties of the APF linac structures;

- design, fabrication, and activation of a 1-MW, 450-MHz, ri-power source to drive the PIGMI Prototype, used successfully in affirming the PIGMI field-gradient design goal;

- ciesign, fabrication, and testing of a six-cell. 45-MeV drift tube geometry, field-gradient test cavity (late: experimentation, based or the acceleration of electrons in the last drift gap, yielded a field of $>9.0 \mathrm{MV} / \mathrm{m}$, a gradient well in excess of the $6.0-\mathrm{MV} / \mathrm{m}$ PIGMI design value);

- successful application of bright-copper plating to linac fabrication (this process's leveling properties are a material asset to the achievement of high gradients and make possible the use of less expensive materials and fabrication techniques):

- introduction of a face angle to the drift tube face (the rationale for this approach was to inhibit electron multipactoring by introducing a path perturbation in the resonance requirements of the phenomenon; the ease of bringing the field-gradient cavity up to design level appears to affirm qualitatively the rationale);

- development of analytical techniques for evaluation of emittance growth in the beam caused by higher order multipole harmonics in the magnet fields of quadrupcle lenses;

- development of an achromatic and isochronous bending system that could bend a PIGMI tunnel back on itself, thus cutting its length in half;

- preliminary investigation of pion-channel designs, based on advanced current-sheet and solenoid technologies;

- successful application of permanent magnets to linac quadrupole-magnet technology (magnetic gradients $>10 \mathrm{kG} / \mathrm{m}$ were achieved in the PIGMI Prototype design, using a samarium-cobalt, circular, pole-geometry. permanent-magnet quadrupole):

- design and testing of most of the prelinac portion of the PIGMI Prototype, including the 250-kV Cockroft-Walton, the high-voltage equipment dome, the ion-source supporting frame. the double-buncher cavity. the solenoid lens, the beam boxes, and the beam diagnostic gear:

- installation and software preparation of a minicomputer system. with peripheral microprocessors, for the PIGMI Prototype and data acquisition:

- design and successful testing of the APF linac structure:

- design and successful testing of the RFO lowenergy linac structure that made the APF concept cbsolete. This is perhaps the most significant development in accelerator technology since the development of the sidecoupled linac structure:

- design and fabrication (in progress) of the DAW high-energy linac structure that promises significant improvement over sidecoupled linac structures.

Figures B-1 through B-24 show hardware designed and fabricated for use with the PIGMI Prototype. The PIGNil Prototype hardware (perhaps stightly modified) is typical of what would be found on a PIGMI accelerator. 


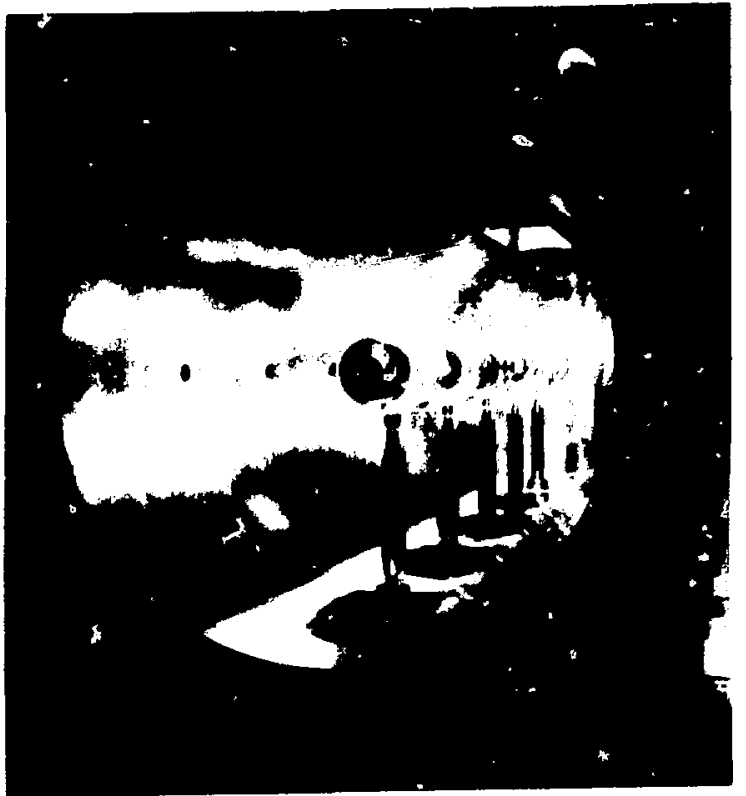

Fig. 0-1.

PICLET tank.

Fig. B-2.

PICLET drift tube (front viow).

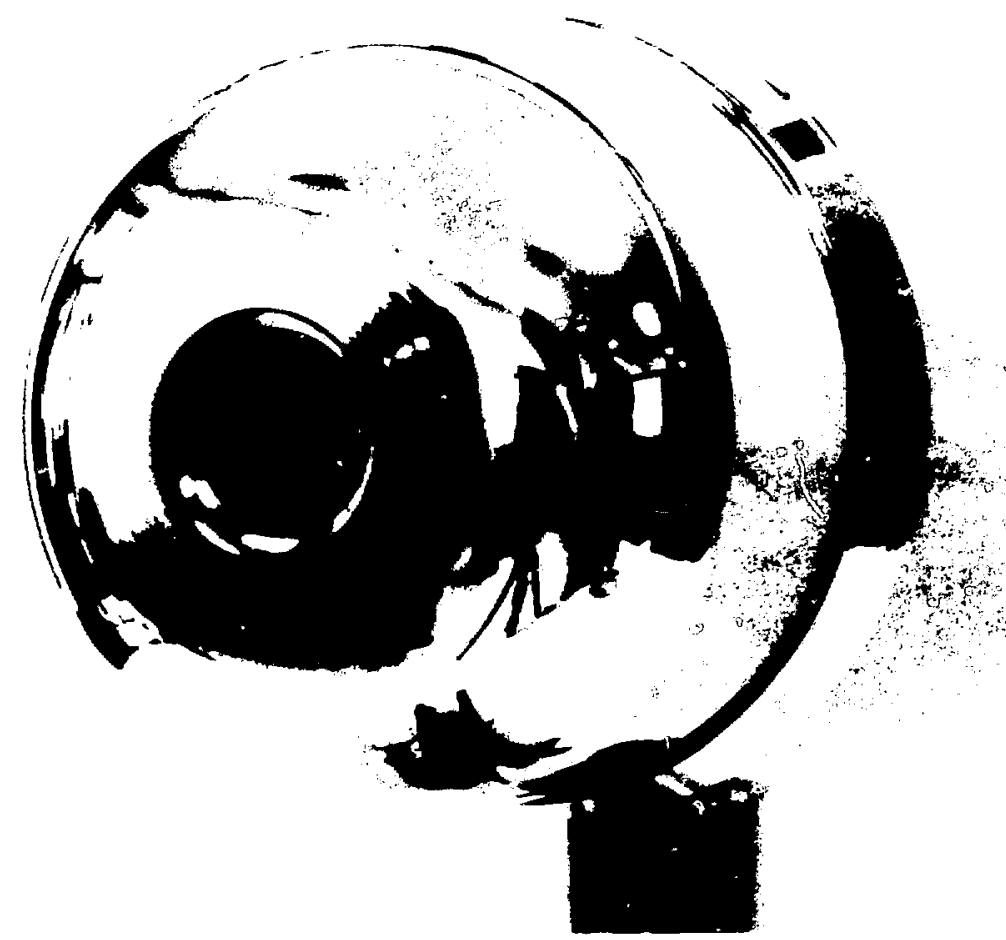




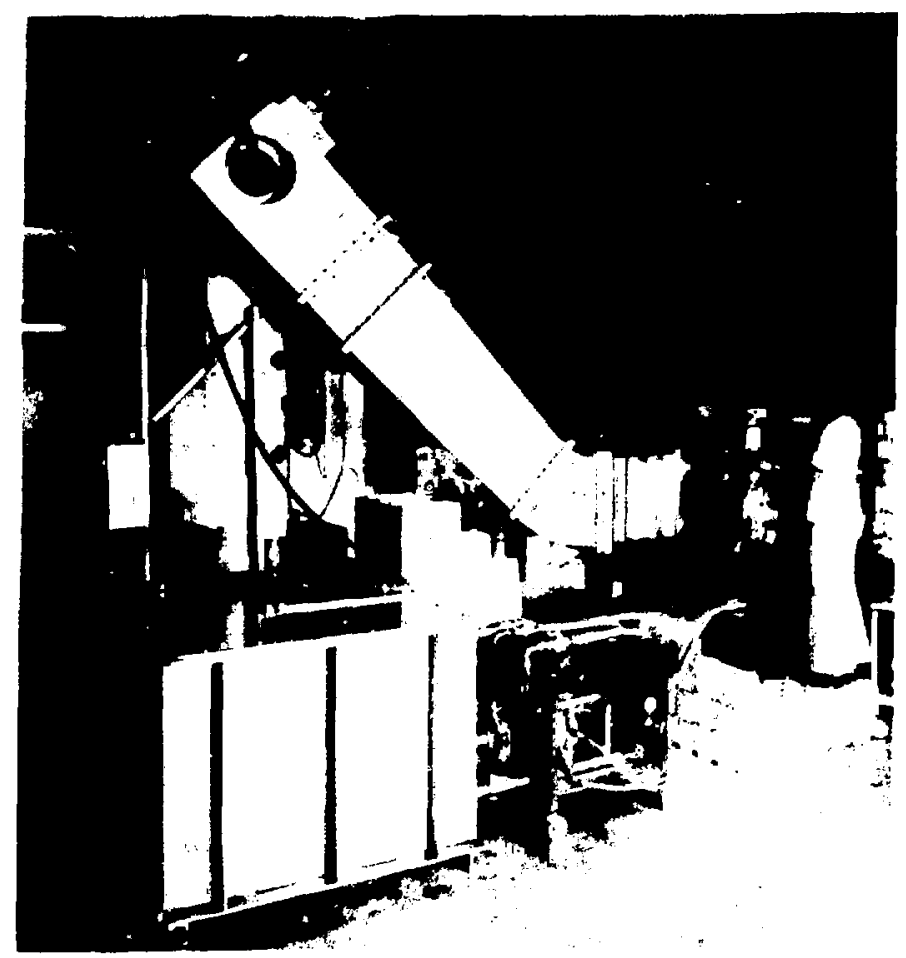

Fig. 0-3.

PICMI Prototype 450-MHz Whatron and PICLET tank.

Fig. 1-4.

PIOMt Prototype diegnotic stray.

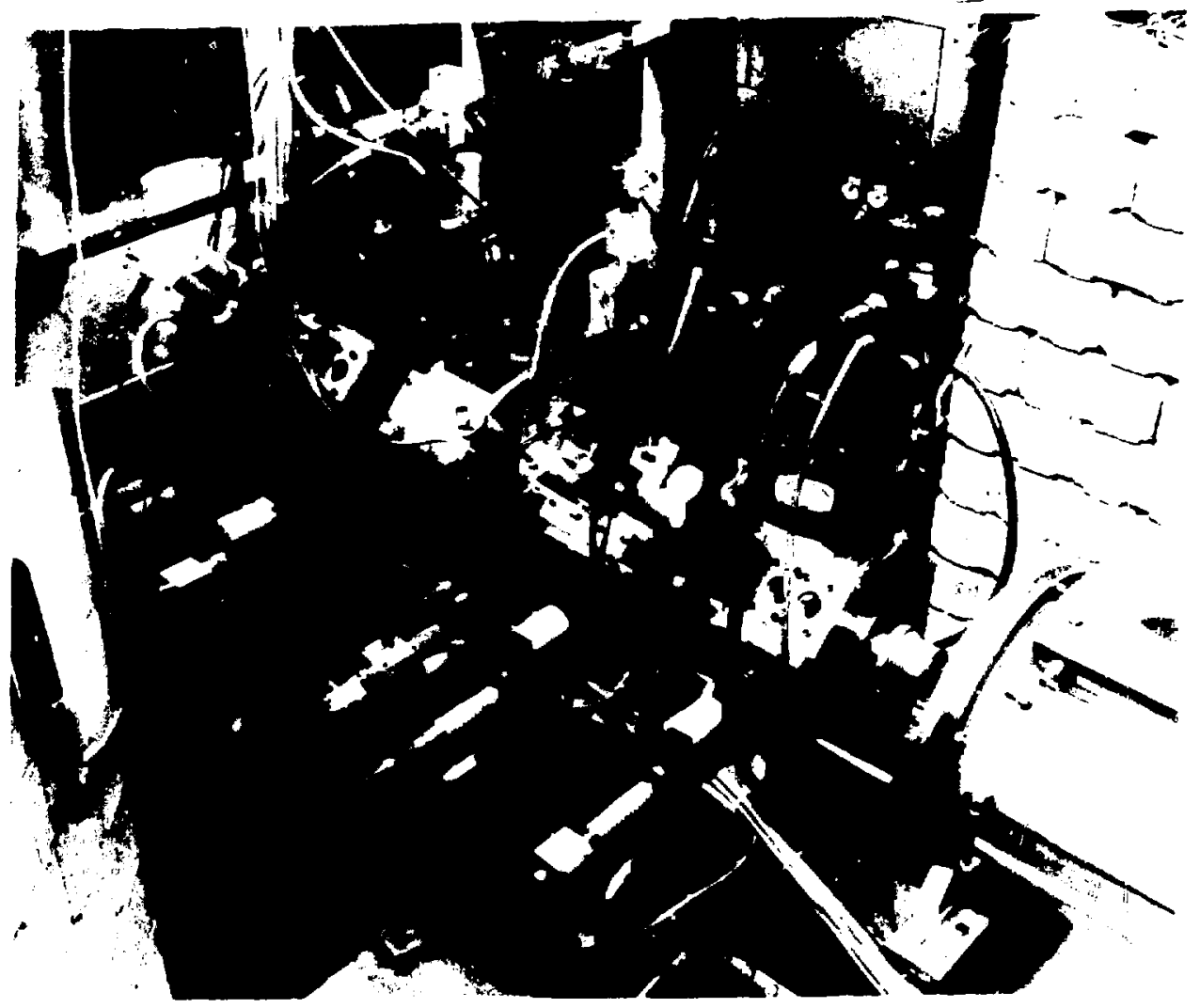




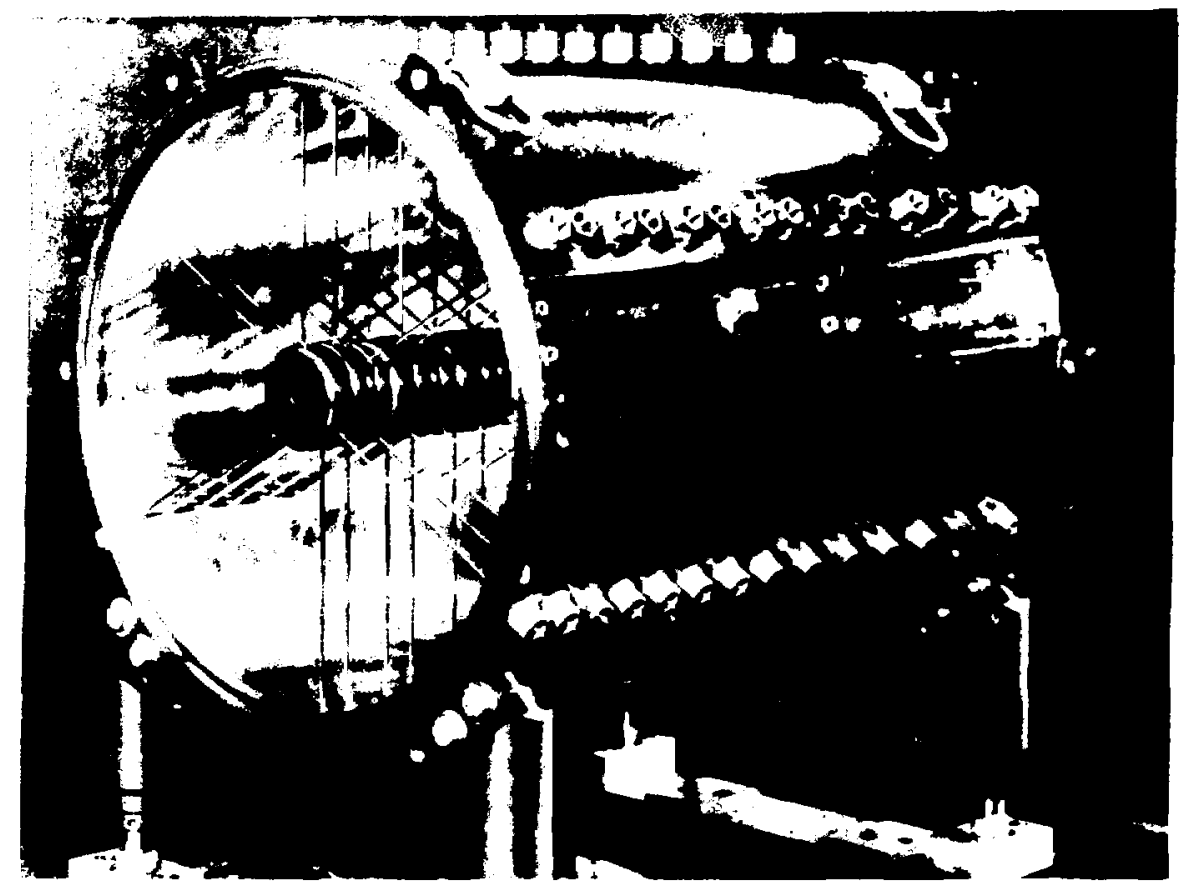

Fig. B-5.

PIGMI Prototype APF tank.

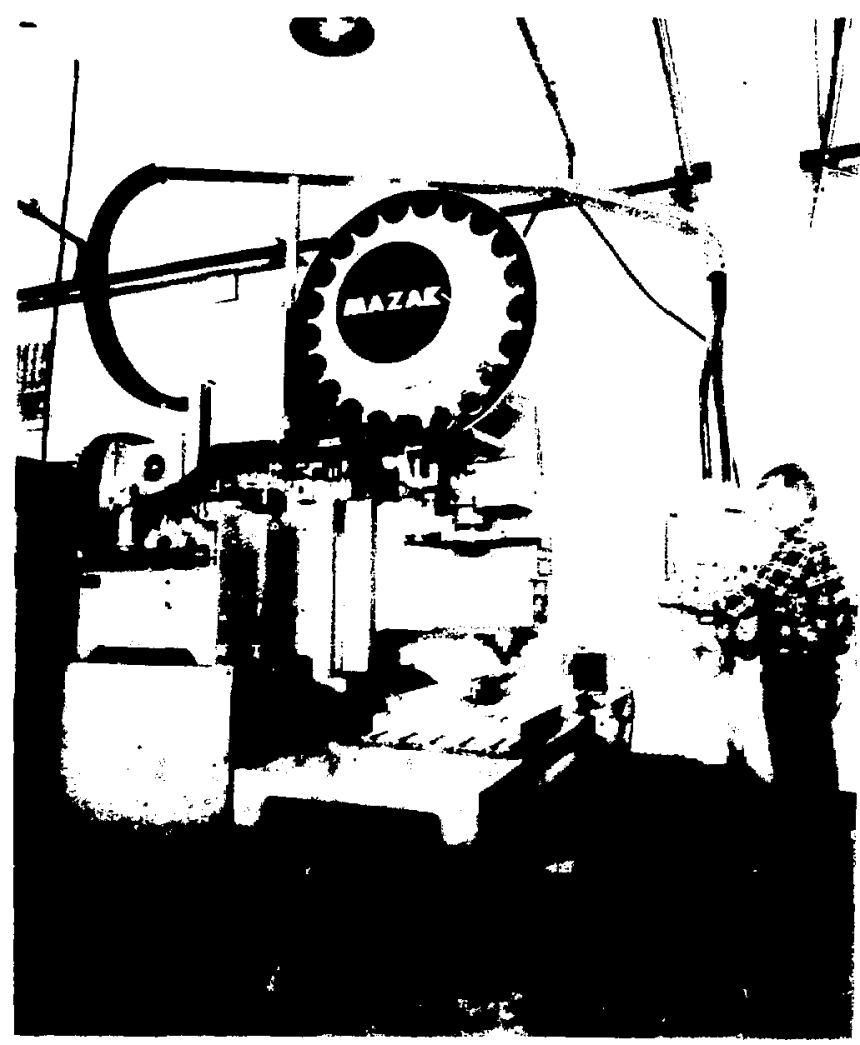

Fig. B-6.

AFO vane-tip machining tacility. 


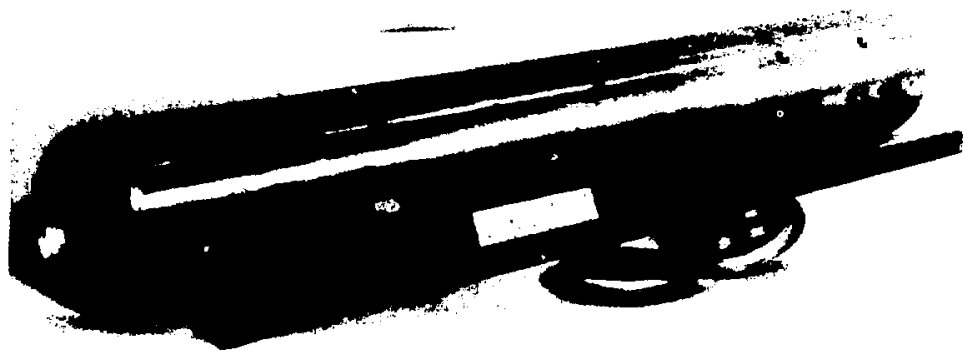

Fig. 8-7.

AFO POP sesembly.

\%

ty.

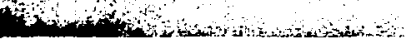

Fig. D-8.

AFO POP test stend.

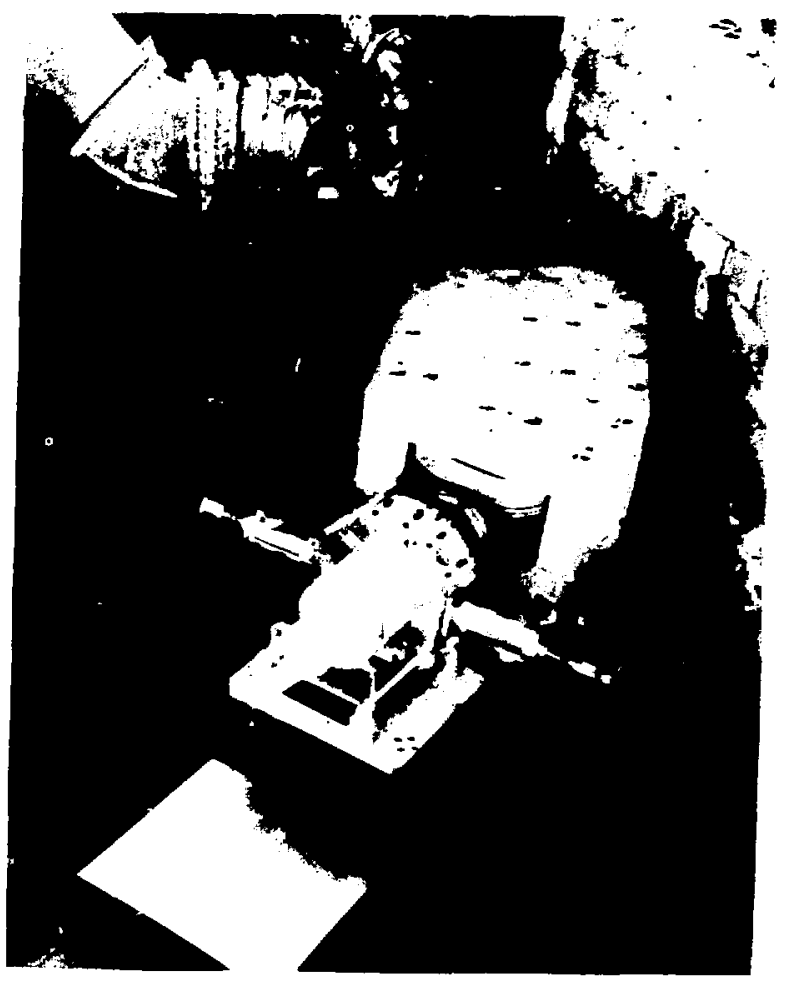


Fig. B-9.

PIGLET drift tube.
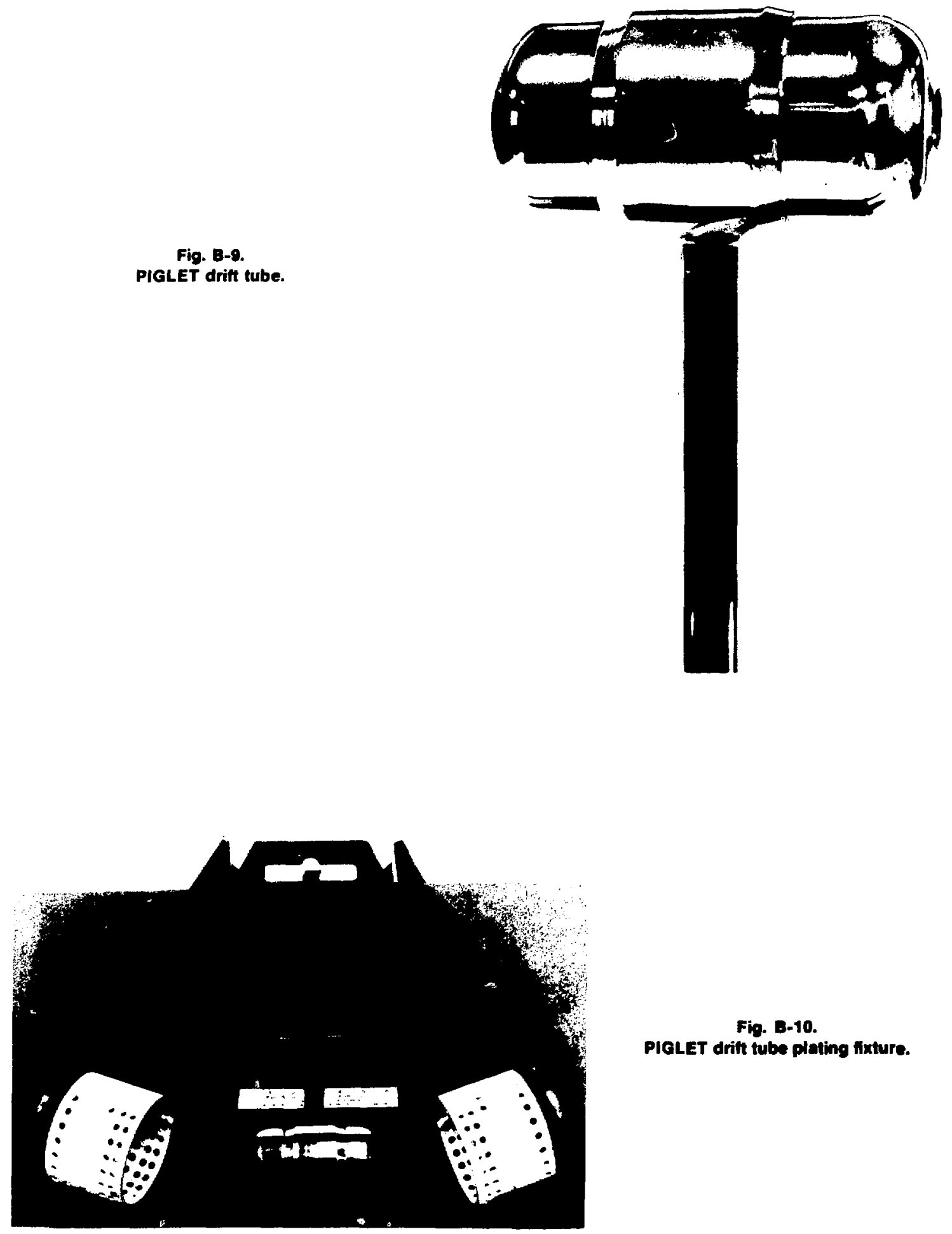

Fig. B-10.

PIGLET drift tube plating fixture. 


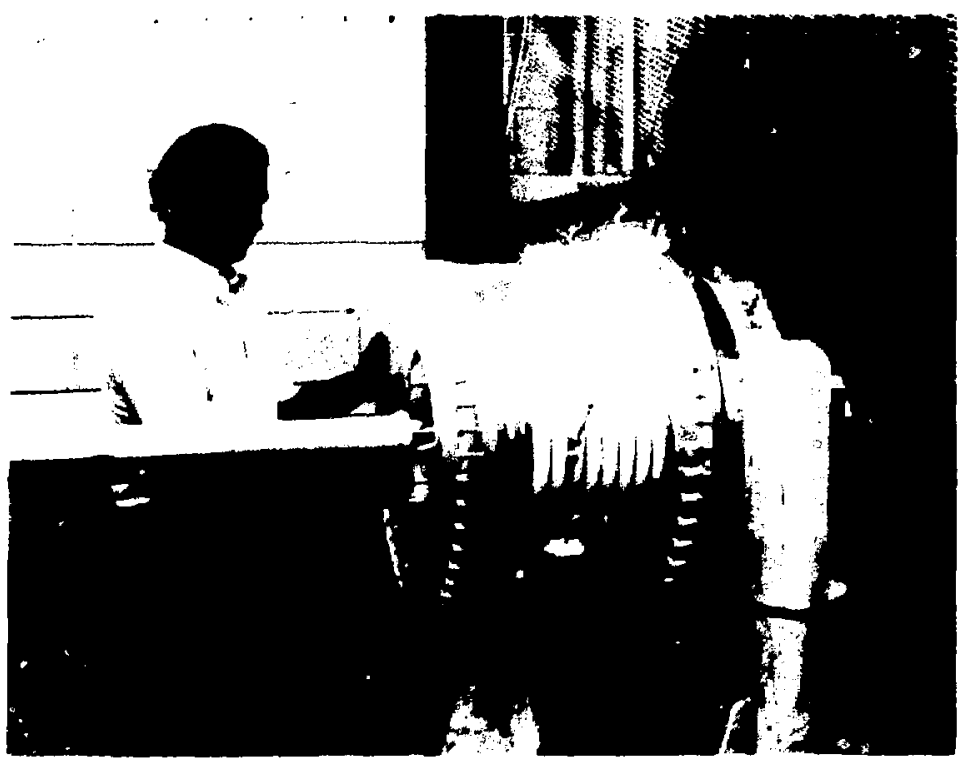

Fig. B-11.

PIQMI Prolotype 250-kV injector.

Fig. B-12.

PIGMI Prototype 250-kV injector exiraction clectrodes.

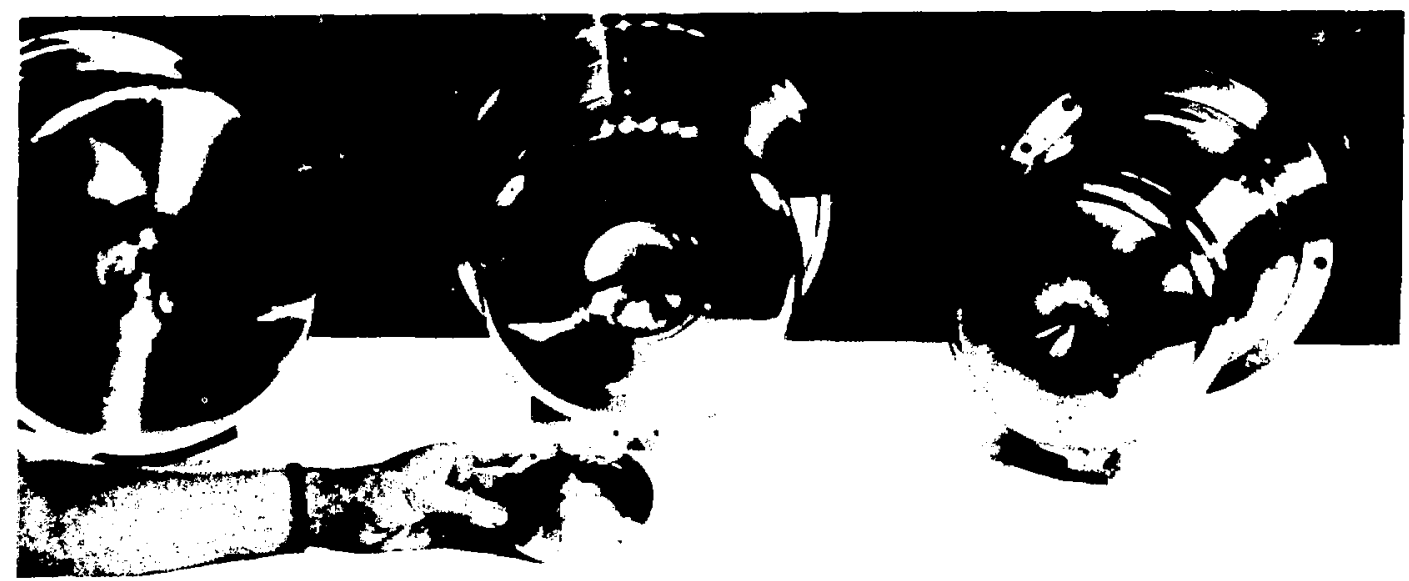




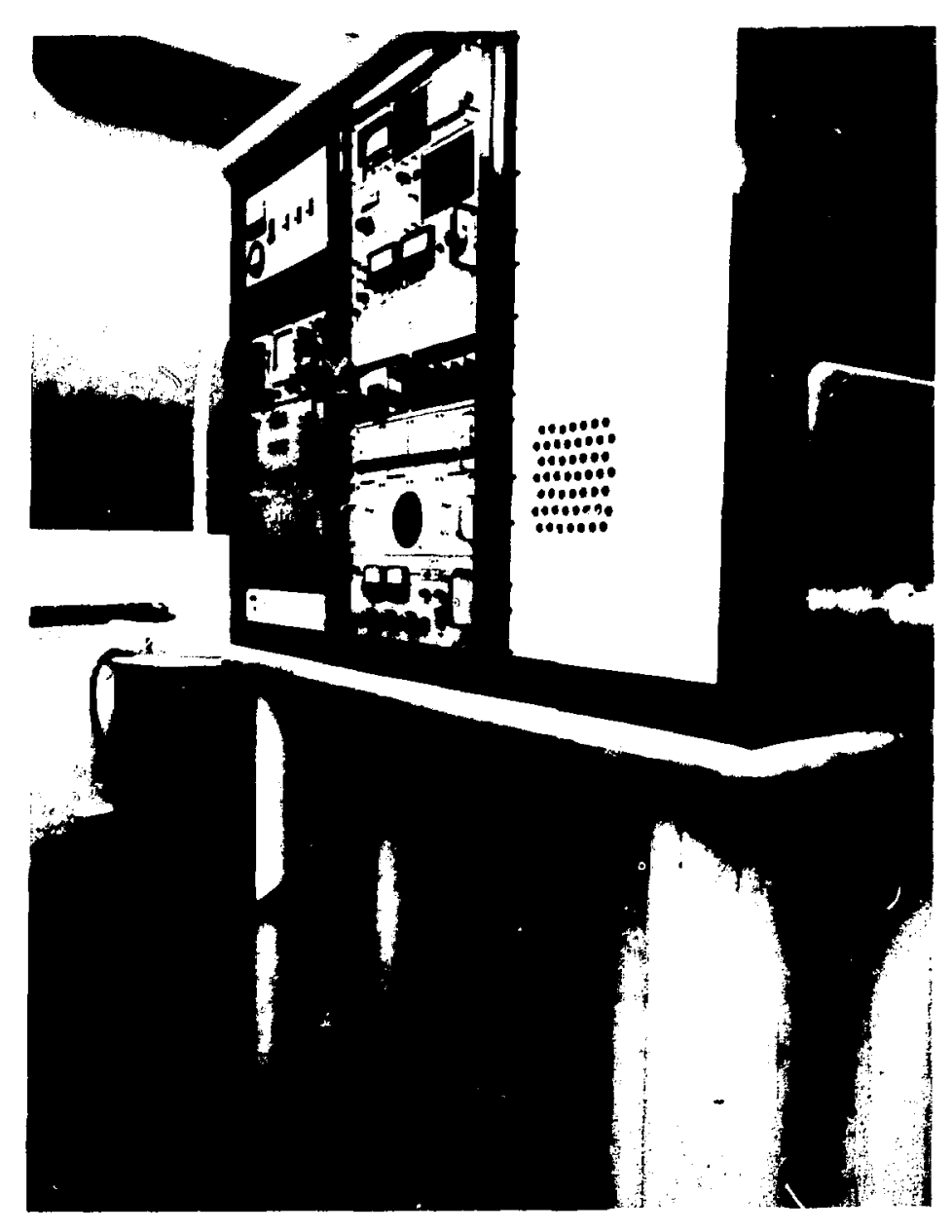

Fig. 0-13.

PICMI Prototype "4-jeme" diegnostics.

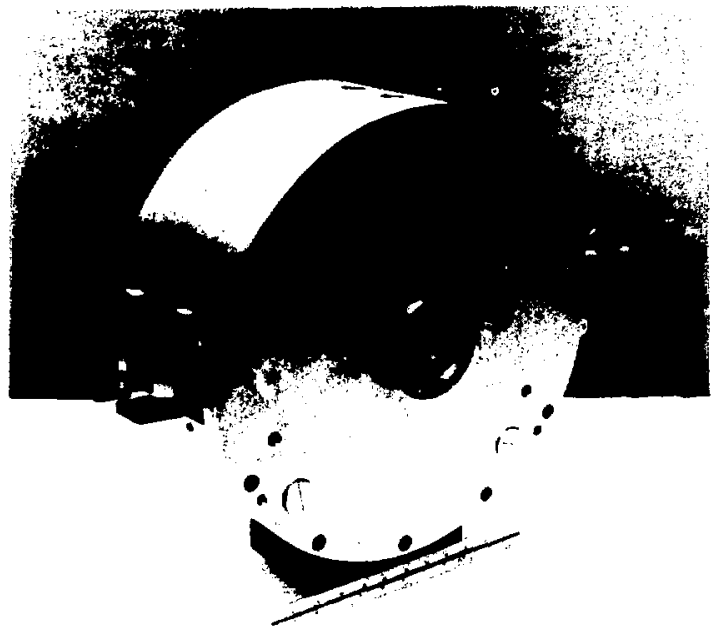

Fin. D-14.

PIGMI Prototype focusing megnet. 


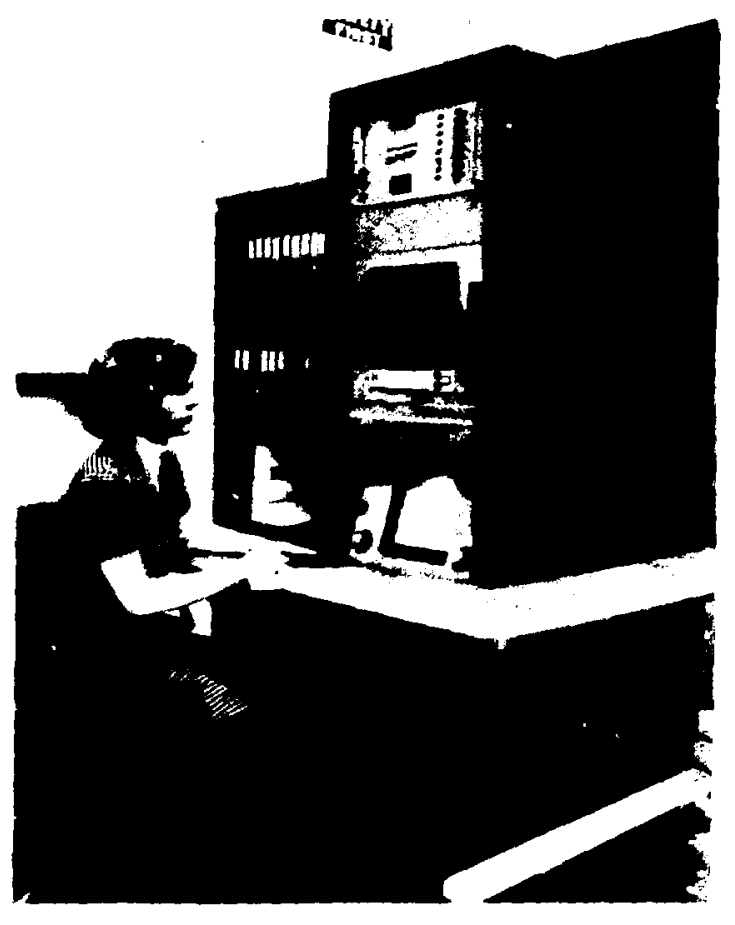

Fig. B-15.

PIaci Prolotype operoting consolb.

Fig. 0-17.

PICMI Prolotype drith tube.

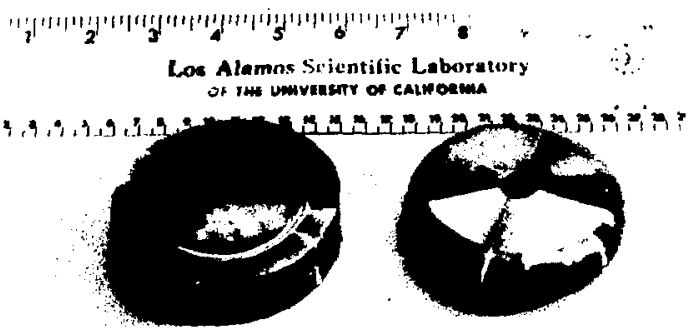

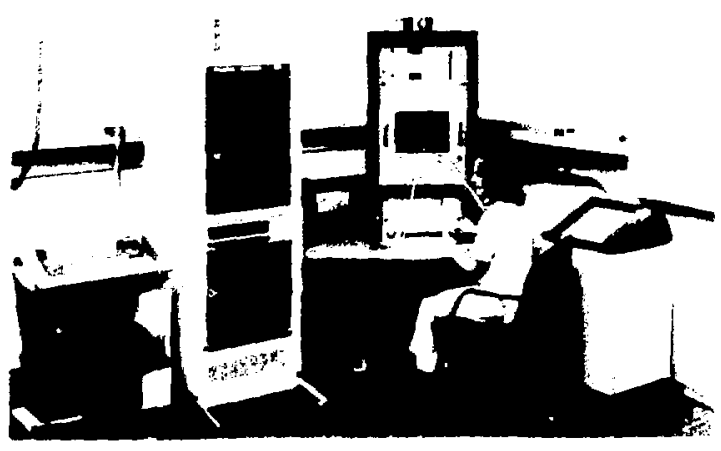

Fi. 0-10.

PIGMI Prototype minicomputer and operating console.

Fig. Q-10.

PIGiMI Prototype emiltence measuring hardware.

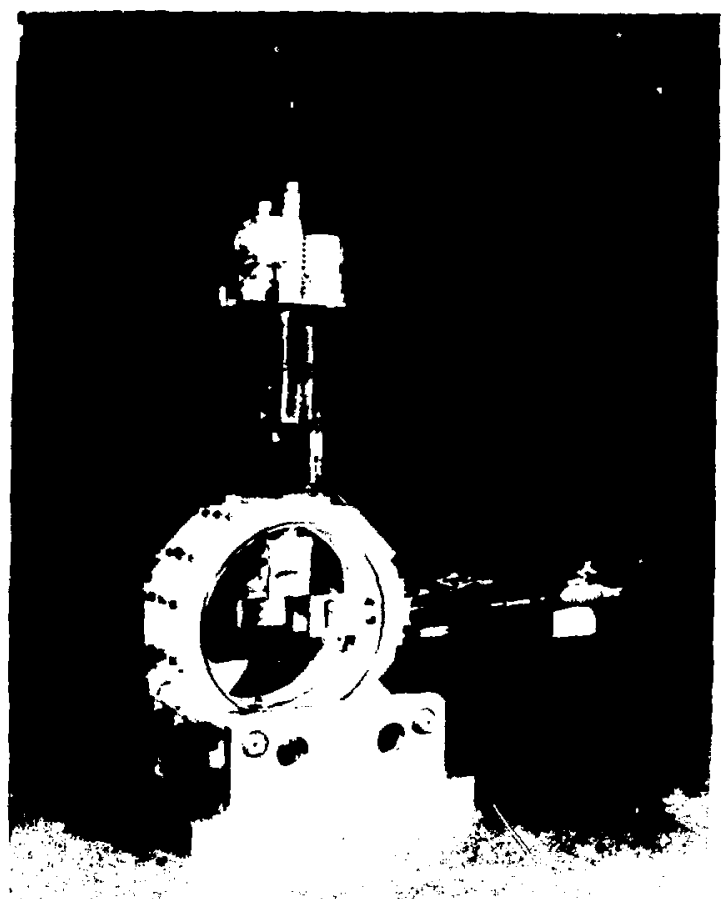




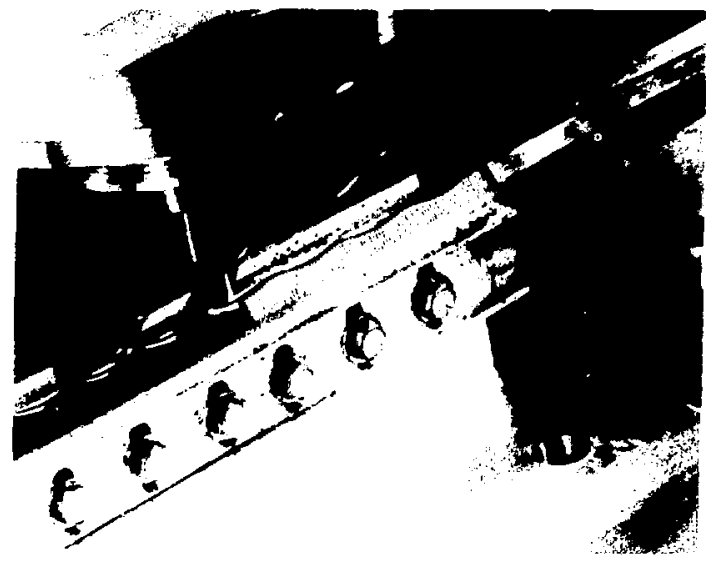

Fig. B-10.

RFO vane-tip machining.

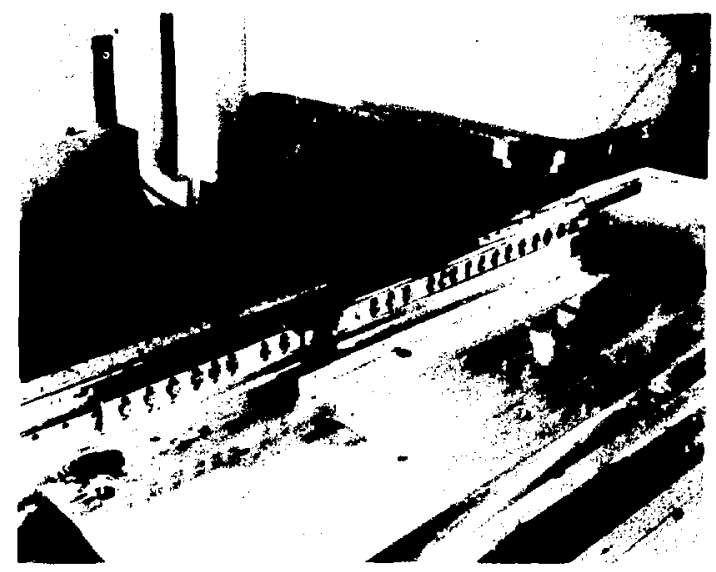

Fig. B-20.

RFO vane-tip in vertical mill.

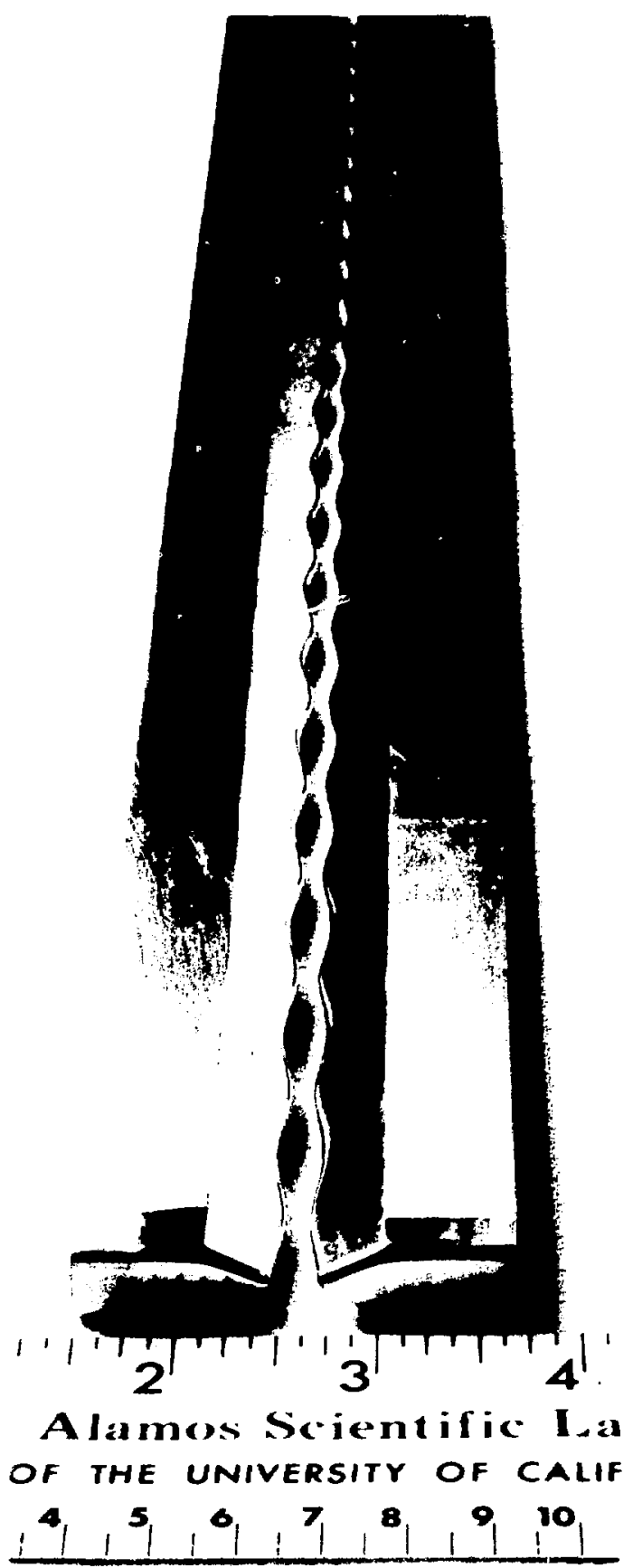

Fig. B-21.

AFO POP yanes. 


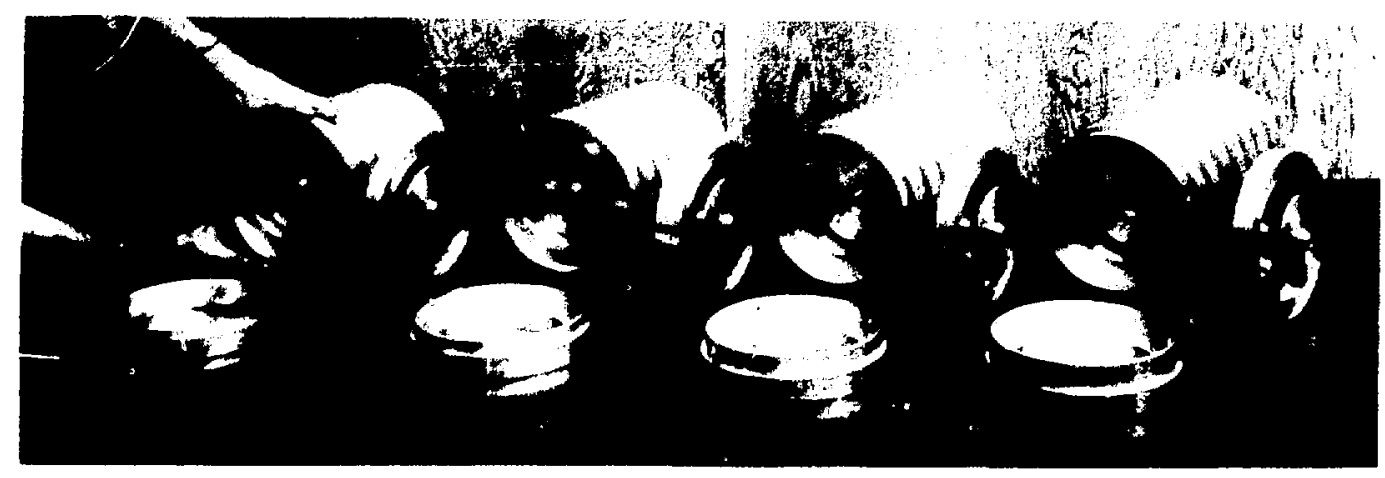

Fig. B-22.

The 2380-MHz DAW lest cavities for $\beta=0.5, \beta-0.6$, and $\beta=0.8$.

Fig. D-23.

DAW real covitios (2350-MHz dize).

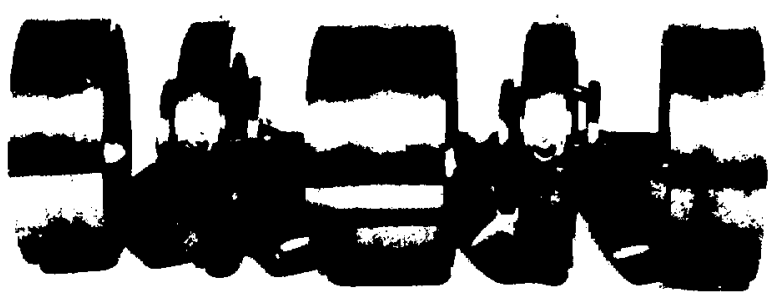

$\ln$

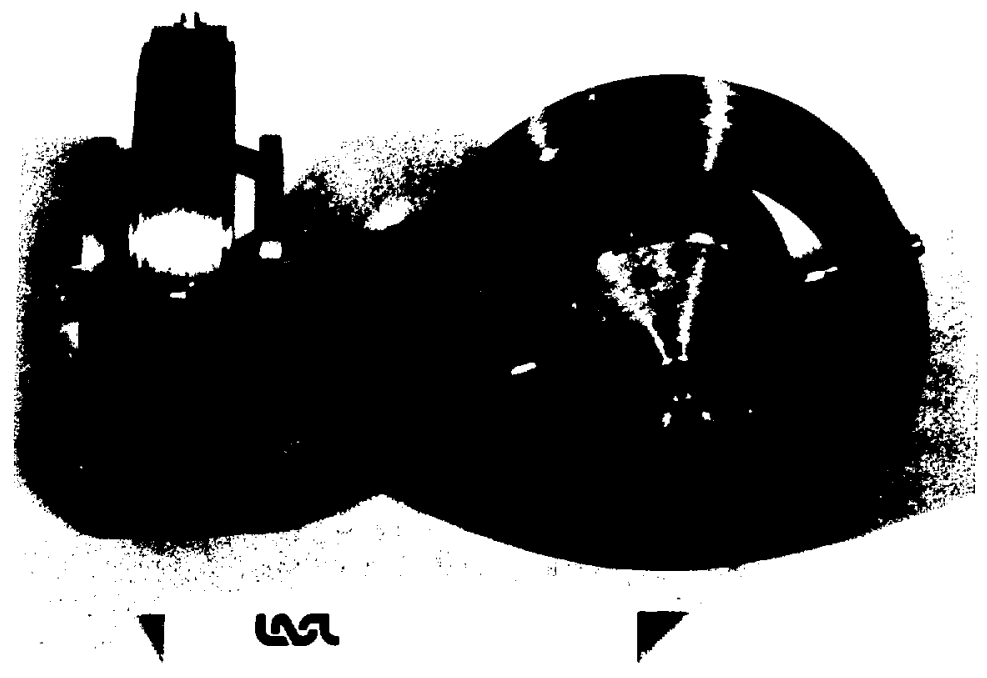

Fig. B-24.

DAW assembly (2350-MHz sizo). 


\section{APPENDIX C \\ PION TREATMENT FACILITY}

Several groups working with the new meson factories are setting up experiments to measure the energy dependence of the pion production cross section for various target materials. At LAMPF the Applied Physics group will measure the yield of pions accepted by the biomedical channel (production angle $70^{\circ}$ from proton-beam direction) for a variety of targets and proton energies. These data, combined with data produced at SIN and TRIUMF. will allow the accelerator energy and channel angle to be specified.

Stanford University has been investigating the double-orange-peel spectrometer system and has constructed a system based on superconducting magnet technology that appears to operate satisfactorily. The output beam configuration is complex, but this group has developed innovative treatment-planning systems indicating that adequate solutions for treatment of a wide variety of tumors may be possible. In Switzerland. SIN has constructed a similar type of pion channel.

The USSR group at Dubna has constructed a shaped solenoidal-field spectrometer system with large solid-angle acceptance and is operating this pion channel in conjunction with their cyclotron. This system also has been considered for use at TRIUMPF in Canada. In this system, pions from the target are refocused to a point in space. Treatment experience at Los Alamos suggests that a parallei pion beam of uniform density is preferable because it is easy to use; however, the channel with an orange sector can collect more pions. Combining the advantages of the two would be desirable.

Significant progress has been made in understanding the operation of large, solid-angle, conventional channels at LAMPF and the other mesonfactory accleratators. The LAMPF pion-treatment room is shown in Fig. C-1. A new method of pion collection that produces a parallel beam by channeling the pions from an orange sector has been proposed. The orange-sector magnet consists of 60 pancake coils with a $40^{\circ}$ azimuthal angle between the two neighboring pancakes. Four sets of solenoids are introduced as shown in Fig. C-2. They are wound around the z-axis. The main solenoids (SOL 1 and SOL 2) make the beam parallel. SOL 3 is effective for achieving a smaller beam spot at the patient, and SOL 4 is used to

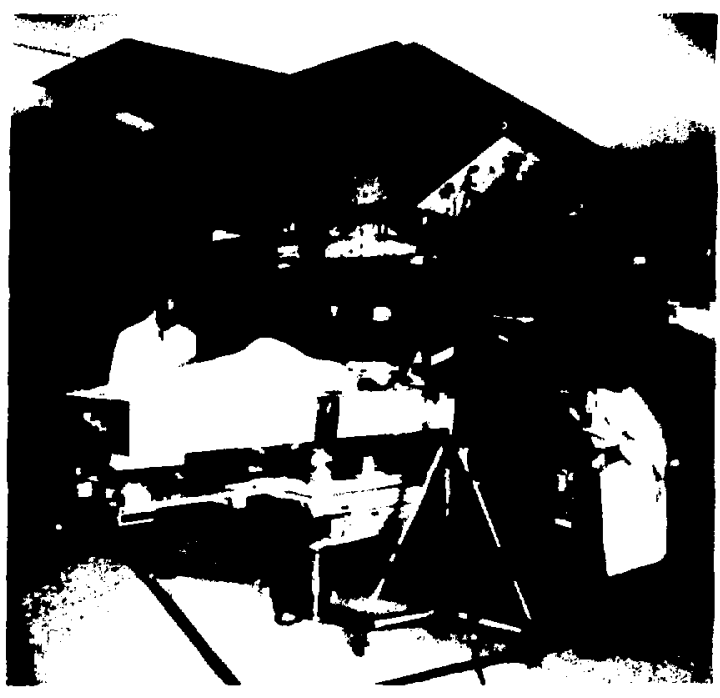

Fig. C.1.

Pion treatment at LAMPF.

cancel the field in the pancake-coil region originating from the other solenoids.

The slit width at the focal plane (SURF 3 ) is adjusted to $10 \mathrm{~cm}$ in z-coordinate, which amounts to an energy spread of $\sim 1.0 \mathrm{MeV}$ for $81-\mathrm{MeV}$ pions. The 2-cm target length is a good size because it results in an additional energy spread of only +1.0 $\mathrm{MeV}$. The target diameter is determined to be 1.0 $\mathrm{cm}$, based on the beam size at the biomedical pion channel in LAMPF. The pion-production angle of $\theta_{7}\left(85+15^{\circ}\right)$ is selected in the present channel. It is probably the best choice, considering the angular dependence of pion-production cross section and a tolerable contamination of muons and electrons.

As expected from Fig. C-2, if the slit at the focal plane is shifted downstream, the pions going through the slit have a higher energy. They are less affected by the solenoid field and are focused nearer the main solenoids. However, if the slit is shifted upstream, the lower energy pions going through the slit are strongly deflected by the solenoid field and focused far beyond the main solenoids. In the latter case, the beam is more parallel to the side of the linac and larger than in the former case. 


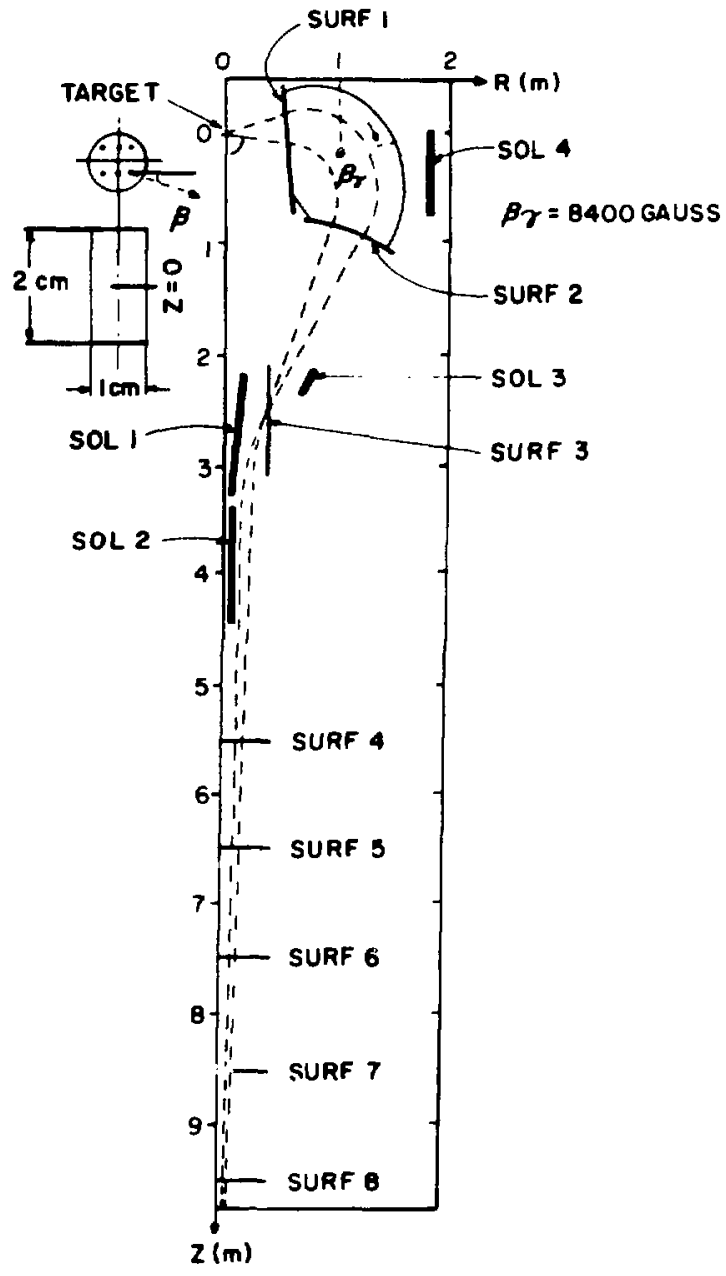

Fig. C-2.

Geometrical configuration of the current sheet and colenoid pion channel. The z-axis is taken along the axis of aymmetry.

After bombarding the target, the proton beam is guided outside making it relatively easy to reduce neutron and gamma-ray background from beam dump at the patient position. In Fig. C-3, SOL 3 and SOL 4 are not shown. For a tumor lying near the surface of the body, the patient can be placed nearer to the main solenoids; for a deep-seated tumor, he or she should be pleced a little downstream to make use of the more parallel beam.

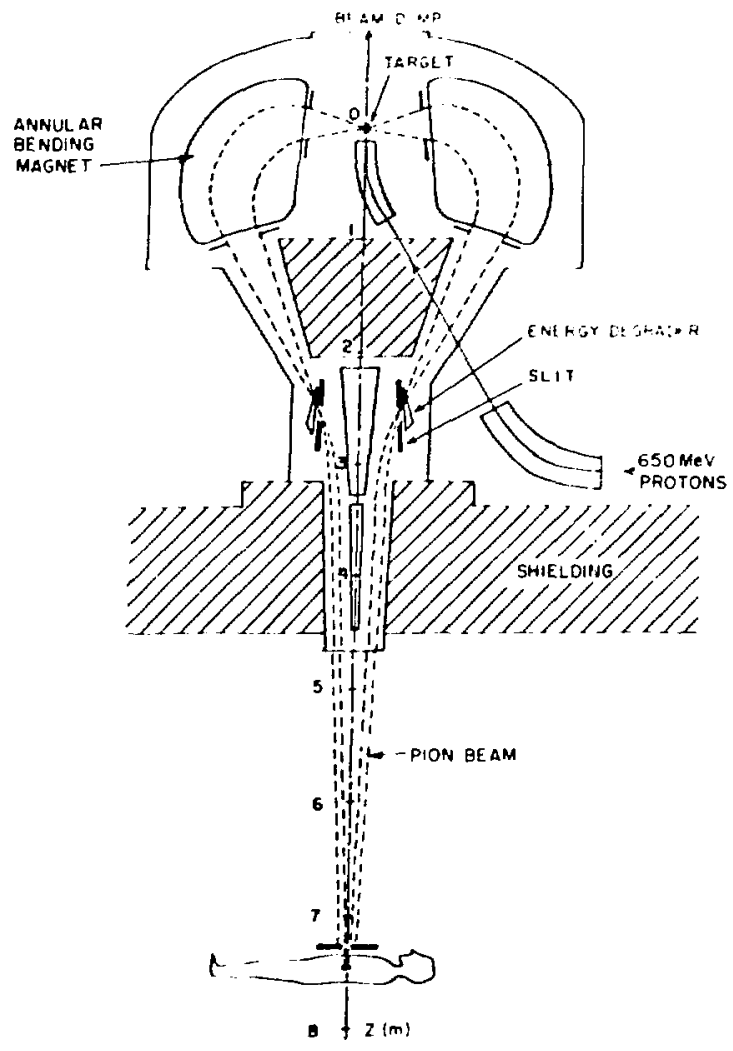

Fig. C-3.

Los Alamos concept for a PIGMI pion colfection system.

Some basic characteristics of the current sheet and solenoid pion channel were explored. The results are summarized in Table $\mathrm{C}-\mathrm{I}$. However. before formulating a practical design, additional work must be done. Some considerations are (1) the bending magnets for the incident proton beam should not interfere magnetically with the arrangement of the sector magnets and solenoids. (2) The appropriate material for each solenoid should be determined. For two main solenoids, superconducting coils are appropriate, whereas the remaining solenoids can be made with conventional copper wire. (3) Tuning the shape of the current sheets yields a sharper focus. Refinement of solenoids would result in a larger effective solid angle. (4) An energy degrader, as in Fig. C-2, can be used to reduce the energy width of particles at 
TABLE C-I

SUMMARY OF RESULTS

\begin{tabular}{|c|c|c|c|c|c|c|c|}
\hline Design & $\begin{array}{l}\text { Slit Setting } \\
\text { (m) }\end{array}$ & $\begin{array}{r}Z_{\text {tocus }} \\
\text { (m) }\end{array}$ & $\begin{array}{c}\Omega_{\text {off }} \\
(\text { otcil) } \\
\left(\gamma<7^{c m}\right)\end{array}$ & $\begin{array}{c}\text { Divergence } \\
\text { (mrad) }\end{array}$ & $\begin{array}{c}r u \\
(\mathrm{~cm})\end{array}$ & $\begin{array}{l}\text { (eter) } \\
(\gamma \leqslant \gamma u)\end{array}$ & $\begin{array}{c}\Omega_{4} \\
\text { Flight Path } \\
\text { (m) }\end{array}$ \\
\hline New Los Alamos' & $\begin{array}{l}2.55-2.65 \\
2.50-2.60 \\
2.475-2.575\end{array}$ & $\begin{array}{l}6.5 \\
7.5 \\
8.5\end{array}$ & $\begin{array}{l}1.40 \\
0.90 \\
0.70\end{array}$ & $\begin{array}{l}\leqslant 1100 \\
\leqslant>80 \\
\leqslant 160\end{array}$ & $\begin{array}{r}7 \\
8 \\
14\end{array}$ & $\begin{array}{l}1.40 \\
1.13 \\
2.16\end{array}$ & $\begin{array}{l}7.5 \\
8.5 \\
9.5\end{array}$ \\
\hline $\operatorname{Sin}^{b}$ & $\ldots$ & --- & $0.6-0.8$ & --- & -- & $\cdots$ & 8.5 \\
\hline DUBNA ${ }^{c}$ & -.. & $\ldots$ & 0.31 & $\cdots$ & -.- & --- & 3.5 \\
\hline Existing LAMPF' & --- & $\ldots$ & 0.015 & -- & -- & -- & 12. \\
\hline
\end{tabular}

the patient position. The loss of beam intensity from multiple scattering in the degrader should be analyzed quantitatively. (5) Consideration of the possibility of some kind of dynamic treatment would be interesting. As the pion energy is in- creased, the pions penetrate deeper and deeper. The shape at each layer should be exactly matched to the shape of the tumor at that point by changing the width of the slits. 


\section{APPENDIX D}

\section{SITING OPTIONS}

Each hospital witl have unique siting requirements and restrictions. Conceivably, PIGMI could be arranged in any orientation: :.orizontally, vertically, or sloped. The horizontal arrangement is commonly used for linacs, and vast amounts of knowledge and experience exist for designing. mounting, aligning, operating, and maintaining horizontal linacs. The horizontal arrangement is a more familiar one and generally is preferred by the accelerator community; the drawback is that an appreciable amount of ground area is required.

A PIGM! could be built either vertically down (that is, beam exit ai the accelerator's low point) or vertically up (that is, beam exit at the accelerator's high point). Each arrangement rquires a mınımum vertical shaft length of from $-140 \mathrm{~m}$ for a straight PIGMI (equivalent to a 40 -story building) $10-80 \mathrm{~m}$ for a folded PIGMI lequivalent to a 22-story building). Although vertical accelerators and beam lines have been buitt, the expertise in this type of accelerator arrangement is limited. The vertical accelerator poses unusual support problems unique to each application, and these problems may not have simple, cheap. and effective solutions. A vertical arrangement wouid siso require a service elevator in the tunnel. posing service and access problems. Should the accelerator be placed withiri a building, adequate radiation shielding would have to be installed. particularly in the high .energy portion of the accelerator. However, this scheme is very economical in terms of required ground area.

An accelerator built on a slope poses problems common to both the horizontal and vertical arrangements, the severity of the problems depending on the angle of the slope. Linear accelerators have boen built on a slight slope (for example. SLAC), but unless the slope is appreciable. this siting option offers no advantage over the horizontal arrangement in the amount of ground space required.

Although PIGMI could be constructed in any one of the above arrangement, it was postulated for the base-case design in this report that a horizontal arrangement will be chosen for the first PIGMI, and the succeeding discussion of siting in this appendix assumes a horizontal arrangement (either folded or straight).
There are many options for the location. size and shape of a horizontal PIGMI accelerator tunnel. These are an underground tunnel, either reclangular. circular, or semicircular; a bored or augered hole: an underground utility trench. a surface building; and an elevated location sımilar to a viaduct.

Addressing these in reverse order, the elevated location requires some surface area. Ii would involve extremely rigid bridge-style construction because vibrations and distortions of the structure would directly affect the alignment of the accelerator and probably would be quite expensive. The klystrons could be located on the ground level to reduce the massiveness of the structure. but radiation shielding would be more complex than an underground-tunnel location.

The use of a surface building to house the accelerator would cause the maximum disruption of the surface area. Accelerator access would be very gjod, and construction costs would be relatively inexpensive. The accelerator would not be subject to vibration and distortion problems encountered in an elevated structure. but radiation shielding would have to be more extensive than with an underground location. The building could be of inexpensive prefabricated metal construction: an attractive accelerator building probably would be difficult and expensive to construct.

For various reasons, underground locations traditionally have been used for accelerator channels Most important, concern for radiation-shielding becomes confined to the area above the accelerator tunnel. Also, the excavated ground provides a very stable platform for mounting the accelerator. Therefore. unless there are overriding objections peculiar to the hospital site, an underground location is strongly recommended.

An underground utility trench with manholes commonly is used to house urban utilities. A utilitytrench approach would limit accelerator access to some degree, and maintenance operation might require intrusion on some ground areas above the accelerator. The trench could probaily be adequately sealed against water invasion. This accelerator-channel technique has not often been 
used and probably offers no cost advantage over tunnel techniques.

A semicircular iunnel has been used at Fermilab and Brookhaven National Laboratozy. A flat floor is poured. then a prefabicated hoop structure is attached to the floor and sealed. This technique is most applicable to a cut-and-fill excavation, and construction time is fairly short; however, experience at Fermilab has shown that the hoop-tofloor joint may be difficult to seal. Nevertheless. this technique may be quite desirable in areas with low water tables.

A circular underground tunnel (using either steel cr precast concrete prefabricated. conduit-type sections) probably provides the shortest construction time possible on a flat site. Sealing between the conduil sections is a well-known technique. and very reliable seals are available. The constructic process involves excavating a trench $\sim 2.5 \mathrm{~m}$ wider than the conduit, laying in a thin bed of soft sand, placing the conduit sections on the sand in the proper alignment, sealing the joints, and backfilling. A flat floor is then poured inside the conduit. and the acclererator is installed.

Four accelerator-tunnel configurations most likely to be selected have been examined and are listed below.

Straight PIGMI with a distributed if system (Fig. 34)

Straight PIGMI with a clustered if system (Fig. D-1)

Straight PIGMI in a mountain-side location (Fig. D-2)

Folded PIGMI with a clustered if system (Fig. D-3)
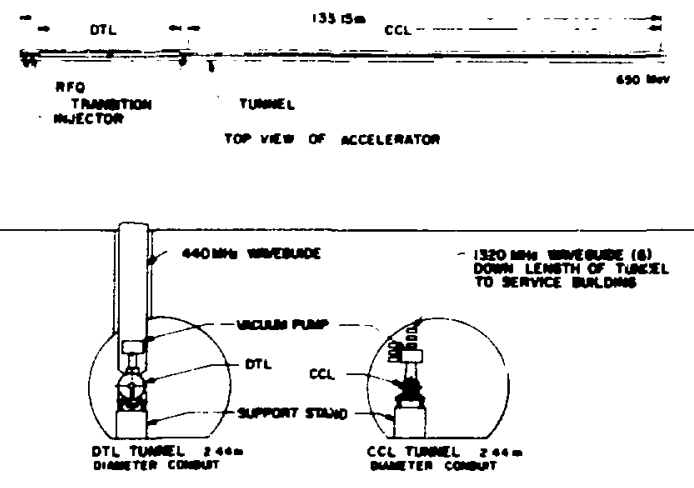

Fig. D-1.

Straight PIGMI with clustered if syotem.
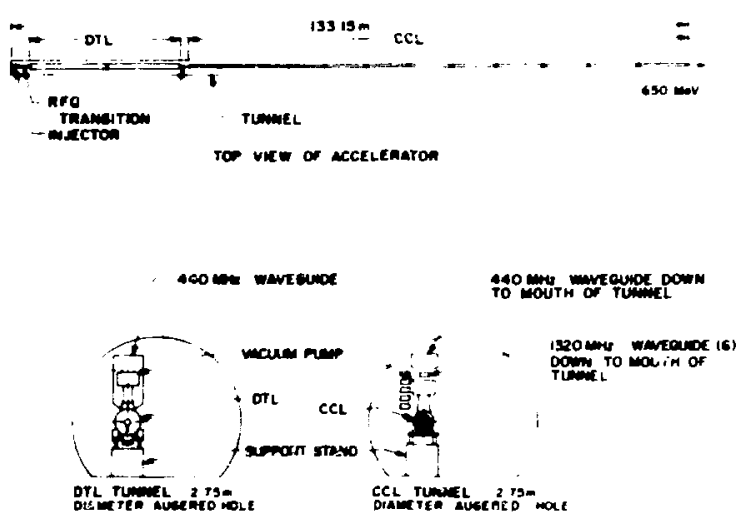

F.9. D-2.

Straight PHaMl in mountain-dids locetion.
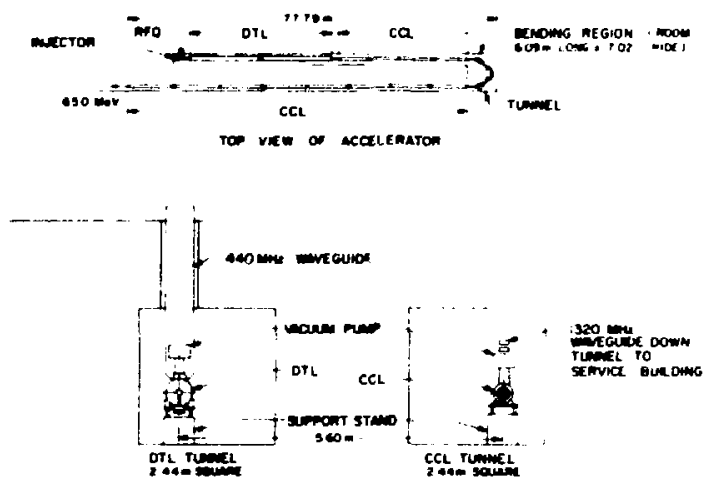

Fig. D-3.

Folded PIGMI with clustered if system.

The straight PIGMI with a distributed if system is considered to be a base-case configuration and was used to describe PIGMI in the body of this report.

The straight PIGMI with a clustered if system (Fig. $D-1)$ is the same base-case accelerator, with all klystrons located in a $12-\mathrm{m}$ by $12-\mathrm{m}$ by $6-\mathrm{m}$-tall surface service building. The $1320-\mathrm{MHz}$ rf power is distributed to the accelerator through waveguides in the tunnel; the $440-\mathrm{MHz}$ power is delivered through a vertical waveguide, as in the base-case PIGMI. A circular tunnel of a minimum size $(2.44-\mathrm{m}$ i.d.) could house a PIGMI accelerator and the waveguide array. The $440-\mathrm{MHz}$ klystron is too tall $(4.05-\mathrm{m})$ to fit into a circular accelerator tunnel of 
reasonable diameter. A tall alcove $(\sim 10 \mathrm{~m}$ high) could house the $440-\mathrm{MHz}$ klystron, but a specia! rigging and transportation cart would be necessary if the klystron tube had to be exchanged. The simplest solution to the placement of the $440-\mathrm{MHz}$ klystron is to house it, at least partially, in a surface building with waveguide access to the DTL portion of PIGMI. The cost per meter of the circular conduitstyle tunnel is $-10 \%$ less than the equivalent 2.44 $\mathrm{m}$-wide rectangular tunnel used for the base-case PIGMI.

Another circular-tunnel approach would be applicable to a mountain-side location for PIGMI. In the mountain, an auger could bore a hole that would be used for the PIGMI accelerator tunnel. This approach is quite attractive, because it requires the minimum amount of surface land and a minimum disruption of that surface. After the hole is bored, a concrete floor is laid and the accelerator is installed, as shown in Fig. D-2. If the $1320-\mathrm{MHz}$ klystrons and the $440-\mathrm{MHz}$ klystron are clustered near the mouth of the tunnel, with waveguides running down the tunnel to the appropriate points on the accelerator, a $2.75-\mathrm{m}$-diam hole would suffice. Location of klystrons in the accelerator tunnel would require a correspondingly larger hole. Cost estimates for this kind of tunnel have not been made because variations in rock type can easily alter the cost per meter by a factor of 2 .

The final PIGMI configuration being considered uses the folded-accelerator option (Fig. D-3). Any of the previously described tunnel techiniques, with either a distributed or clustered rf system, could be used. Above the cost of a straight PIGMI, the folding option accrues the costs of three bending magnets. magnet power supplies, magnet-cooling equipment, and the space in which to place this equipment. The cost of parallel tunnels should be about the same as that for a linear tunnel because the required tunnel length is the same. Further details of the folding option are discussed in Appendix $E$.

In summary, the PIGMI medical-facility site and consequent considerations will determine the type of accelerator tunnel selected. Perhaps a combination of tunnel options would be desirable; however. only one of the four prime options may be the most desirable. The lour prime PIGMI configurations illustrate the flexibility for building a PIGMI near a hospital site. In addition, it is possible to significantly shorten the accelerator whiie paying the penalty of increased rf-power costs, as described in Appendix $G$. 


\section{APPENDIX E}

\section{FOLOED ACCELERATOR OPTION}

One possibility for reducing the total length of the PIGMI facility is to bend the linac back on itseli at about the halfway point. However, the $180^{\circ}$ bending system used for this purpose must have the very special properties of being both achromatic and isochronous to transport the proton beam without destroying the transverse or longitudinal gimensions of the bunch. In the FisMI design, the optimum point at which to bend the beam is between $C C L$ Niodule $B$ and Moduie $C$. where the beam energy is $271 \mathrm{MeV}$. A second possible location at which to bend the beam is between Module $C$ and Module $D$, where the beam energy is $357 \mathrm{MeV}$.

The case of bending a 100- $\mathrm{A}$ proton beam at an arbitrary energy of $250 \mathrm{MeV}$ has been studied in detail, and the remainder of this appendix is a condensation of that study.

A $180^{\circ}$ bending system would be positioned at about the halfway point in the PIGMI linac structure; at this position the energy is $250 \mathrm{MeV}$. The bending system would consist of several bending and quadrupole magnets; design parameters for these magnets are given in Table E-I.

The design takes advantage of a symmetric configuration of magnets with respect to a plane

TABLE E-I

\section{SOME DESIGN PARAMETERS FOR BENDING AND QUADRUPOLE MAGNETS}

\begin{tabular}{lc} 
Parameter & Value \\
\hline & \\
Bending magnet & \\
Bending radius & $1.40 \mathrm{~m}$ \\
Field strength & $17.4 \mathrm{kG}$ \\
Field gradient & 0 \\
Pole gap & $8.0 \mathrm{~cm}$ \\
Angle of pole face & $0^{\circ}$ \\
Quadrupole magnet & \\
Effective length & $20.0 \mathrm{~cm}$ \\
Aperture & $6.0 \mathrm{~cm}$ \\
\hline
\end{tabular}

perpendicular to the central ray at the $90^{\circ}$ bend point. The first half of the system should conform to the following.

(1) A horizontally diverging beam at the entrance must be immediately focused at the center of symmetry. The longer path length of a particle diverging outside in the first half of the system can be canceled by the shorter one in the second half to give a path length (to first order) equal to the central ray in the total system. This assures the same transit time for any particles in the diverging monochromatic beam.

(2) A parallel beam at the entrance must be transformed to a parallel beam at the center of symmetry. This assures an outcoming parallel beam at the exit of the full system. To assire the same Iransit time. the path-length difference must be canceled within the first half of the system.

(3) An off-momentum particle, entering along the central trajectory. must travel on a parallel dispersive trajectory at the center. This makes the total system achromatic, both in position and in angle.

(4) The isochronous condition for half the system must be gained by making the particle's path length proportional to its velocity.

(5) The mode of the particle's vertical motion must be chosen to be compatible with the restrictions imposed on the horizontal motion. A point-topoint imaging and a parallel-to-parallel transformation could be the best choice for the vertical motion.

A flat, semicircular bending magnet can achieve isochronous but not achromatic bending. When two idential $90^{\circ}$ bending magnets are used with a quadrupole magnet between them, a system can be made either achromatic or isochronous (depending on the field strength of the quadrupole magnet), but it cannot be made simultaneousiy achromatic and isochronous. Therefore, three or more separate bending magnets are necessary to build the desired system.

Figure E-1 shows an achromatic and isochronous system, consisting of three bending magnets. Particle trajectories of special interest are shown in Fig. E-2. The z-axis coincides with the central ray. The $x$-and $y$-axes indicate the deviation 


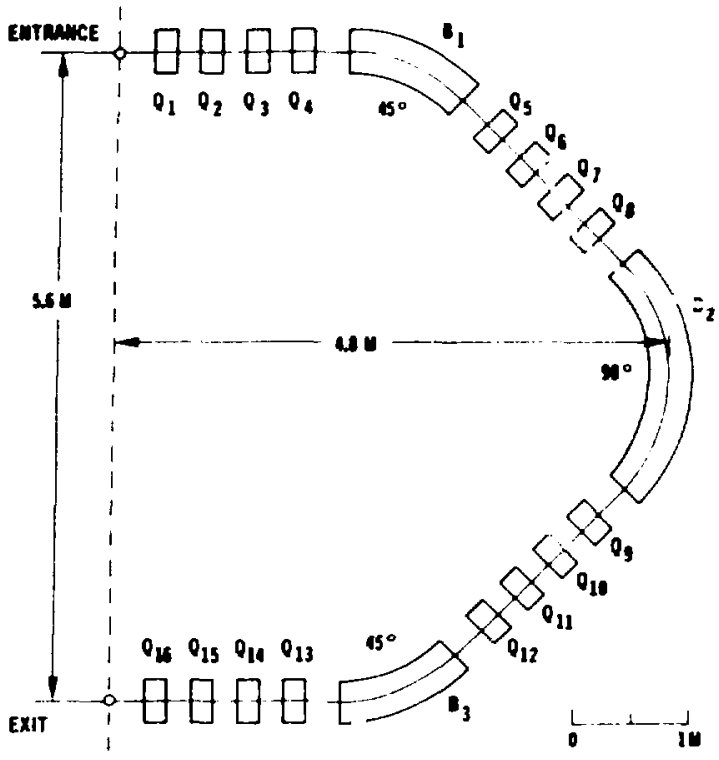

Fig. E-1.

An achromatic and isochronous bending system.

(The bend radius of each magnet is $1.4 \mathrm{~m}$.) from the central ray in horizontal and vertical motoons. respectively. A monochromatic beam. diverging at the entrance. forms an intermediate doublefocusing image at the symmetry center of the second bending magnet $B_{\text {: }}$ and converges again to the exit

A representative trajectory of $\theta_{0}, 4 \mathrm{mrad}$ and $B_{\text {. }}$ 4 mrad is drawn with solid lines in Fig. E-2. An incoming monochromatic beam. paraliel to the central ray. again becomes parallel at the symmetry center and is transported to an outgoing parallel oeam at the exit. A representative trajectory of $x_{i} . \quad 5 \mathrm{~mm}$ and $y . \quad 5 \mathrm{~mm}$ is drawn with dotted lines An off-momentum particle. incoming on the central ray at the entrance. deviates horizontally from the central ray in the first bending magnet and travels on a dispersive trajectory. which becomes parallel to the central ray at the symmetry center. So that the particle again is on the central ray at the exit. A iypical trajectory for $1 p / p \quad 0.2^{\circ} \circ$ is shown as a solid line in the $X Z$-plane labeled is $0.2^{\circ} \mathrm{c}$. A relatively large dispersion at the symmetry center is necessary to make the system
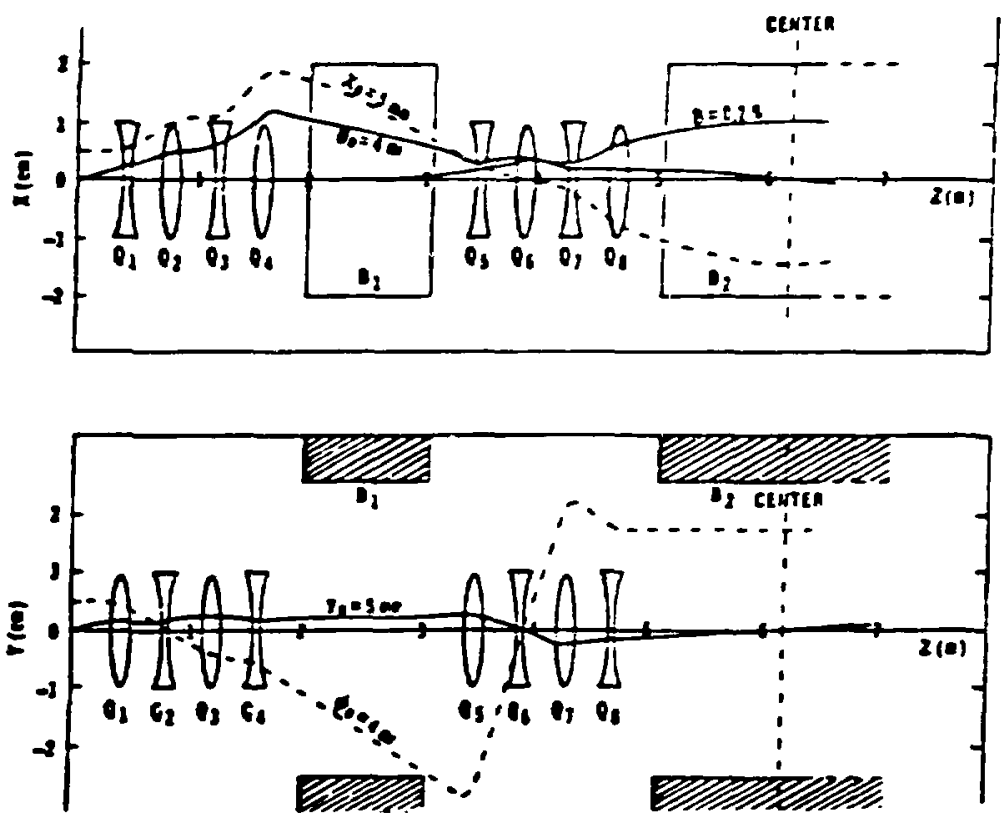

Fin. E-2.

Pertich trajectorice of epecial intereat. (The solid line and the dotted line show trajoctories of partickes of central momentum. The solid line labeled $\delta=0.2 \%$ is that of an off-momentum particle.) 
TABLE E-II

\section{FIELD STRENGTHS OF THE OUADAUPOLE MAGNETS}

\begin{tabular}{l}
$\begin{array}{l}\text { Ousdrupole } \\
\text { Magnet }\end{array}$ \\
\hline
\end{tabular}

\begin{tabular}{lr}
$Q_{1}, Q_{1,}$ & -9.63 \\
$Q_{2}, Q_{15}$ & 5.13 \\
$Q_{3}, Q_{14}$ & -7.04 \\
$Q_{4}, Q_{13}$ & 5.34 \\
$Q_{5}, Q_{12}$ & -11.17 \\
$Q_{3} Q_{11}$ & 9.02 \\
$Q_{1} Q_{10}$ & -14.10 \\
$Q_{1}, Q_{1}$ & 3.33 \\
\hline
\end{tabular}

isochronous. The is strengths of the quadrupole magnets are listed in Table E-II. The large. negative values of $Q$, and $Q$, compared with the counterparts of $Q_{6}$ and $Q_{n}$. realize the desired large dispersion. The drift lengths between quadrupole magnets are $0.2 \mathrm{~m}$; the other drif! lengths are $0.3 \mathrm{~m}$. An additional constraint is applied to keep the beam size small within the system.

For this system, the separation between the incoming and outgoing beams is $5.6 \mathrm{~m}$, although this requires two separate tunnels (as shown in Fig. $D-3)$. This is considered a more desirable solution than a more complex system with smaller separation. which requires one fewer quadrupole magnet but five more bending magnets. 


\section{APPENDIX F}

\section{CLUSTERED h-sYSteM OPTION}

In the base-case accelerator design presented in the body of this report, the six $1320-\mathrm{MHz}$ klystrons were located in the accelerater tunnel beside the $\mathrm{CCL}$ modules. However, this arrangement requires a tunnel larger than one nousing the accelerator alone, and some of the klystron electronics would have to be shielded or "hardened" against the radiation being emitted from the accelerator. Although the PFN cabinets use air, the klystron tanks must use oil as an insulator; this placement for the klystrons requires a large amount of transformer oil (2400 gal.) to be in the tunnel. Therefore, in some cases, it may be desirable to cluster the $1320-\mathrm{MHz}$ klystrons in the above ground service building (with the $440-\mathrm{MHz}$ klystron) and pipe the radio-frequency to the $\mathrm{CCL}$ modules by waveguides.

A clustered $1320-\mathrm{MHz}$ if system is more difficult to control than a distributed if system because of the varying length of the waveguides; the shortest waveguide would be $\sim 30 \mathrm{~m}$, the longest $\sim 100 \mathrm{~m}$. These lengths will result in delay times of between 0.14 and $0.46 \mu \mathrm{s}$ between initiation of the pulses by the klystrons to delivery to the accelerator. The power losses in the waveguides are relatively modest $(-100 \mathrm{~W} / \mathrm{m})$.
By clustering the $1320-\mathrm{MHz}$ klystrons in the service building, if-power systems are centralized with resultant simplification in klystron power supplies and cooling systems. Except for a few controlsystem modules in the accelerator tunnel, thie electronics do not have to be shielded from radiation. Because the accelerator can be operated with only five of the six $1320-\mathrm{MHz}$ klystrons, maintenance may be perfermed during operation in a radiation free environment. In addition, the problems associated with handling large amounts of transformer oil would be confined to the service building.

A clustered if system would require a larger service building (a total additional space of $180 \mathrm{~m}^{2}$ for the six klystrons), and the large amount of waveguide necessary (about $300 \mathrm{~m}$ ) would result in an additional cost of $\sim \$ 64000$. Because a smaller tunnel is possible and because the tunnel costs scale approximately with the square of the tunnel cross section, the tunnel costs would be reduced by $-\$ 95000$. 


\section{APPENDIX G}

\section{ACCELERATOR DESIGN OPTIONS}

The base-case PIGMI is $\sim 134 \mathrm{~m}$ long; this length resul's iw $n$ the chosen accelerating gradients 16 $\mathrm{MV} / \mathrm{n}$. in the DTL and $8 \mathrm{MV} / \mathrm{m}$ in the $\mathrm{CCL}$ ). These accelerating gradients are believed to be somewhat conservative. In linacs, the accelerator length $(L)$ is inversely proportional to the accelerating gradient $\left(E_{v}\right)$ required to achieve the desired final energy such that

$L \sim E^{\prime}$

$\Delta W=E_{0} L T$

$P=E_{0}^{2} L^{\prime} Z^{\prime}$.

where $\Delta W=$ energy gain, $E_{0}=$ average accelerating gradient, $L=$ accelerator length, $T=$ transit time, $P$ $=$ if power required, and $Z=$ shunt impedance.

Combining Eqs. (G-1) and (G-3) yields

$$
P L=E_{v}^{2} L^{2} Z^{\prime} \text {. }
$$

Multiplying by $T^{2}$ in both numerator and denominator of Eq. (G-2) and (G-3) yields

$$
\begin{aligned}
P L & =E_{0}^{2} L^{2} T^{2}\left(Z T^{2}\right)^{\prime} \\
& =\Delta W^{2}\left(Z T^{2}\right)^{\prime} .
\end{aligned}
$$

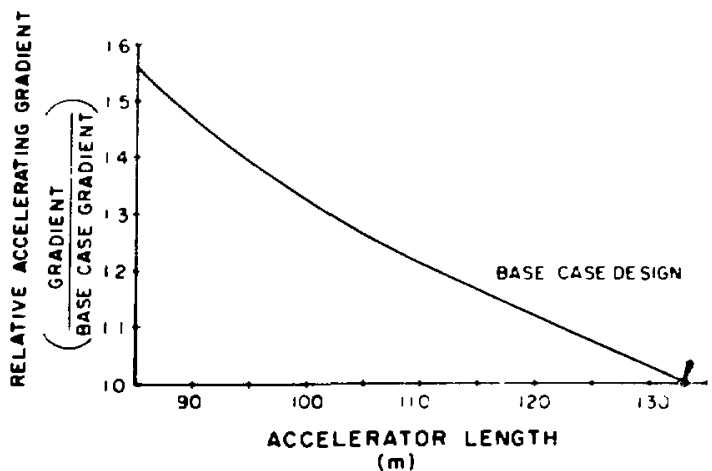

Fin. 0-1.

Accelerating gredient us secelerator length.
Therefore, $P L=$ a constant $=P_{B C} L_{B C}$, where $P_{B C}$ base-case design if power, and $L_{a c}=$ base-case accelerator length.

Figure G-1 shows the effect on length by increases in the DTL and CCL acceler ating gradients The injector. RFQ, and transition-region lengths remain constant. By operating at an accelerating gradient $-33 \%$ higner than the designed (base-case; accelerating gradient. the accelerator's total length can be reduced to $-100 \mathrm{~m}$. This would require operating the DTL at $7.8 \mathrm{MV} / \mathrm{m}$. and the CCL at $10.4 \mathrm{MV} / \mathrm{m}$; the PIGLET cavity has already demonstrated that DTL accelerating gradients in excess of $9.0 \mathrm{MV} / \mathrm{m}$ are possible. Field-gradient tests of the 1300-MHz DAW power cavity may also demonstrate the achievability of very high gradients in the $\mathrm{CCL}$ structure.

Figure G-2 shows the effect on if power from decreased accelerator length. The shape of the curve is very similar to that in Fig. G-1. and if the accelerator length is reduced by a certain percentage, the if power required is increased by that same percentage.

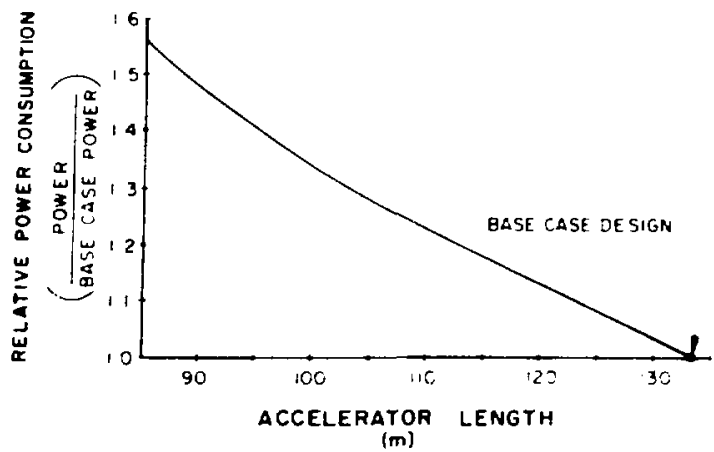

Fig. 6-2.

Power consumption ve sccelerabor length. 


\section{APPENDIX H}

\section{VACUUM SYSTEM OPTIONS}

Traditionally. ion pumps have been used on particle accelerators for many reasons. They are inexpensive to operate. perform well in a radiation environment, are very reliable. and any performance degradation can be easily assessed. However, ion pumps are expensive. heavy. difficult 10 handle manually, and require the system pressure to be reduced to $\sim 5 \times 10^{\circ}$ torr before they can operate efficiently. This requirement necessitates another relatively sophisticated vacuum system to lower pressure so the ion pumps can be turned on Ion pumps also are very poor at pumping the inert gases (argon, neon, etc.).

An intriguing alternative to ion pumps for accelerator applications are cryopumps. Cryopumps operate by freezing oul vapors on a cryogenic surface, and they will pump all gases except helium. Cryopumps are lightweight and can be handled by one person. Their cost is $-25 \%$ of that of an equivalent ion pump. Cryopumps can be started at relatively high syslem: pressures of $\sim 5 x$ $10^{\prime}$ torr. well within the capability of an unsophisticated roughing vacuum system. The use of mechanical refrigerator units has eliminated the need for a separate cryogenics installation. Although the refrigerators are mechanical (with moving parts). sufficient experience now exists with cryopump units to have achieved excellent reliability. Experience in the use of cryopumps in a radiation environment (as lound next to an operating accelerator) is limited but favorable.

The use of cyropumps on PIGMl could reduce the estimated cost of the vacuum system from $\$ 428000$ to $-\$ 218000$. This possible saving of $-\$ 210000$ in the construction costs of PIGMI is a strong incentive to consider the use of cryopumps as a system option. 


\section{APPENDIX I}

\section{RFO PARAMETERS}

The following appendix is a computer listing of the required parameters for the AFO $(30$ - to 2.5 MeV) section of PIGMI. The basic RFO geometry is shown in Fig. 1-1. The listed parameters are defined as lollows

NC - Cell number

$V$ = Voltage between vanes (MV)

WS - Kinetic energy at the end of the cell (MeV)

BETA : $\beta$ at the end of the cell
EZ Peak longitudinal tilld in the cell (MV/m)

CAPA A, the acceleraing elficiency parameter

PHI Synchronous phase (degrees)

A a. minimum aperture size $(\mathrm{cm})$

$M \quad m$. vane modulation parameter

$B \quad$ Focusing strength

RFD $\mathrm{rl}$-defocusing strength

$\mathrm{CL} \quad$ Cell length $(\mathrm{cm})$

$T L \quad$ Total length $(\mathrm{cm})$

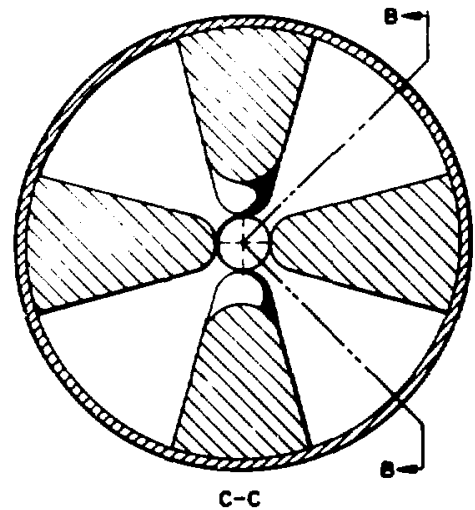

$c-c$

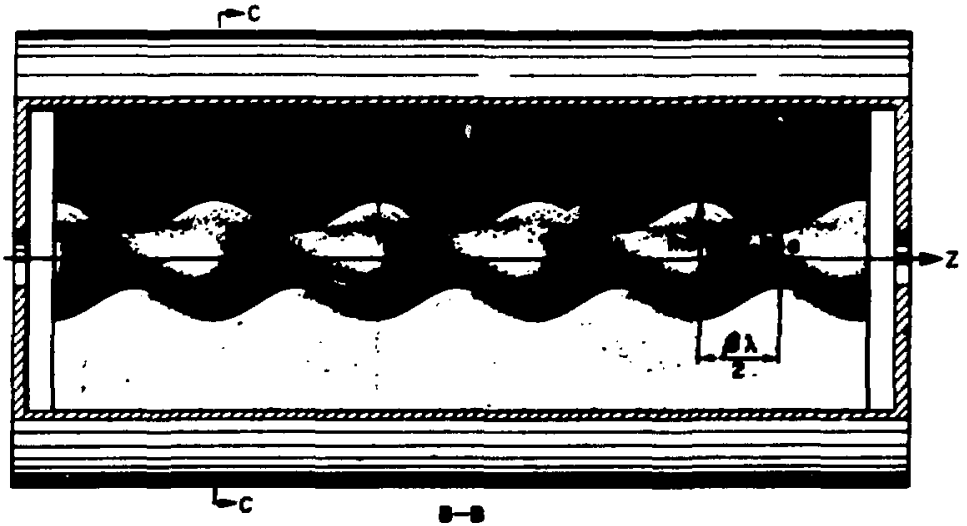

Fig. 1-1.

Decie RFO geometry. 
TANK I IENGTHE 177.92 CW. 270 CELIS, CHARGE STATE 1.

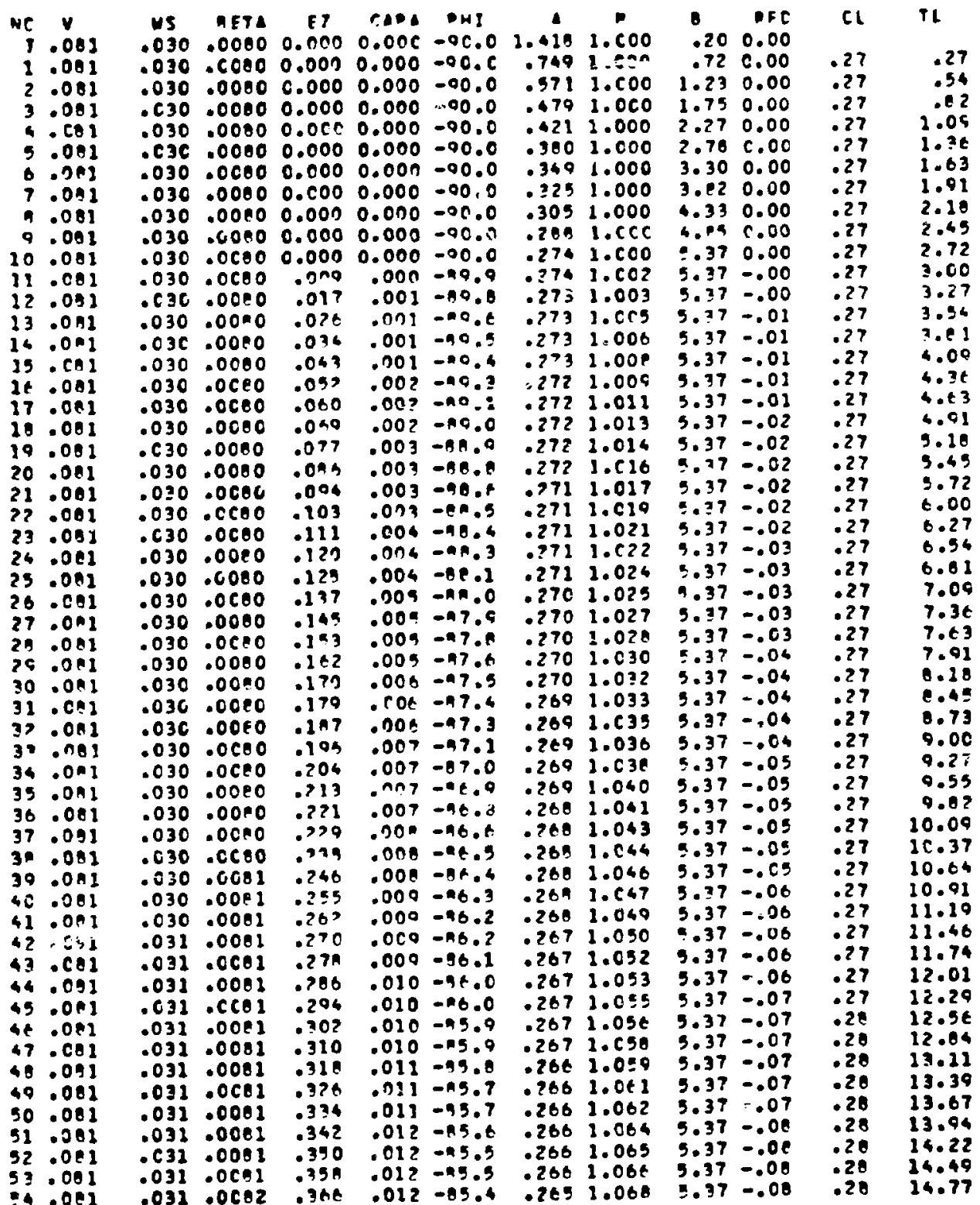




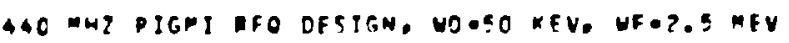

- AGE 2

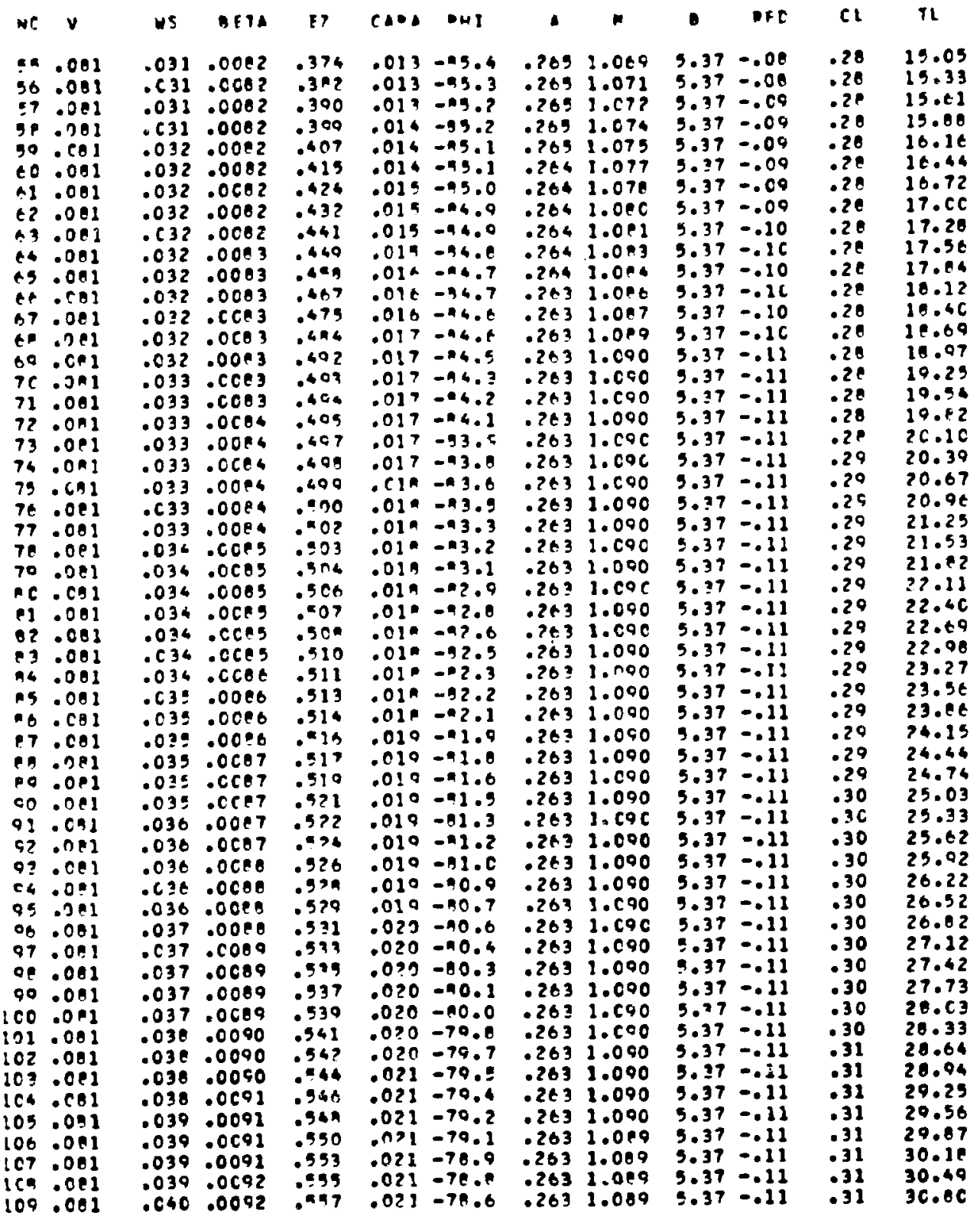




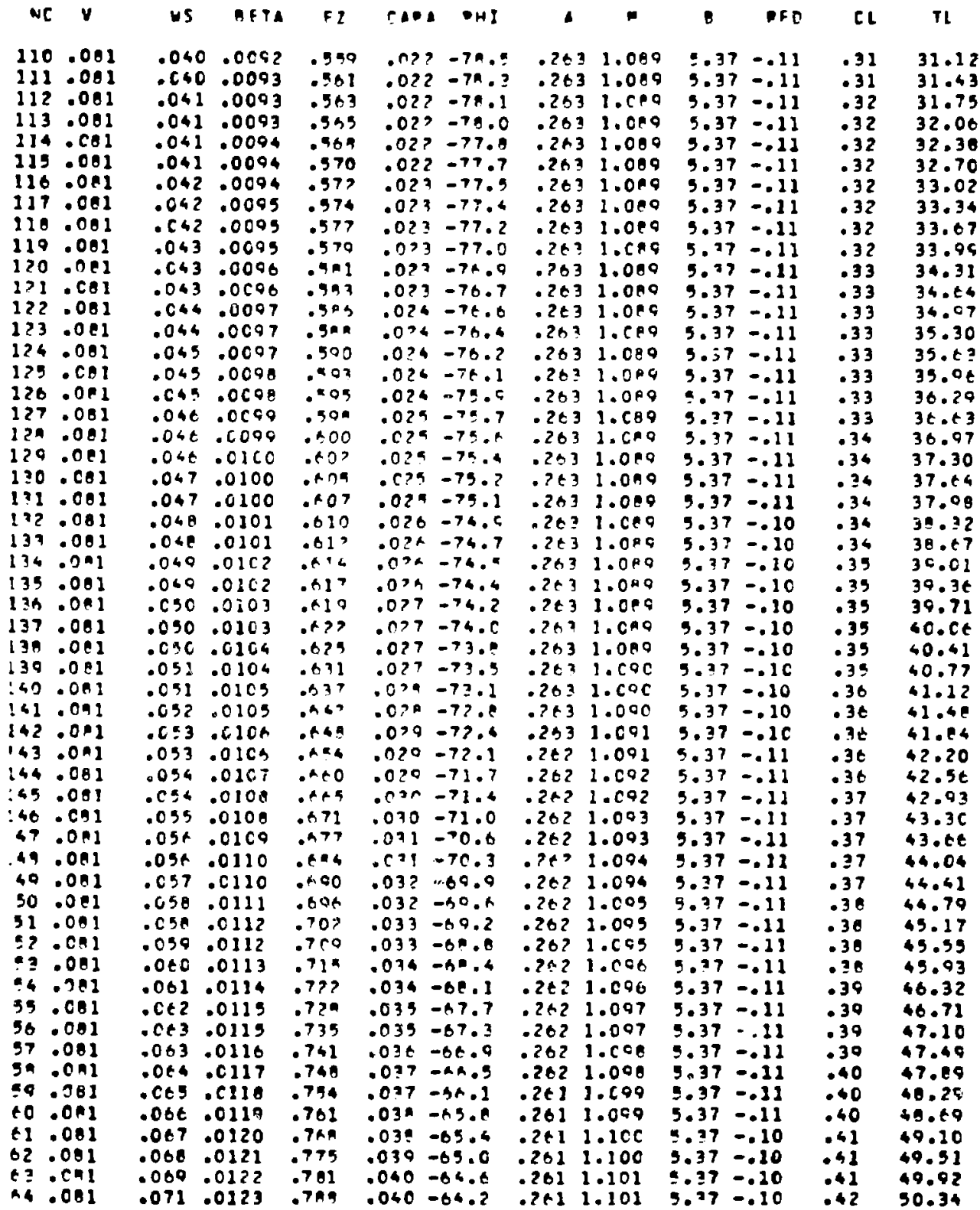


44O WHT PIGPI RFO DESIFW, NOESO REV, WF-2.S MEV

PAGe 4

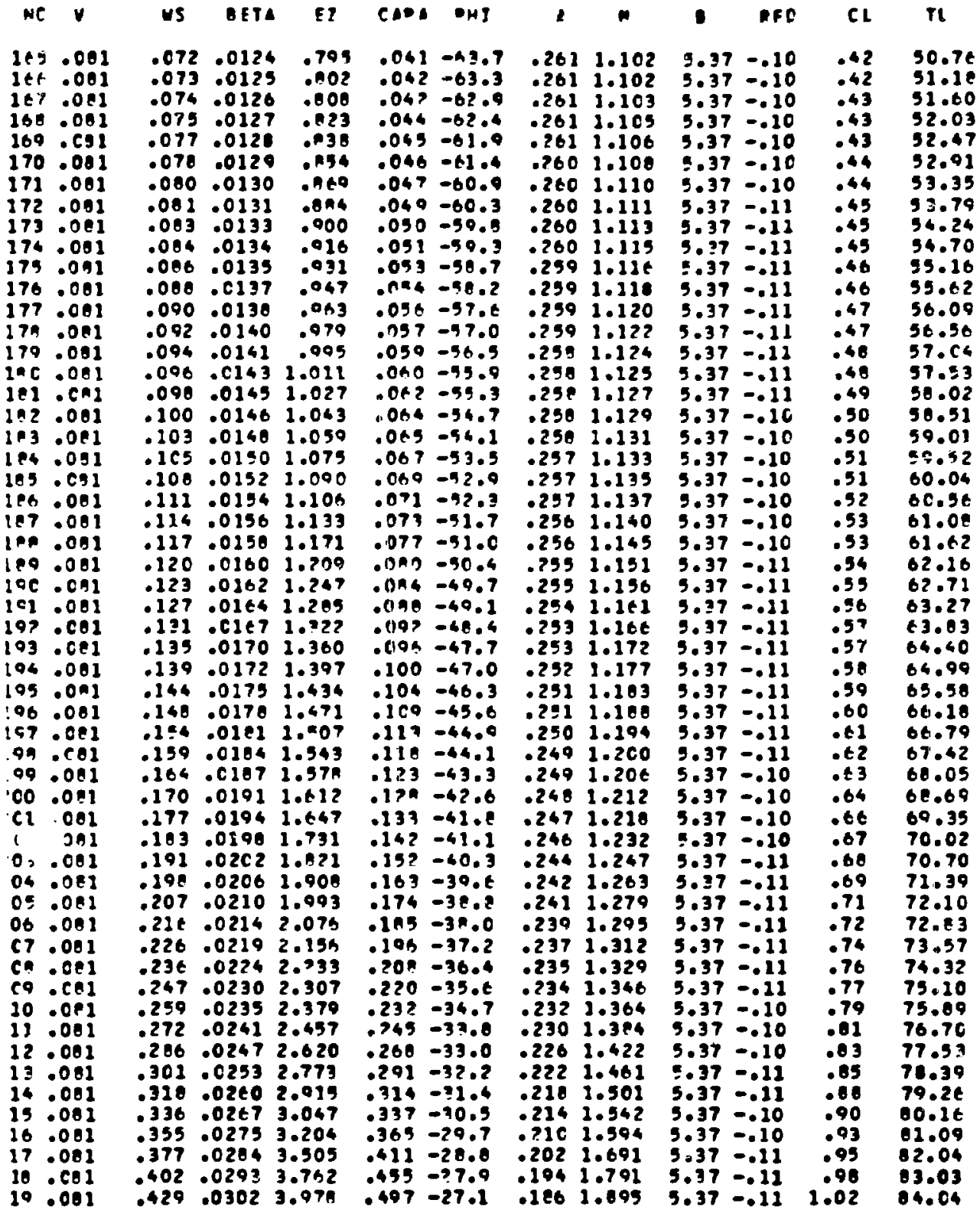


440 4HZ DIGMI EFO DESITH, VO-50 REY, UF-2.5 MFV

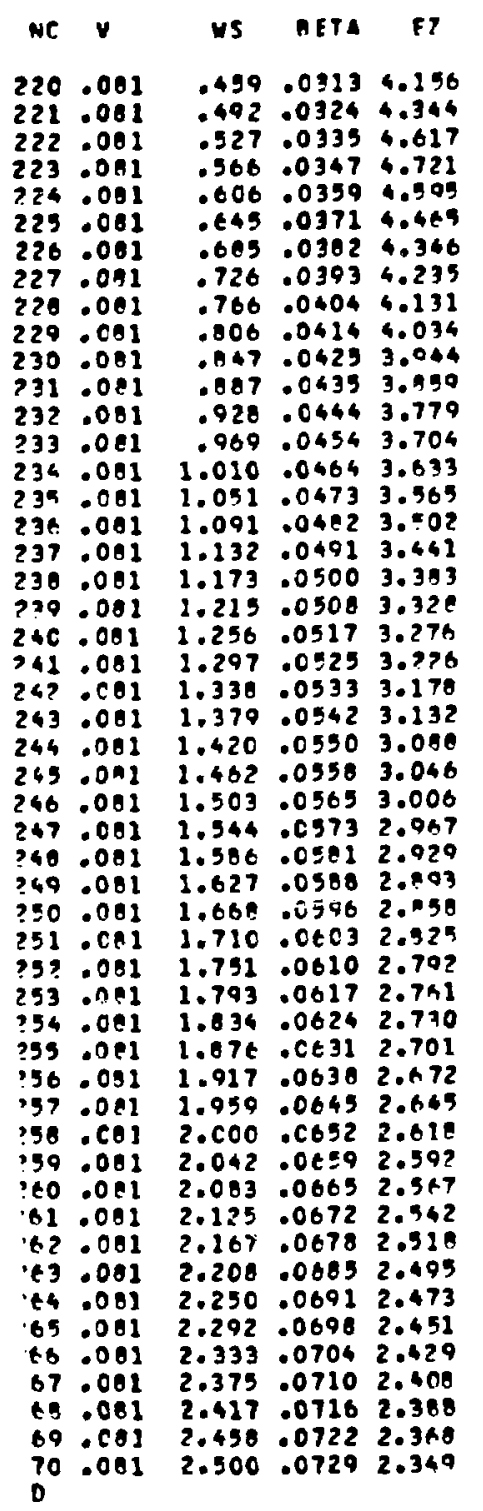

CAES ONI 4

$.537-36.1 .1732 .0 \mathrm{CZ}$ $.500-25.2+1702.235$

$.630-24.50 .1572 .346$

$.675-24.0 \quad .1492 .500$

$.679-24.0 \quad .1492 .500$

$.681-74.0 \quad 1492.500$

$.484-24.0 \quad .1402 .500$

.tiat $-24.0 \quad .1402 .500$

$.649-24.0 \quad .14 \% 2.500$

$.49 C-24.0 \quad .1402 .5 C C$

$.607-24.0$

$.094-24.0$

$.695-24 . C$

$.696=74.0$

$.697-24.0$

$.698-24.0$

$.+99-24.0$

$.700-24.0$

$.701-24.0$

$.707-24.0$

$.703=24.0$

$.704-34.0$

$.704-24.0$

$.705-24.0$

$.705-74.0$

$.706-94.0$

$.706-24.0$

$.707 \rightarrow 4 . c$

$.707-24.0$

$.70=-24.0$

.70 - 24.0

$.709-24.0$

$.709-24.0$

$.709-24 . \mathrm{C}$

$.710-24.0$

$.710-24.0$

$.710-24.0$

$.711-24.0$

$.711=74.0$

$.711-24.0$

$.711-24.0$

$.712-24.0$

$.712-24.0$

$.712-24.0$

$.712-24.0$

$.713=24.0$

$.713-24.0$

$.713-24.0$

$.713-24.0$

$.713-24.0$

$.714-24.0$
.1472 .300

$.1472 .5 \mathrm{CC}$

.1472 .500

.1472 .500

.1472 .500

.1472 .500

.1472 .500

.1462 .500

.1462 .500

.1462 .500

.1462 .300

.1462 .500

$.146 \quad 2.500$

.1462 .500

$.146 \quad 2.500$

.1462 .500

$.246 \quad 2.900$

.1462 .500

$.146 \quad 2.500$

.1462 .500

.1462 .500

.1452 .500

.1452 .500

.1452 .500

.1452 .500

.1452 .500

$.1452 .5 \mathrm{CC}$

.1452 .500

.1452 .500

.2452 .500

$.1452 .5 \mathrm{CC}$

.2452 .500

.1452 .300

.1452 .500

.2432 .300

.1452 .000

.1452 .500

.1452 .500

.1452 .500

.1492 .500

.1452 .500

PaG 5

\begin{abstract}
- PF
\end{abstract}
$5.37-.11$

$5.37=.20$

$3.37-.10$

$5.37-.10$

$5.37-.10$

$5.37=.09$

$5.37=.08$

$5.37=.00$

$5.37-.08$

$5.37-.07$

$3.37-.07$

$5.37=.07$

$5.37=.06$

$5.37-.66$

$5.37-.06$

$5.37=.06$

$5.97-.05$

$5.37-.05$

$5.37=.05$

$5.37=.05$

$5.37=.05$

$5.37-.05$

$3.37=.04$

$5.37=.04$

$3.37=.04$

$5.37=.04$

$0.37=.04$

$5.37=.04$

$5.37=.04$

$5.37=.04$

$5.37-.04$

$5.37=.03$

$5.37-.03$

$5.37-.03$

$5.37=.03$

$5.37=.03$

$5.27-.03$

$5.37=.03$

$5.37-.03$

$5.37=.03$

$5.37-.03$

$5.37-.03$

$5.37-.03$

$5.37-.03$

$3.37=.03$

$5.37=.03$

$5.37-.03$

$5.37-.02$

$5.37-.02$

$5.37-.02$

$5.37-.02$
Cl Tl

1.0503 .09

$2.69 \quad 06.28$

1.1287 .30

1.1600 .46

1.2009 .66

$1.2490 .9 \mathrm{C}$

1.2892 .10

$1.32 \quad 93.50$

1.3594 .06

$1.39 \quad 96.25$

1.4397 .67

1.4699 .13

1.49100 .13

$1.53 \quad 102.16$

$1.56 \quad 103.72$

$1.59 \quad 105.31$

$1 . t 2 \quad 206.93$

1.65108 .59

$1.69 \quad 110.27$

$1.71 \quad 111.99$

$1.74 \quad 113.73$

1.77115 .51

1.00117 .31

1.63119 .14

$1.06 \quad 120.99$

2.00 122.08

$1.91 \quad 124.79$

$1.94 \quad 126.73$

$1.96 \quad 120.49$

1.99130 .68

2.01132 .49

$2.04 \quad 134.73$

2.00136 .80

$2.09 \quad 130.09$

$2.11 \quad 141.00$

$2.14 \quad 143.14$

$2.16 \quad 145.30$

2.10147 .48

$2.21 \quad 169.69$

$2.23 \quad 151.92$

$2.25 \quad 154.17$

2.28156 .45

$2.30 \quad 150.79$

$2.32 \quad 161.07$

$2.34 \quad 163.41$

2.36169 .78

2.39168 .16

$2.41 \quad 170.57$

$2.43 \quad 173.00$

$2.45 \quad 175.45$

$2.47 \quad 177.92$ 


\section{APPENDIX J}

\section{DTL PARAMETERS}

The following appendix is a computer listing of the rquired parameters for the DTL $(2.5-\mathrm{meV}$ to $125-\mathrm{MeV}$ ) section of PIGMI. This design is based on the high sparking limit observed in the PIGLET test cavity. A more conservative design might ramp the electric field down in the early cells to reduce the surface fields. The basic DTL geometry is shown in Fig. J-1 and Fig. J-2. The listed parameters are defined as follows.

ENERGY : Design energy for the synchronous particle (MeV).

POWER = Includes peak cavity and beam power (MW).

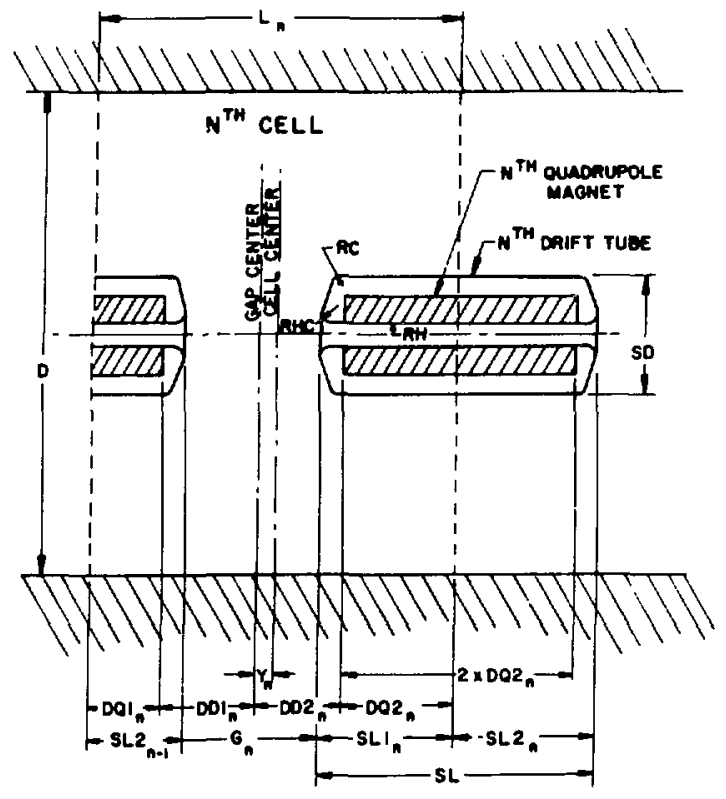

Fig. J-1.

Standard drift tube cell geometry.
BETA Relativistic velocity of synchronous particle $\beta$ Vs/c

$T$ Transit-time factor.

TP.S. SP. Higher order dynamical parameters derived from cavity field analysıs.

QUAD LENGTH Effective length of quadrupole linacs in an equal-10-physical-length of permanent magnets $(\mathrm{cm})$.

QUAD GRADIENT Magnetic gradient $(\mathrm{kG} / \mathrm{cm})$. EZERO Average electric field gradient on the axis.

$Z$. Shunt impedance (MS2/rn).

TOTAL LENGTH = Cumulative length $(\mathrm{cm})$.

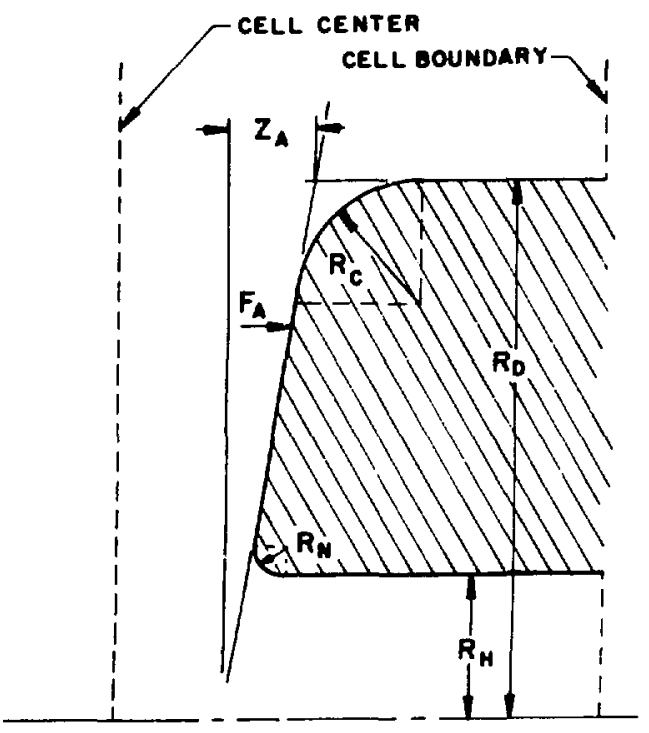

Fig. J-2.

Standard drift tube "face contour." $\left(R_{\mathrm{b}}=3.00 \mathrm{~cm} ; \mathbf{R}_{\mathrm{C}}=\right.$ $1.50 \mathrm{~cm} ; A_{N}=0.50 \mathrm{~cm}$; and $A_{:}=0.05 \mathrm{~cm}$.) 
TANK LENGTH. 3006.146 CENTIMETERS PONE - 17.475 UV

151 CELLS

\begin{tabular}{|c|c|c|c|c|c|c|c|c|c|c|c|c|}
\hline $\begin{array}{l}\text { ELL } \\
\text { ND }\end{array}$ & $\begin{array}{l}\text { ENERGY } \\
\text { HEV }\end{array}$ & & $\begin{array}{l}\text { CELL } \\
\text { LENGTH }\end{array}$ & $\mathbf{T}$ & To & 5 & SP & $\begin{array}{l}\text { OUAD } \\
\text { LENGTH }\end{array}$ & $\begin{array}{l}\text { OUAN } \\
\text { CRAD }\end{array}$ & $\begin{array}{r}\text { ETERO } \\
\text { MVIM }\end{array}$ & 2 & $\begin{array}{l}\text { TOTAL } \\
\text { LENGTH }\end{array}$ \\
\hline $\begin{array}{c}7 N T T \\
1 \\
2 \\
3 \\
4 \\
5 \\
6 \\
7 \\
8 \\
9 \\
10 \\
11 \\
12 \\
13 \\
14 \\
13 \\
16 \\
17 \\
20 \\
19 \\
20 \\
21 \\
22 \\
23 \\
24 \\
25 \\
26 \\
27 \\
29 \\
29 \\
30 \\
31 \\
32 \\
33 \\
34 \\
35 \\
36 \\
37 \\
38 \\
39 \\
40 \\
41 \\
42 \\
43 \\
44 \\
39\end{array}$ & 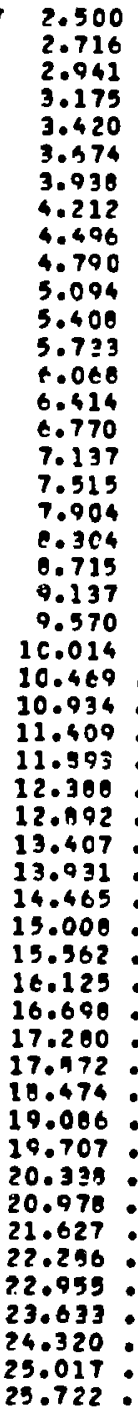 & 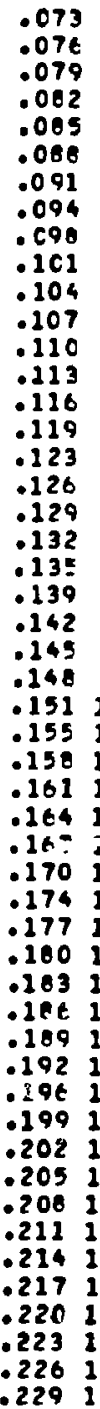 & 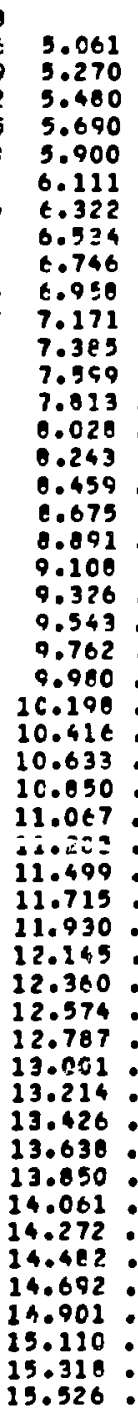 & 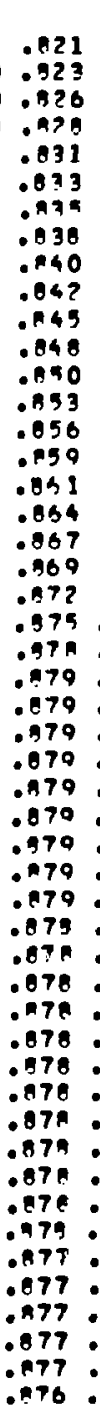 & 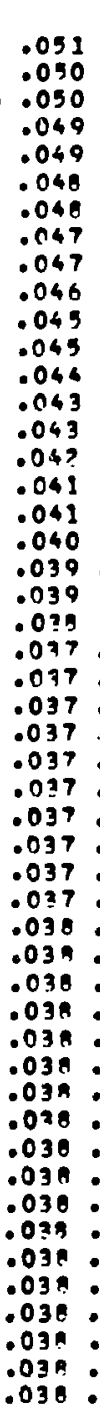 & 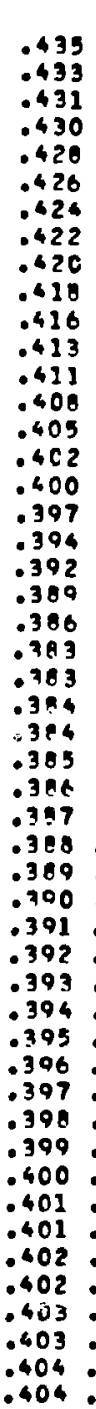 & $\begin{array}{l}.051 \\
.051 \\
.051 \\
.051 \\
.051 \\
.051 \\
.052 \\
.052 \\
.052 \\
.052 \\
.052 \\
.052 \\
.052 \\
.052 \\
.052 \\
.052 \\
.052 \\
.052 \\
.051 \\
.051 \\
.051 \\
.051 \\
.051\end{array}$ & $\begin{array}{l}2.54 \\
2.54 \\
2.54 \\
2.54 \\
2.54 \\
2.54 \\
2.54 \\
2.54 \\
2.54 \\
2.54 \\
2.54 \\
2.54 \\
2.54 \\
2.54 \\
2.54 \\
2.54 \\
2.54 \\
2.54 \\
2.54 \\
2.54 \\
2.54 \\
2.54 \\
2.54 \\
2.54 \\
2.54 \\
2.54 \\
2.54 \\
2.54 \\
2.54 \\
2.54 \\
2.54 \\
2.54 \\
2.54 \\
2.54 \\
2.54 \\
2.54 \\
2.54 \\
2.54 \\
2.54 \\
2.54 \\
2.54 \\
2.54 \\
2.54 \\
2.54 \\
2.54 \\
2.54\end{array}$ & $\begin{array}{r}20.00 \\
-20.00 \\
20.00 \\
-20.00 \\
20.00 \\
-20.00 \\
20.00 \\
-20.00 \\
20.00 \\
-20.00 \\
20.00 \\
-20.00 \\
20.00 \\
-20.00 \\
20.00 \\
-20.00 \\
20.00 \\
-20.00 \\
20.00 \\
-20.00 \\
20.00 \\
-20.00 \\
20.00 \\
-20.00 \\
20.00 \\
-20.00 \\
20.00 \\
-20.00 \\
20.00 \\
-20.00 \\
20.00 \\
-20.00 \\
20.00 \\
-20.00 \\
20.00 \\
-20.00 \\
20.00 \\
-20.00 \\
20.00 \\
-20.00 \\
20.00 \\
-20.00 \\
20.00 \\
-20.00 \\
20.00 \\
-20.00 \\
20.00 \\
-20.000 \\
20.00 \\
2000\end{array}$ & $\begin{array}{l}6.000 \\
6.000 \\
6.000 \\
6.000 \\
6.000 \\
6.000 \\
6.000 \\
6.000 \\
6.000 \\
6.000 \\
6.000 \\
6.000 \\
6.000 \\
6.010 \\
6.000 \\
6.000 \\
6.000 \\
6.000 \\
6.000 \\
6.000 \\
6.000 \\
6.000 \\
6.000 \\
6.000 \\
6.000 \\
6.000 \\
6.000 \\
6.000 \\
6.000 \\
6.000 \\
6.000 \\
6.000 \\
6.000 \\
6.000 \\
6.000 \\
6.000 \\
6.000 \\
6.000 \\
6.000 \\
6.000 \\
6.000 \\
6.000 \\
6.000 \\
6.000 \\
6.000 \\
6.000 \\
6.000 \\
6.000 \\
6.000 \\
6.000 \\
6.000\end{array}$ & $\begin{array}{l}228.26 \\
127.59 \\
126.92 \\
126.24 \\
125.56 \\
124.08 \\
124.20 \\
123.52 \\
122.03 \\
122.15 \\
122.78 \\
123.78 \\
124.79 \\
125.79 \\
126.80 \\
127.81 \\
128.82 \\
129.83 \\
130.84 \\
131.86 \\
132.88 \\
133.90 \\
134.92 \\
134.97 \\
134.12 \\
133.28 \\
132.44 \\
131.60 \\
130.76 \\
129.92 \\
129.98 \\
128.25 \\
127.42 \\
126.58 \\
125.75 \\
124.92 \\
124.10 \\
123.27 \\
12.9 .45 \\
121.62 \\
120.80 \\
119.98 \\
119.17 \\
118.37 \\
117.57 \\
116.76 \\
115.96 \\
115.17 \\
124.37 \\
113.58\end{array}$ & $\begin{array}{r}c .00 \\
5.04 \\
1 C .33 \\
15.81 \\
21.50 \\
27.40 \\
33.51 \\
39.03 \\
46.37 \\
53.11 \\
60.07 \\
67.24 \\
74.63 \\
62.23 \\
90.04 \\
90.07 \\
106.31 \\
114.77 \\
123.44 \\
132.34 \\
141.46 \\
150.77 \\
166.31 \\
170.07 \\
160.05 \\
190.25 \\
200.67 \\
211.30 \\
222.15 \\
233.27 \\
244.50 \\
256.00 \\
267.72 \\
279.65 \\
291.79 \\
304.15 \\
316.72 \\
329.51 \\
342.51 \\
355.73 \\
369.15 \\
322.79 \\
396.64 \\
119.70\end{array}$ \\
\hline
\end{tabular}


PTEA DEIfT-tueE LINAC

- age 2

\begin{tabular}{|c|c|c|c|c|c|c|c|c|c|c|c|c|}
\hline $\begin{array}{l}\text { ELL } \\
\text { NO }\end{array}$ & $\begin{array}{l}\text { ENED GT } \\
\text { NEV }\end{array}$ & $E T$ & $\begin{array}{c}\text { CELL } \\
\text { LENGTH }\end{array}$ & $\boldsymbol{T}$ & 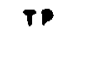 & $\mathbf{S}$ & $S \bullet$ & $\begin{array}{l}\text { OLSO } \\
\text { LENGTH }\end{array}$ & $\begin{array}{l}C U \triangle O \\
\text { GR } \triangle 0\end{array}$ & $\begin{array}{l}E Z E R O \\
P V / N\end{array}$ & 2 & $\begin{array}{l}\text { TOTAL } \\
\text { LEWETh }\end{array}$ \\
\hline $\begin{array}{l}51 \\
32 \\
53 \\
54 \\
55 \\
56 \\
57 \\
59 \\
59 \\
60 \\
61 \\
62 \\
63 \\
64 \\
65 \\
66 \\
67 \\
68 \\
60 \\
70 \\
71 \\
72 \\
73 \\
74 \\
75 \\
76 \\
77 \\
78 \\
79 \\
10 \\
81 \\
82 \\
193 \\
14 \\
95 \\
66 \\
67 \\
08 \\
89 \\
90 \\
91 \\
92 \\
93 \\
94 \\
95 \\
96 \\
97 \\
98 \\
99 \\
00 \\
01\end{array}$ & $\begin{array}{l}26.420 \\
27.162 \\
27.495 \\
20.638 \\
29.390 \\
30.151 \\
30.921 \\
31.700 \\
32.4199 \\
33.286 \\
34.092 \\
34.908 \\
35.732 \\
36.565 \\
37.407 \\
36.258 \\
39.118 \\
39.986 \\
40.062 \\
41.744 \\
42.631 \\
43.525 \\
44.424 \\
45.320 \\
46.238 \\
47.153 \\
46.073 \\
46.999 \\
49.929 \\
50.165 \\
51.305 \\
52.750 \\
53.700 \\
54.655 \\
55.614 \\
56.578 \\
57.546 \\
51.510 \\
59.595 \\
60.476 \\
61.461 \\
62.450 \\
63.442 \\
64.438 \\
65.430 \\
66.441 \\
67.447 \\
68.457 \\
69.470 \\
70.487 \\
71.506\end{array}$ & 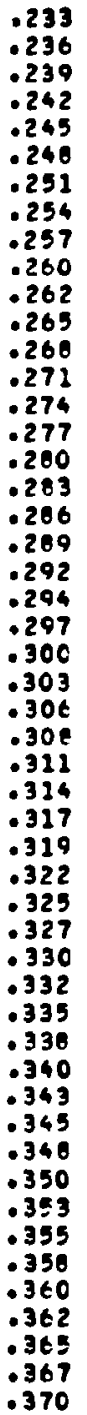 & $\begin{array}{l}19.733 \\
15.940 \\
16.146 \\
16.352 \\
16.557 \\
16.762 \\
16.966 \\
17.170 \\
17.373 \\
17.576 \\
17.778 \\
17.980 \\
18.181 \\
10.301 \\
10.581 \\
10.780 \\
10.979 \\
19.177 \\
19.375 \\
19.571 \\
19.766 \\
19.960 \\
20.153 \\
20.345 \\
20.535 \\
20.724 \\
20.913 \\
21.160 \\
21.285 \\
21.470 \\
21.654 \\
21.836 \\
22.010 \\
22.198 \\
22.377 \\
22.555 \\
22.732 \\
22.968 \\
23.082 \\
23.256 \\
23.429 \\
23.600 \\
23.771 \\
23.940 \\
24.108 \\
24.275 \\
24.442 \\
24.607 \\
24.771 \\
24.934 \\
25.096\end{array}$ & 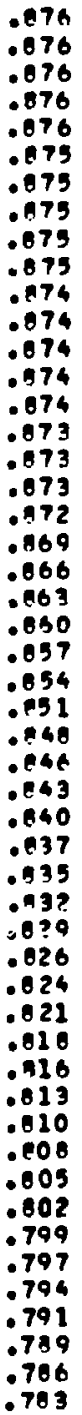 & $\begin{array}{l}.038 \\
.039 \\
.038 \\
.038 \\
.038 \\
.039 \\
.039 \\
.039 \\
.039 \\
.039 \\
.039 \\
.039 \\
.039 \\
.039 \\
.030 \\
.039 \\
.039 \\
.039 \\
.039 \\
.040 \\
.041 \\
.042 \\
.043 \\
.044 \\
.044 \\
.045 \\
.046 \\
.047 \\
.046 \\
.048 \\
.049 \\
.050 \\
.051 \\
.051 \\
.052 \\
.053 \\
.054 \\
.054 \\
.058 \\
.056 \\
.057 \\
.058 \\
.058 \\
.059 \\
.060 \\
.061 \\
.061 \\
.062 \\
.063 \\
.064 \\
.065\end{array}$ & $\begin{array}{l}.405 \\
.405 \\
.406 \\
.406 \\
.406 \\
.407 \\
.407 \\
.400 \\
.408 \\
.409 \\
.409 \\
.410 \\
.410 \\
.411 \\
.411 \\
.412 \\
.412 \\
.413 \\
.415 \\
.419 \\
.423 \\
.428 \\
.432 \\
.436 \\
.440 \\
.444 \\
.446 \\
.452 \\
.456 \\
.460 \\
.464 \\
.468 \\
.472 \\
.476 \\
.460 \\
.464 \\
.487 \\
.491 \\
.495 \\
.499 \\
.502 \\
.505 \\
.408 \\
.512 \\
.515 \\
.518\end{array}$ & $\begin{array}{l}.054 \\
.054 \\
.054 \\
.054 \\
.055 \\
.055 \\
.055 \\
.055 \\
.055 \\
.056 \\
.056 \\
.056 \\
.056 \\
.056 \\
.057 \\
.057 \\
.057 \\
.057 \\
.058 \\
.058 \\
.056 \\
.059 \\
.059 \\
.059 \\
.060 \\
.060 \\
.060 \\
.061 \\
.061 \\
.061 \\
.061 \\
.062 \\
.062 \\
.062 \\
.063 \\
.063 \\
.063 \\
.064 \\
.064 \\
.064 \\
.064 \\
.064 \\
.065 \\
.065 \\
.065 \\
.065 \\
.065 \\
.065 \\
.066 \\
.066\end{array}$ & $\begin{array}{l}2.54 \\
2.54 \\
2.54 \\
2.54 \\
2.54 \\
2.54 \\
2.54 \\
2.54 \\
2.54 \\
2.54 \\
2.54 \\
2.54 \\
2.54 \\
2.54 \\
2.54 \\
2.54 \\
2.54 \\
2.54 \\
2.54 \\
2.54 \\
2.54 \\
2.94 \\
2.54 \\
2.54 \\
2.54 \\
2.54 \\
2.54 \\
2.54 \\
2.54 \\
2.54 \\
2.54 \\
2.54 \\
2.54 \\
2.54 \\
2.54 \\
2.54 \\
2.54 \\
2.54 \\
2.54 \\
2.54 \\
2.54 \\
2.54 \\
2.54 \\
2.54 \\
2.54 \\
2.54 \\
2.54 \\
2.54 \\
2.54 \\
2.54\end{array}$ & $\begin{array}{r}-20.00 \\
20.00 \\
-20.00 \\
20.00 \\
-20.00 \\
20.00 \\
-20.00 \\
20.00 \\
-20.00 \\
20.00 \\
-20.00 \\
2 C .0 C \\
-20.00 \\
20.00 \\
-20.00 \\
20.00 \\
-20.00 \\
20.00 \\
-20.00 \\
20.00 \\
-20.00 \\
20.00 \\
-20.00 \\
20.00 \\
-20.00 \\
20.00 \\
-20.00 \\
20.00 \\
-20.00 \\
20.00 \\
-20.00 \\
21.00 \\
-20.0 C \\
20.00 \\
-20.00 \\
20.00 \\
-20.00 \\
20.00 \\
-20.00 \\
20.00 .00 \\
20.00 \\
-20.00 \\
-20.00 \\
20.00 \\
-20.00 \\
20.00 \\
-20.00 \\
20.00 \\
2000\end{array}$ & $\begin{array}{l}6.000 \\
6.000 \\
6.000 \\
6.000 \\
6.000 \\
6.000 \\
6.000 \\
6.000 \\
60000 \\
6.000 \\
6.000 \\
6.000 \\
6.000 \\
6.000 \\
6.000 \\
6.000 \\
6.000 \\
6.000 \\
6.000 \\
6.000 \\
6.000 \\
6.000 \\
6.000 \\
6.000 \\
6.000 \\
6.000 \\
6.000 \\
6.000 \\
6.000 \\
6.000 \\
6.000 \\
6.000 \\
6.000 \\
6.000 \\
6.000 \\
6.000 \\
6.000 \\
6.000 \\
6.000 \\
6.000 \\
60000 \\
6.000 \\
6.000 \\
6.000 \\
6.000 \\
60000 \\
6.000 \\
6.000 \\
6.000 \\
6.000\end{array}$ & $\begin{array}{l}112.70 \\
111.99 \\
112.20 \\
110.42 \\
109.63 \\
100.85 \\
101.07 \\
107.29 \\
106.92 \\
105.74 \\
104.97 \\
104.20 \\
103.43 \\
102.66 \\
101.90 \\
101.14 \\
100.38 \\
99.62 \\
99.21 \\
99.19 \\
99.14 \\
99.14 \\
99.12 \\
99.09 \\
99.07 \\
99.05 \\
99.02 \\
99.00 \\
98.98 \\
98.96 \\
98.93 \\
90.91 \\
98.89 \\
90.87 \\
98.65 \\
98.03 \\
90.80 \\
90.76 \\
98.71 \\
98.74 \\
90.52 \\
98.29 \\
98.06 \\
97.84 \\
97.61 \\
97.30 \\
47.16 \\
96.94 \\
96.72 \\
96.50 \\
96.20\end{array}$ & 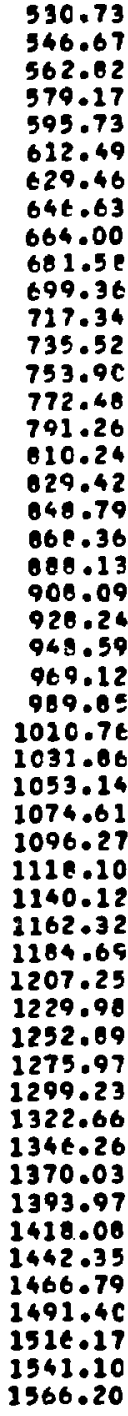 \\
\hline
\end{tabular}


-tgPI DAIfT-tuBe linat

-age 3

\begin{tabular}{|c|c|c|c|c|c|c|c|c|c|c|c|c|}
\hline $\begin{array}{l}\text { ELI } \\
\text { NO }\end{array}$ & $\begin{array}{l}\text { ENERGY } \\
\text { PEY }\end{array}$ & & $\begin{array}{l}\text { CELL } \\
\text { ENGTH }\end{array}$ & & 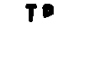 & $\$$ & 58 & & $\begin{array}{l}O U \triangle O \\
G R \triangle O\end{array}$ & $\begin{array}{l}\text { EIEFO } \\
\text { MYIM }\end{array}$ & & $\begin{array}{l}\text { TOTAL } \\
\text { LENETH }\end{array}$ \\
\hline $\begin{array}{l}114 \\
115 \\
116 \\
117 \\
119 \\
19 \\
120 \\
121 \\
122 \\
123 \\
124 \\
125 \\
26 \\
177 \\
128 \\
120 \\
120 \\
131 \\
122 \\
133 \\
134 \\
135 \\
136 \\
137 \\
38 \\
39 \\
40 \\
41 \\
42 \\
43 \\
44 \\
45 \\
46 \\
47 \\
48 \\
49\end{array}$ & 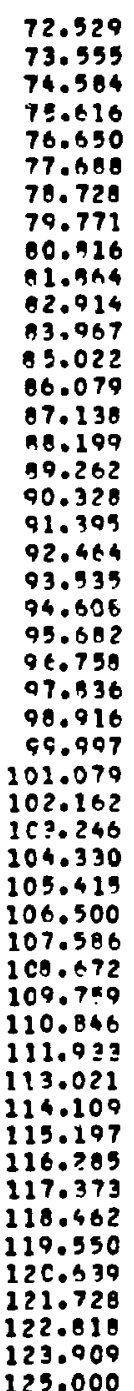 & 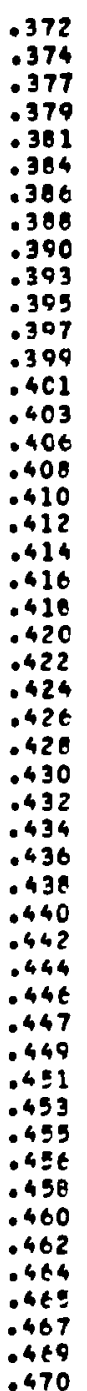 & 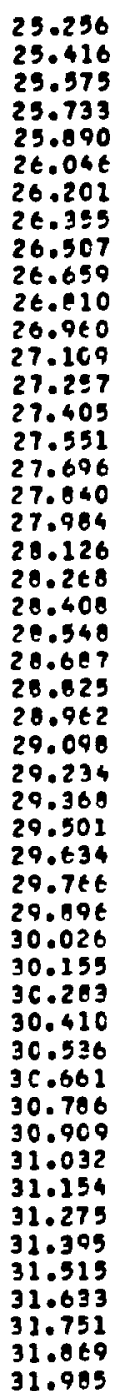 & $\begin{array}{l}.711 \\
.778 \\
.775 \\
.773 \\
.770 \\
.768 \\
.765 \\
.763 \\
.760 \\
.758 \\
.755 \\
.753 \\
.750 \\
.741 \\
.745 \\
.743 \\
.740 \\
.738 \\
.735 \\
.733 \\
.730 \\
.724 \\
.726 \\
.723 \\
.721 \\
.710 \\
.716 \\
.714 \\
.711 \\
.708 \\
.795 \\
.703 \\
.700 \\
.697 \\
.694 \\
.692 \\
.689 \\
.686 \\
.664 \\
.611 \\
.679 \\
.670 \\
.674 \\
.671 \\
.668 \\
.466 \\
.646 \\
.662 \\
.660 \\
.790\end{array}$ & 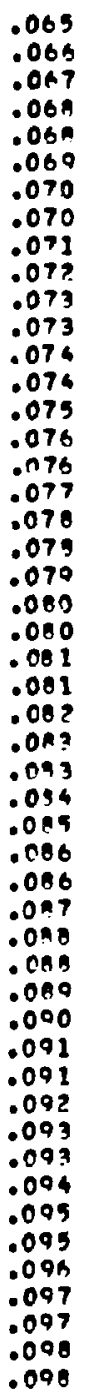 & 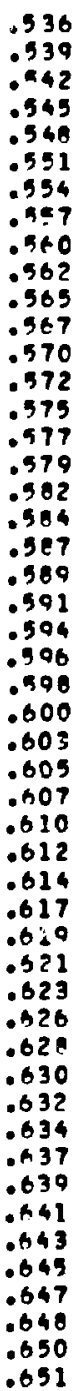 & $\begin{array}{l}.06 \\
.06 \\
.06 \\
.06 \\
.06 \\
.06 \\
.06 \\
.06 \\
.06 \\
.06 \\
.06 \\
.06 \\
.06 \\
.06 \\
.06 \\
.06 \\
.06 \\
.06 \\
.06 \\
.06 \\
.06 \\
.06 \\
.06 \\
.06 \\
.06 \\
.06 \\
.06 \\
.06 \\
.06 \\
.06 \\
.06 \\
.06 \\
.06 \\
.06 \\
.06 \\
.06 \\
.06 \\
.06 \\
.06 \\
.06 \\
.06 \\
.06 \\
.06 \\
.06 \\
.06 \\
.06 \\
.06 \\
.06 \\
.06 \\
.06 \\
.06\end{array}$ & $\begin{array}{l}2.54 \\
2.54 \\
2.54 \\
2.54 \\
2.54 \\
2.54 \\
2.54 \\
2.54 \\
2.54 \\
2.54 \\
2.54 \\
2.54 \\
2.54 \\
2.54 \\
2.54 \\
2.54 \\
2.54 \\
2.54 \\
2.54 \\
2.54 \\
2.54 \\
2.54 \\
2.54 \\
2.54 \\
2.54 \\
2.54 \\
2.54 \\
2.54 \\
2.54 \\
2.54 \\
2.54 \\
2.54 \\
2.54 \\
2.54 \\
2.54 \\
2.54 \\
2.54 \\
2.54 \\
2.54 \\
2.54 \\
2.34 \\
2.54 \\
2.54 \\
2.54 \\
2.54 \\
2.54 \\
2.54 \\
2.54 \\
2.54\end{array}$ & $\begin{array}{r}2 \\
-2 \\
2 \\
-2 \\
2 \\
-2 \\
2 \\
-2 \\
2 \\
-2 \\
2 \\
-2 \\
2 \\
-2 \\
2 \\
-2 \\
2 \\
-2 \\
2 \\
-2 \\
2 \\
-2 \\
2 \\
-2 \\
2 \\
-2 \\
2 \\
-2 \\
2 \\
-2 \\
2 \\
-2 \\
-2 \\
-2 \\
2 \\
-2\end{array}$ & & $\begin{array}{l}96.06 \\
99.95 \\
95.63 \\
95.42 \\
95.21 \\
95.00 \\
94.79 \\
94.59 \\
94.38 \\
94.17 \\
93.95 \\
93.74 \\
93.53 \\
93.33 \\
93.12 \\
92.92 \\
92.71 \\
92.51 \\
92.31 \\
92.11 \\
91.91 \\
91.71 \\
91.52 \\
91.32 \\
91.13 \\
90.94 \\
90.75 \\
90.64 \\
90.63 \\
90.62 \\
90.61 \\
90.60 \\
90.59 \\
90.59 \\
96.50 \\
90.57 \\
90.56 \\
90.55 \\
90.54 \\
90.54 \\
90.53 \\
90.52 \\
90.51 \\
90.51 \\
90.50 \\
90.499 \\
90.30 \\
90.12 \\
99.94\end{array}$ & $\begin{array}{l}2 \\
2 \\
2 \\
2\end{array}$ \\
\hline
\end{tabular}




\section{APPENDIX $\mathrm{K}$}

\section{PARAMETERS}

The following appendix is a computer listing of the required parameters for the $\mathrm{CCL}$ (125- to $650-\mathrm{MeV}$ ) section of PIGMI. The CCL is composed of 108 accelerating tanks, with each tank consisting of 11 identical accelerating cells. The standard DAW half-cell geometry is shown in Fig. K-1. Between each accelerating tank is a coaxial coupling cavity (bridge coupler). Each coupling cavity contains a $4.5-\mathrm{kG} / \mathrm{cm}$ permanent magnet quadrupole $5 \mathrm{~cm}$ long. The quadrupole polarity alternates at each tank. The peak axial electric field is 7.819 $M V / m$, and a synchronous phase of $-30^{\circ}$ is maintained throughout. The remaining parameters are given in the computer listing and are defined as follows (see Appendixes I and $\mathrm{J}$ ).

\footnotetext{
TANK = Tank number.

WIN = Beam energy into tank (MeV).

WOUT $=$ Beam energy out of tank (MeV).

$L T=$ Tank length $(\mathrm{m})$.

LTOTAL $=$ Total length $(\mathrm{m})$.

$L B C=$ Length of bridge coupler $(m)$.

$N C=$ Number of cells.

$L C=$ Cell length (in).

PCU = Power loss in copper (MW).

PBEAM = Power into beam (MW).

PTOTAL = PCU + PBEAM (MW).

BETAD $=$ Design $\beta$ (each cell is $\beta \gamma 1 / 2$ in length\}.
}

$$
\begin{aligned}
\mathrm{PB} / \mathrm{PT}= & \text { Beam loading. } \\
\mathrm{ZT}^{*-2}= & \text { Froduct of shunt impedance and } \\
& \text { square of transit-time } \\
& \text { factor }(\mathrm{M} \Omega / \mathrm{m}) . \\
\text { PHIMID }= & \text { Phase of design particle at middie } \\
& \text { of tank }(\mathrm{deg}) .
\end{aligned}
$$

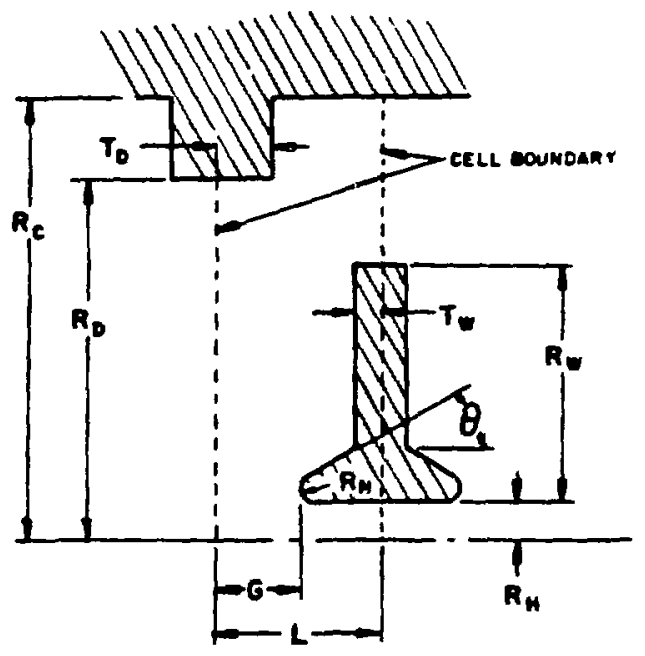

Fig. K-1.

stendard DAW half-cell geomotry. 
PIGN] DYSK-AND-HASHE I INAC, EO-7.PI9 MVIM

page 1

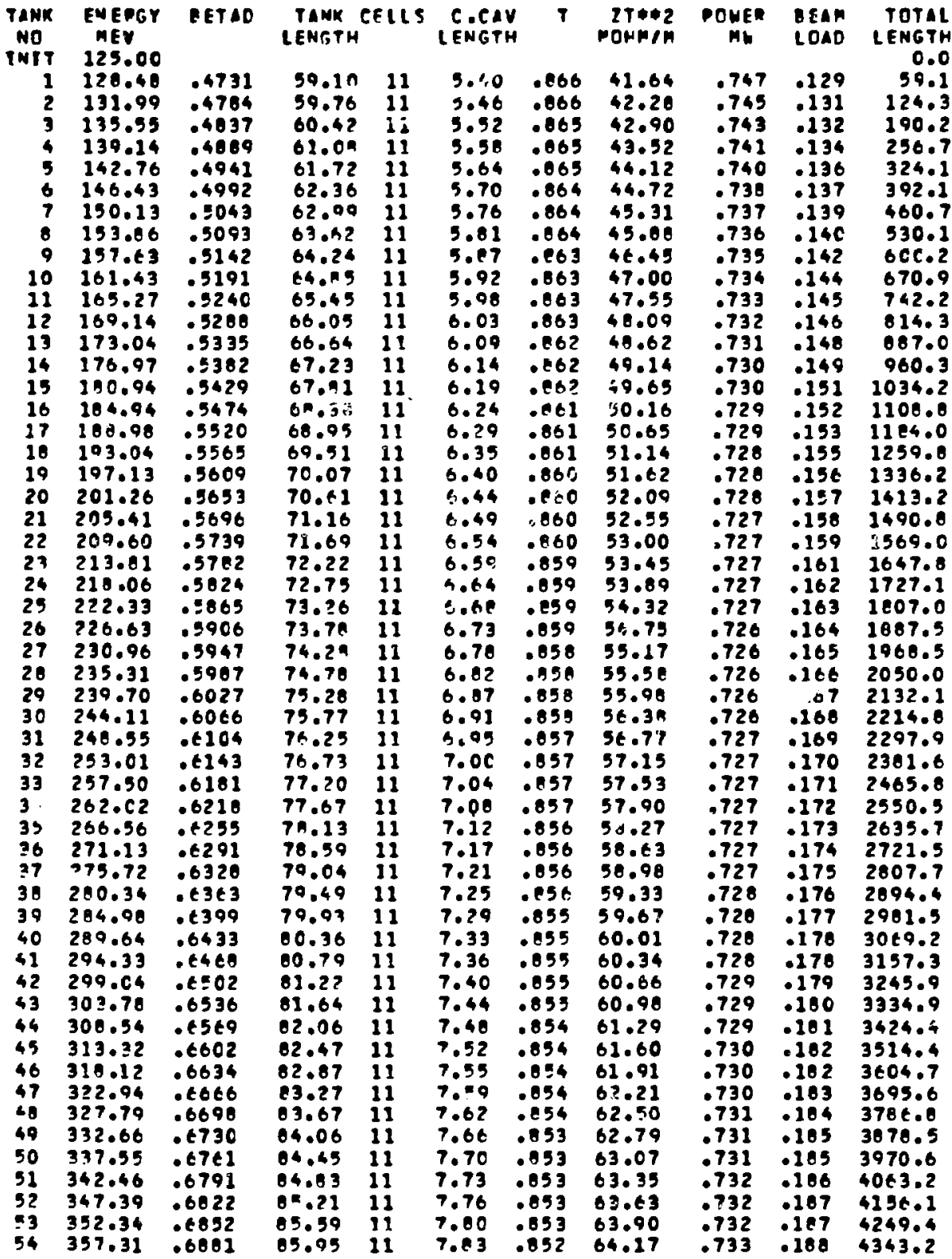




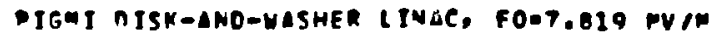

\begin{tabular}{|c|c|c|c|c|c|c|c|c|c|c|}
\hline $\begin{array}{l}\text { TANK } \\
\text { MO }\end{array}$ & $\begin{array}{l}\text { ENERGY } \\
\text { MEY }\end{array}$ & QETAD & $\begin{array}{l}\text { TAUH } \\
\text { LENGTH }\end{array}$ & eELLS & $\begin{array}{l}\text { CoCAV } \\
\text { LENGTH }\end{array}$ & $\mathbf{T}$ & $\begin{array}{r}\tau T \bullet \bullet z \\
\text { भOHPI }\end{array}$ & POWEE & $\begin{array}{l}\text { EEAP } \\
\text { LOAD }\end{array}$ & $\begin{array}{l}\text { TCTAL } \\
\text { LENGTH }\end{array}$ \\
\hline $\begin{array}{l}55 \\
56 \\
57 \\
58 \\
59 \\
60 \\
61 \\
62 \\
63 \\
64 \\
65 \\
66 \\
67 \\
60 \\
69 \\
70 \\
71 \\
72 \\
73 \\
74 \\
75 \\
76 \\
77 \\
79 \\
79 \\
80 \\
91 \\
12 \\
13 \\
14 \\
15 \\
86 \\
197 \\
18 \\
19 \\
90 \\
91 \\
92 \\
93 \\
94 \\
95 \\
96 \\
97 \\
98 \\
99 \\
100 \\
101 \\
102 \\
103 \\
104 \\
105 \\
106 \\
107 \\
108\end{array}$ & 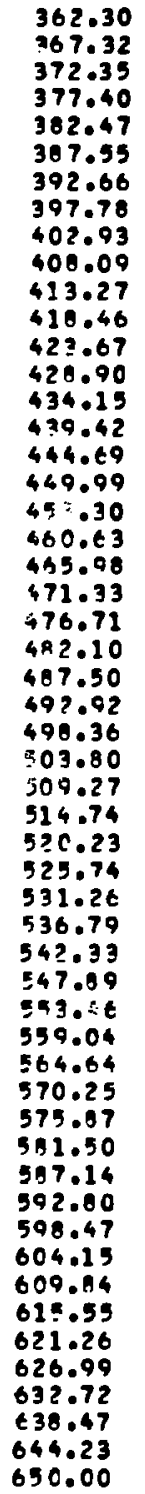 & 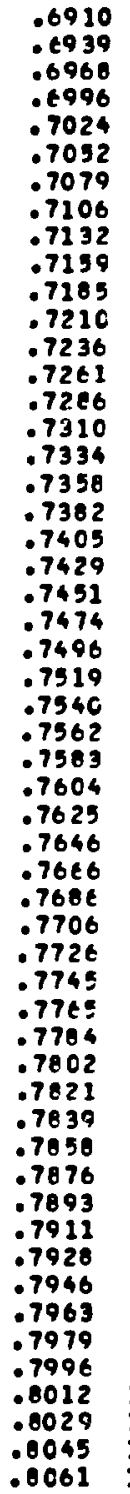 & 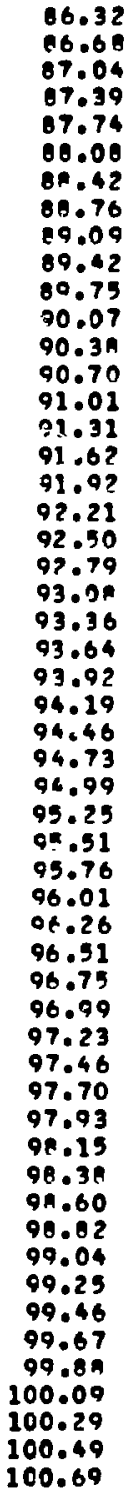 & $\begin{array}{l}11 \\
11 \\
11 \\
11 \\
11 \\
11 \\
11 \\
11 \\
11 \\
11 \\
11 \\
11 \\
11 \\
11 \\
11 \\
11 \\
11 \\
11 \\
11 \\
11 \\
11 \\
11 \\
11 \\
11 \\
11 \\
11 \\
11 \\
11 \\
11 \\
11 \\
11 \\
11 \\
11 \\
11 \\
11 \\
11 \\
11 \\
11 \\
11 \\
11 \\
11 \\
11 \\
11 \\
11 \\
11 \\
11 \\
11 \\
11 \\
11 \\
-i\end{array}$ & 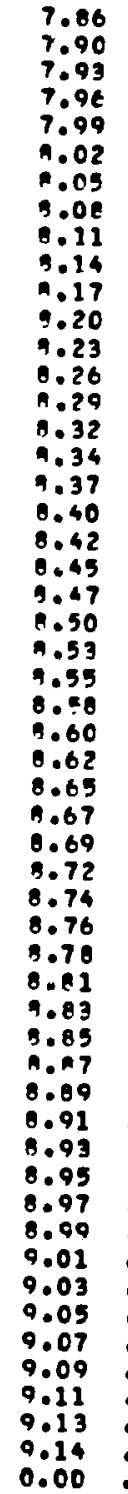 & $\begin{array}{l}.852 \\
.852 \\
.852 \\
.852 \\
.852 \\
.851 \\
.851 \\
.851 \\
.851 \\
.851 \\
.851 \\
.850 \\
.850 \\
.850 \\
.850 \\
.850 \\
.850 \\
.850 \\
.849 \\
.849 \\
.849 \\
.849\end{array}$ & $\begin{array}{l}64.43 \\
64.69 \\
64.94 \\
63.19 \\
65.43 \\
65.60 \\
65.91 \\
66.15 \\
66.30 \\
64.60 \\
66.83 \\
67.05 \\
67.26 \\
67.48 \\
67.68 \\
67.89 \\
60.09 \\
68.29 \\
68.49 \\
68.49 \\
60.87 \\
69.06 \\
69.25 \\
69.43 \\
69.61 \\
69.70 \\
69.96 \\
70.13 \\
70.30 \\
70.46 \\
70.63 \\
70.79 \\
70.95 \\
71.10 \\
71.26 \\
71.41 \\
71.56 \\
71.70 \\
71.85 \\
71.99 \\
72.13 \\
72.27 \\
72.41 \\
72.54 \\
72.68 \\
72.81 \\
72.94 \\
73.06 \\
73.19 \\
73.31 \\
73.43 \\
73.56 \\
73.67 \\
73.79\end{array}$ & 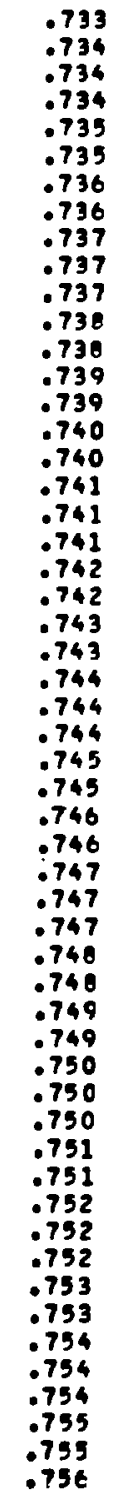 & 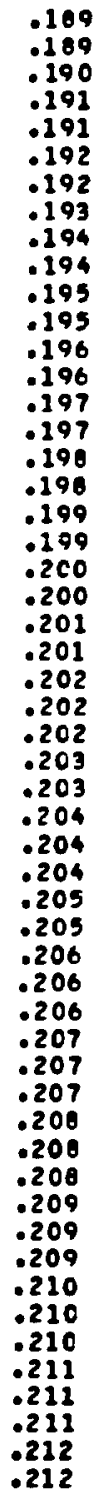 & 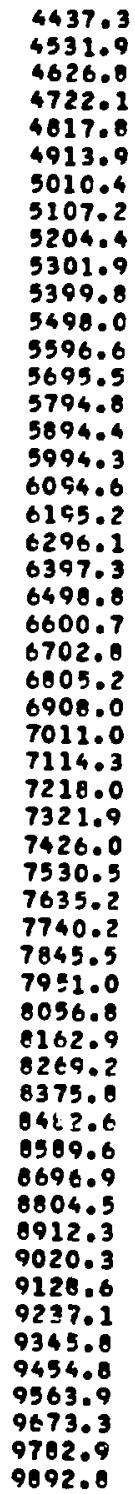 \\
\hline
\end{tabular}


APPENDIX L

LIST OF CONTRIBUTORS TO PIGMI TECHNOLOGY

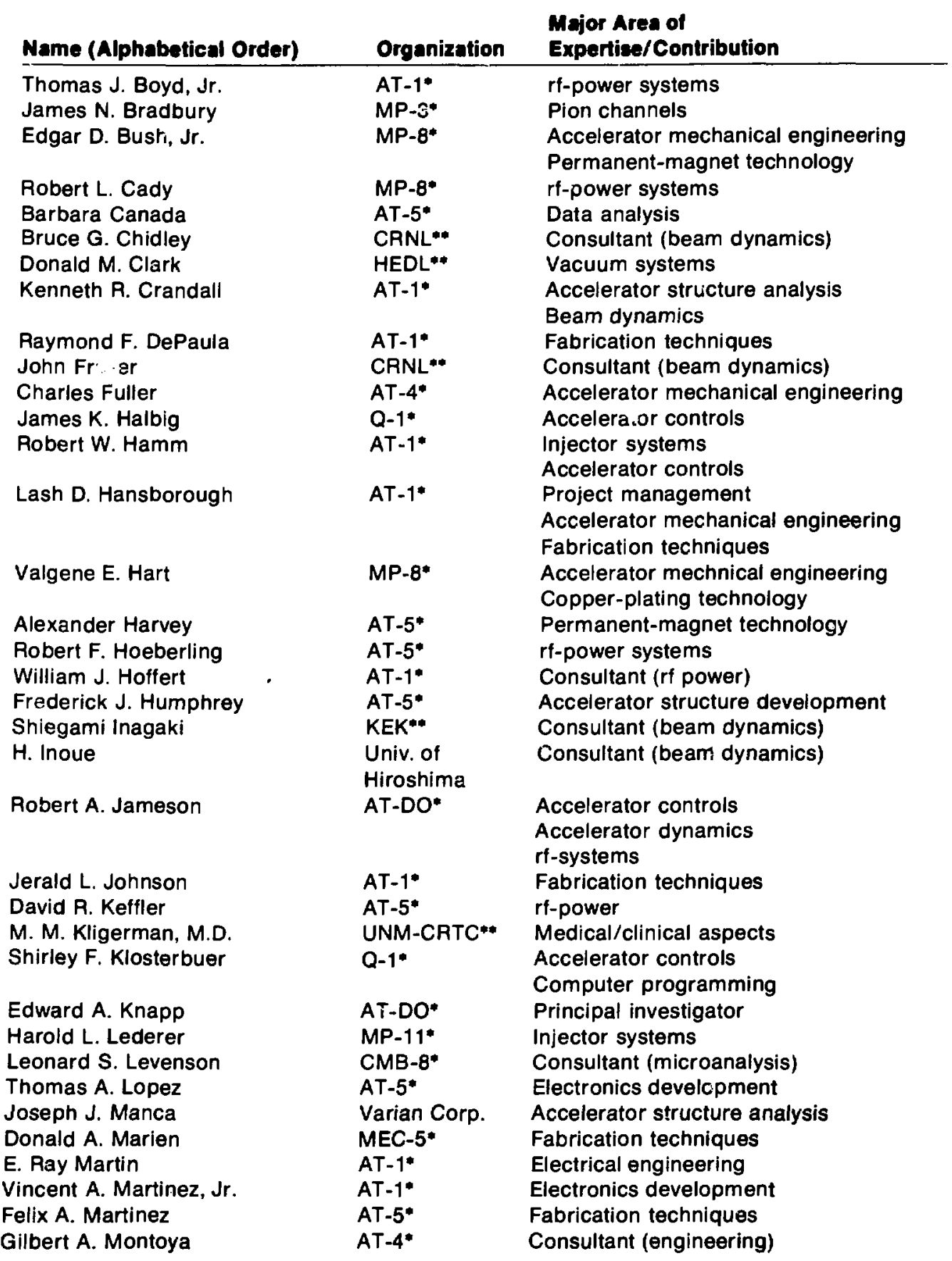


APPENDIX L LIST OF CONTRIBUTOAS TO PIGMI TECHNOLOGY (CONT)

Name (Alphabetical Order) Organization $\quad \begin{aligned} & \text { Major Area of } \\ & \text { Expertice/Contribution }\end{aligned}$

\begin{abstract}
Donald W. Mueller Michael A. Paciotti James M. Potter James E. Rankin Donald W. Reid Robert D. Reiswig Gary W. Rodenz Louis Rosen Phillip L. Roybal James R. Ruhe Nario Salto
\end{abstract}

Constance M. Schneider Stan O. Schriber

Alfred R. Smith, M.D.

Brian Smith

Raymond E. Squires Ralph R. Stevens, Jr. Richard H. Stokes

James E. Stovall

Robert $G$. Sturgess

Tsuyoski Sugimitsu

Donald A. Swenson

Paul J. Tallerico Joseph W. VanDyke

Thomas $P$. Wangler

Roger W. Warren

Lloyd C. Wilkerson

Steven $W$. Williams

Mahlon T. Wilson

H. G. Worstell

Lloyd Young

\begin{abstract}
MP-11*
MP-3*

AT $-5^{*}$

AT-1"

AT-5*

CMB-8*

AT-4*

MP-DO*

AT-1*

MEC-4*

Hitachi

Corp.

AT-1*

CRNL**
\end{abstract}

UNM-

CRTC"*

HEDL"*

MEC-5*

MP-DO*

AT-1*

AT-1*

AT-1*

Kyushu Univ.

AT-1*

AT-5*

MP-8*

AT-1*

WSTGH**

WX-4*

HEDL**

AT-DO*

MP-DO*

AT $-1 *$
Injector systems

Pion channels

Accelerator structure development

Computer analysis

rf-power systems

Consultant (microanalysis)

Accelerator structure analysis

Consultant

Mechanical design

Vacuum system analysis

Consultant (permanent-magnet technology)

Computer programming

Consultant (accelerator structure analysis and beam dynamics)

Medical/clinical aspects

Beam diagnostics

Fabrication techniques

injector systems

Accelerator structure analysis

Beam dynamics

Project management

Beam dynamics

Control systems

Electronics development

Consultant (pion channels)

Project coordinator

Accelerator structure analysis

Beam dynamics

Control systems

rf-power systems

Vacuum system technology

Accelerator-structure analysis

Beam dynamics

Vacuum engineering

Accelerator mechanical engineering

Accelerator structure development

Consultant (engineering)

Consultant (mechanical engineering)

Accelerator structure analysis

- Los Alamos National Laboratory group designator.

* See glossary. 